\title{
EFFECT OF SUSTAINABLE AND COMPOSITE MATERIALS ON THE MECHANICAL BEHAVIOR OF SANDWICH PANELS UNDER EDGEWISE COMPRESSIVE LOADING
}

\author{
A Thesis Presented to \\ The Faculty of California Poytechnic State University, \\ San Luis Obispo
}

In Partial Fulfillment

Of the Requirements for the Degree of Masters of Science in Aerospace Engineering

by

Justin A. Tafoya

March 2015 
(c) 2015

Justin A. Tafoya

ALL RIGHTS RESERVED 


\section{COMMITTEE MEMBERSHIP}

TITLE:

AUTHOR:

DATE SUBMITTED:

COMMITTEE CHAIR:

COMMITTEE MEMBER:

COMMITTEE MEMBER:

COMMITTEE MEMBER:
Effect of Sustainable and Composite Materials on the Mechanical Behavior of Sandwich Panels under Edgewise Compressive Loading

Justin A. Tafoya

March 2015

Faysal Kolkailah, Ph.D, P.E

Professor of Aerospace Engineering

Eric Kasper, Ph.D., P.E.

Professor of Civil Engineering

Eltahry Elghandour, Ph.D

Lecturer of Aerospace Engineering

Dianne DeTurris, Ph.D

Professor of Aerospace Engineering 


\begin{abstract}
Effect of Sustainable and Composite Materials on the Mechanical Behavior of Sandwich Panels under Edgewise Compressive Loading

Justin A. Tafoya
\end{abstract}

Over the last three decades, the aerospace industry has gradually shifted from metals to composites in many different applications due to the lightweight properties of composite materials. Some benefits of composites include higher strength-to-weight ratio and corrosion resistance. At this point in time, the composite industry researchers are focusing on renewable and sustainable materials (bio-composites). By understanding the structural capabilities of bio-composites that have been used for centuries, new developments of sustainable materials will spark more interest throughout the industry. Bio-composites include fibers such as hemp, bamboo, flax, etc. The high demand for bio-composites in composite structures can also reduce raw material costs.

This study investigated, through experimental and numerical analysis, the mechanical behavior of sandwich panels under edgewise compressive loading. The first task of the study was to use four different facesheet materials and the same Nomex honeycomb core. The number of facesheet layers consecutively increased from one layer to four layers on each side of the core for each material. The facesheet materials used were Hexply AGP280-5H Carbon Fiber Pre-Preg, B601 Plain Weave Hemp, D118DKBR Split Herringbone Weave Hemp, and NB308T 7725 Texalium Fiberglass Pre-Preg. The sandwich panels were cured using a composite heat press and followed the recommended cure cycle for the material's resin matrix. The variation of the facesheet materials while keeping the core consistent showed how the edgewise strength and displacement of the composite sandwiches were affected under compressive loading. The second task of the study was to try and create a multifunctional hybrid composite sandwich with two different facesheet materials; using one hemp material and one pre-preg material. The goal of this task was to try and minimize 
the damage occured upon failure. Being that the pre-preg materials are more brittle than the hemp material, the hybrid composite sandwiches can potentially create a superior composite structure. The sequence of stacking of the facesheet materials was manipulated to study how changing the outer and inner layers affected the results. All the specimen were loaded at a rate of $0.05 \mathrm{in} / \mathrm{min}$ in a steel jig specifically made per ASTM C364 standard using an Instron 8801 to determine the mechanical behavior. These experimental results combined with results from theoretical and finite element analysis using Matlab and Abaqus, respectively, were used to compare composite sandwich designs under compressive loadings. Failure mode comparison between the individual material composites and the hybrid composites were also discussed.

Keywords: Aerospace Engineering, Composite Materials, Composite Sandwich Structures, Edgewise Compressive Loading 


\section{ACKNOWLEDGMENTS}

I would like to begin by thanking my graduate advisors, Dr. Kolkailah and Dr. Elghandour. A special thank you to Dr. Elghandour for his continuous effort helping me with experimental testing and for his support throughout my college career. His encouraging words, life lessons, and faith in me will always be remembered. Thank you to the other members of my committee, Dr. Kasper and Dr. DeTurris.

I would also like to thank my good friends and colleagues, Jeff Carter and Josh Lister, for their help and effort through the many hours spent in the lab during testing. It was always a great fun time with them in the lab and would have not been possible to complete this project without them. Also, thank you to Cody, the best lab technician at Cal Poly, for his help making this project feasible by creating the testing apparatus used throughout the experiment.

Lastly, a very special thank you to my parents, Glenn and Cindy, for their love and support throughout my entire college career. It has been a long and stressful journey and I would not be where I am without you two. Your positive and encouraging words have always lifted my spirits through the tough times of college, and now that we have finally made it, I can't wait to see what the future holds for us.

I would also like to dedicate this thesis to my late cousin Jerome Anthony Romero, who was my best friend and like a brother to me throughout my entire life. For you were never given the opportunity to complete a project like this. You taught me many valuable life lessons growing up, and were always there to support me and my education. I love you, miss you, and you will live in my heart forever. 


\section{TABLE OF CONTENTS}

LIST OF TABLES X xii

LIST OF FIGURES Xiv

LIST OF EQUATIONS X Xvii

NOMENCLATURE Xviii

1 INTRODUCTION 1

1.1 Composites Overview . . . . . . . . . . . . . . . . . 1

1.1.1 Introduction to Composites . . . . . . . . . . . . 1

1.1.2 Types of Materials ................... 4

1.1.2.1 Composite Materials . . . . . . . . . . . . 4

1.1.2.2 Bio-Composite Materials ............ . 5

1.1.3 Manufacturing Techniques ............... 6

1.2 Composite Sandwich Overview . . . . . . . . . . . . . . . 8

1.2.1 Facesheets ................... 8

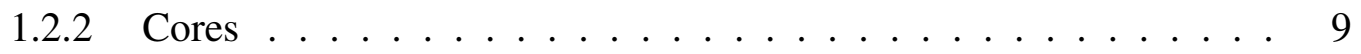

1.2.3 Advantages and Disadvantages of Composite Sandwiches . . . . . 10

1.2.4 Edgewise Compressive Behavior of Composite Sandwiches . . . . 10

1.2.5 Applications of Composite Sandwiches . . . . . . . . . . . . 11

1.3 Previous Research of Edgewise Compression of Composite Sandwiches . . 13

1.4 Main Objective and Scope of Study . . . . . . . . . . . . . . 15 
2.1 Composite Sandwich Design and Materials Used . . . . . . . . . . . 17

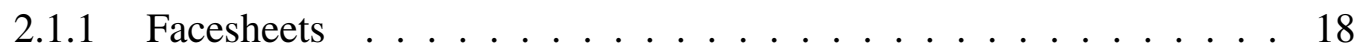

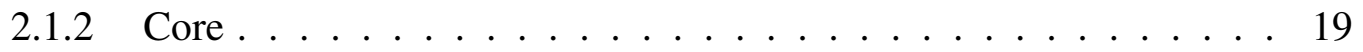

2.1.3 Adhesives ..................... 20

2.2 Specimen Manufacturing . . . . . . . . . . . . . . 20

2.2.1 Layup Methods . . . . . . . . . . . . . . . . . 22

2.2.1.1 Non-Automated Tape Layup . . . . . . . . . . . . 22

2.2.1.2 Wet Layup Technique . . . . . . . . . . . . . 23

2.2.2 Curing and Post-Curing Process . . . . . . . . . . . . . . 24

2.2.3 Issues Faced During Hybrid Manufacturing . . . . . . . . . . . 26

2.3 Mechanical Properties Testing of Composite Sandwich Constituent Materials 28

2.3.1 Preparing Specimen . . . . . . . . . . . . . . . 29

2.3.2 Strain Gage Application for Poisson's Ratio Tests . . . . . . . . . . 30

2.3.3 Tensile Testing Procedure (ASTM D3039) . . . . . . . . . . . 31

2.3.4 Compressive Testing Procedure (ASTM D3410) . . . . . . . . . 32

2.3.5 Poisson's Ratio Testing Procedure (ASTM E132) . . . . . . . . . . 33

2.3.6 Poisson's Ratio Testing of Honeycomb Core (ASTM D6790) . . . . 34

2.3.7 Facesheet Fiber Volume Fraction Calculation (ASTM D2584) . . . 36

2.4 Composite Sandwich Experimental Testing . . . . . . . . . . . 36

2.4.1 Instron Machine setup for Edgewise Compression . . . . . . . . . 37

2.4.2 Edgewise Compression Testing Procedure (ASTM C364) . . . . . . 37

3 EXPERIMENTAL TESTING RESULTS AND DISCUSSION 39

3.1 Material Properties Testing . . . . . . . . . . . . . . . 39

3.1.1 Tensile Testing Results . . . . . . . . . . . . . . . . . 40

3.1.2 Compressive Testing Results . . . . . . . . . . . . . . . 42

3.1.3 Poisson's Ratio Testing Results . . . . . . . . . . . . . . . 43 
3.1.4 Honeycomb Poisson's Ratio Testing Results . . . . . . . . . . . . . 44

3.1.5 Shear Moduli of Facesheet Materials . . . . . . . . . . . . . 45

3.1.6 Fiber Volume Fractions for Facesheet Materials . . . . . . . . . . . 45

3.1.7 Summary of Material Properties Testing . . . . . . . . . . . . . 46

3.2 Edgewise Compressive Testing Results and Discussion . . . . . . . . . . . 47

3.2.1 Carbon Fiber Facesheet Sandwiches . . . . . . . . . . . . . . 48

3.2.2 Plain Weave Hemp Facesheet Sandwiches . . . . . . . . . . . . . 51

3.2.3 Herringbone Weave Hemp Facesheet Sandwiches . . . . . . . . . . 53

3.2.4 Glass Fiber (Texalium) Facesheet Sandwiches . . . . . . . . . . . . 55

3.2.4.1 Individual to Hybrid Facesheets . . . . . . . . . . . . . 57

3.2.5 Hybrid Sandwiches . . . . . . . . . . . . . . . 59

3.2.6 Comparison of Individual and Hybrid Facesheets . . . . . . . . . 60

3.2.6.1 Average Strength for Individual Facesheet Materials . . . 60

3.2.6.2 Average Weight for Individual Facesheet Materials . . . . 61

3.2.6.3 Average Strength for Hybrid Facesheet Materials . . . . . 62

3.2.6.4 Average Weight for Hybrid Sandwiches . . . . . . . . 62

3.2.6.5 Strength-to-Weight Results of All Sandwiches . . . . . . 63

3.3 Failure Mode Discussion . . . . . . . . . . . . . . . . . 64

3.3.1 Carbon Fiber Facesheet Sandwiches . . . . . . . . . . . . . . . 65

3.3.2 Plain Weave Hemp Facesheet Sandwiches . . . . . . . . . . . . . . 67

3.3.3 Herringbone Weave Hemp Facesheet Sandwiches . . . . . . . . . . 69

3.3.4 Glass Fiber (Texalium) Facesheet Sandwiches . . . . . . . . . . . . 71

3.3.5 Hybrid Sandwiches . . . . . . . . . . . . . 73

3.3.6 Discussion of Individual and Hybrid Facesheets . . . . . . . . . . 75

4 THEORETICAL ANALYSIS

4.1 Edgewise Compression Analysis Method . . . . . . . . . . . . 77

4.1.1 Orthotropic Plates under In-plane Uniaxial Compression . . . . . . 77 
4.2 Theoretical Deflection Results . . . . . . . . . . . . . . . . . 79

4.2.1 Carbon Fiber Sandwiches _ . . . . . . . . . . . . . 80

4.2.2 Plain Weave Hemp Sandwiches . . . . . . . . . . . 80

4.2.3 Herringbone Weave Hemp Sandwiches _ . . . . . . . . . . . 81

4.2.4 Glass Fiber (Texalium) Sandwiches _ . . . . . . . . . . . . . . 81

4.2.5 Hybrid Sandwiches . . . . . . . . . . . . . . . . . 81

5 FINITE ELEMENT ANALYSIS AND RESULTS 82

5.1 Finite Element Methodology . . . . . . . . . . . . . . . . . 82

5.1 .1 Geometric Definitions . . . . . . . . . . . . . . . 83

5.1.2 Material Creation and Section Assignments . . . . . . . . . 85

5.1 .3 Assembly and Steps _. . . . . . . . . . . . . . 85

5.1.4 Boundary Conditions, and Loads . . . . . . . . . . . . . . . 87

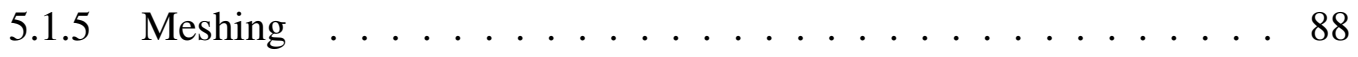

5.1.6 Edgewise-Compressive Model with $1000 \mathrm{lbf}$ load applied . . . . 89

6 COMPARISON OF NUMERICAL, THEORETICAL, AND EXPERIMENTAL $\begin{array}{ll}\text { RESULTS } & 92\end{array}$

6.1 Theoretical and Numerical $\ldots \ldots$. . . . . . . . . . . . . . 92

6.2 Theoretical and Experimental . . . . . . . . . . . . . . . . . . 92

6.3 Numerical and Experimental $\ldots \ldots$. . . . . . . . . . . . . 93

6.4 Overall Comparison of Deflections at $1000 \mathrm{lbf} \ldots \ldots \ldots$

7 CONCLUSION 96

7.1 Future Considerations . . . . . . . . . . . . . . . . . . 96

$\begin{array}{ll}\text { BIBLIOGRAPHY } & 98\end{array}$

$\begin{array}{ll}\text { APPENDICES } & 101\end{array}$

A.1 Layer Comparison . . . . . . . . . . . . . . . . . . 101 
A.2 Boundary Condition Cases . . . . . . . . . . . . . . . . 102

A.3 Numerical Model Mesh Convergence Plot . . . . . . . . . . . . . . . 102 


\section{LIST OF TABLES}

2.1 Hemp fabrics used as facesheets . . . . . . . . . . . . . . . . 19

3.1 Tensile moduli and strengths of each facesheet material used . . . . . . . . 40

3.2 Compressive moduli and strengths of each facesheet material used . . . . . . . 42

3.3 Honeycomb material properties . . . . . . . . . . . . . . . . 44

3.4 Fiber volume percentages from ignition loss . . . . . . . . . . . . 46

3.5 Edgewise-compressive results for carbon fiber facesheet sandwiches . . . . . . 49

3.6 Edgewise-compressive results for plain weave hemp facesheet sandwiches . . . 51

3.7 Edgewise-compressive results for herringbone hemp facesheet sandwiches . . . 53

3.8 Edgewise-compressive results for glass fiber facesheet sandwiches . . . . . . . 55

3.9 Edgewise-compressive results for hybrid sandwiches . . . . . . . . . . . . 59

3.10 Edgewise-compressive strength comparison for individual facesheet materials . 61

3.11 Average weight comparison for individual materials . . . . . . . . . . . 62

3.12 Edgewise-compressive strength comparison for hybrid sandwiches . . . . . . . 62

3.13 Average weight comparison for hybrid sandwiches . . . . . . . . 63

3.14 Edgewise-compressive failure mode for carbon fiber sandwiches . . . . . . . 65

3.15 Edgewise-compressive failure mode for plain weave hemp sandwiches . . . . . 67

3.16 Edgewise-compressive failure mode for herringbone weave hemp sandwiches . 69

3.17 Edgewise-compressive failure mode for glass fiber sandwiches $\ldots \ldots$. . . . 71

3.18 Edgewise-compressive failure mode for hybrid sandwiches . . . . . . . . . 73

4.1 Theoretical deflection of carbon fiber sandwiches . . . . . . . . . . . 80 
4.2 Theoretical deflection of plain weave hemp sandwiches . . . . . . . . . . . 80

4.3 Theoretical deflection of herringbone weave hemp sandwiches . . . . . . . 81

4.4 Theoretical deflection of glass fiber (texalium) sandwiches . . . . . . . . 81

4.5 Theoretical deflection of hybrid sandwiches . . . . . . . . . . . 81

6.1 Numerical, theoretical, and experimental comparison of carbon fiber sandwiches 93

6.2 Numerical, theoretical, and experimental comparison of plain weave hemp fiber sandwiches . . . . . . . . . . . . . . . . . . . . . 94

6.3 Numerical, theoretical, and experimental comparison of herringbone weave hemp fiber sandwiches . . . . . . . . . . . . . . . . . . 94

6.4 Numerical, theoretical, and experimental comparison of glass fiber sandwiches 95

6.5 Numerical, theoretical, and experimental comparison of hybrid sandwiches . . 95

A.1 Boundary condition comparison of carbon fiber sandwiches . . . . . . . 102 


\section{LIST OF FIGURES}

1.1 Eco-friendly hemp composite cars . . . . . . . . . . . . . . 3

1.2 Types of composites . . . . . . . . . . . . . . . . 5

1.3 Industrial hemp farming $[11] \ldots \ldots \ldots \ldots$

1.4 The uses of industrial hemp [12] . . . . . . . . . . . . . . 6

1.5 Composite sandwich advantage $[16] \ldots \ldots \ldots$. . . . . . . . . 8

1.6 Nomex honeycomb . . . . . . . . . . . . . . . . . . . 9

1.7 ASTM C364 failure modes of composite sandwiches [17] . . . . . . . . 11

1.8 Composites used on Boeing $787[20] \ldots \ldots \ldots \ldots$

2.1 Weaves of hemp fibers used . . . . . . . . . . . . . . 18

2.2 Comparison of bending strength and stiffness of carbon fiber/honeycomb composite sandwiches manufactured with the two different adhesive materials . . . 21

2.3 Non-automated tape layup of carbon fiber . . . . . . . . . . . . . . 23

2.4 Aeropoxy resin and hardener with dry hemp fiber, adhesive, and honeycomb core 23

2.5 Cal Poly Aerospace Structures lab heat press . . . . . . . . . . . . . . . 24

2.6 Cure cycles of each composite sandwich . . . . . . . . . . . . 25

2.7 Fully cured and cut sandwich specimen . . . . . . . . . . . . . 26

2.8 Hybrid sandwich with hemp outer face . . . . . . . . . . . . . . . 27

2.9 Problem of delamination between facesheet materials in hybrid sandwiches . . 28

2.10 Specimen with aluminum tabs bonded . . . . . . . . . . . . . 29

2.11 Poisson's ratio specimen with strain gages . . . . . . . . . . . . 30

2.12 Hemp specimen under tensile characteristic test . . . . . . . . . . . . . 31 
2.13 Hemp specimen under compressive characteristic test . . . . . . . . . . 32

2.14 Strain indicator used with a quarter bridge circuit $\ldots . . \ldots 33$

2.15 Example of anticlastic curvature with a honeycomb core[27] . . . . . . . . 34

2.16 How to calculate Poisson's ratio of honeycomb using anticlastic curvature [27] 35

2.17 Custom steel fixture . . . . . . . . . . . . . . . 36

2.18 Fixture loaded in Instron $\ldots \ldots \ldots$. . . . . . . . . . . . . 37

3.1 Tensile testing failures of facesheet materials $\ldots \ldots \ldots \ldots$. . . . . . 41

3.2 Compressive testing failures of facesheet materials $\ldots \ldots$. . . . . . . 43

3.3 Fiber volume fraction materials . . . . . . . . . . . . . . 46

3.4 ASTM C364 failure modes of composite sandwiches [17] . . . . . . . . . . . . 48

3.5 Edgewise-compressive testing of carbon fiber facesheet sandwiches . . . . . 50

3.6 Edgewise-compressive testing of plain weave hemp facesheet sandwiches . . . 52

3.7 Edgewise-compressive testing of herringbone hemp facesheet sandwiches . . . 54

3.8 Edgewise-compressive testing of glass fiber facesheet sandwiches . . . . . . 56

3.9 Edgewise-compressive testing of hybrid facesheet sandwiches . . . . . . . 60

3.10 Strength-to-Weight vs. number of layers . . . . . . . . . . . . . . . 64

3.11 Failure mode of all carbon fiber sandwiches . . . . . . . . . . . 66

3.12 Failure mode of all plain weave hemp sandwiches . . . . . . . . . . . 68

3.13 Failure mode of all herringbone weave hemp sandwiches . . . . . . . . . . 70

3.14 Failure mode of all glass fiber sandwiches . . . . . . . . . . . . 72

3.15 Failure mode of all hybrid sandwiches . . . . . . . . . . . . . 74

4.1 Orthotropic plate under in-plane uniaxial compression [30] . . . . . . . . . 78

5.1 Facesheet, core and top plate sketched as 3D parts . . . . . . . . . . . . 84

5.2 Full assembly of composite sandwich with top and bottom plates . . . . . . . 86

5.3 Composite sandwich constraints and boundary conditions . . . . . . . . . 88

5.4 Edgewise compressive load applied . . . . . . . . . . . . . . 89 
5.5 Facesheet, core and plate meshes . . . . . . . . . . . . . . . . 90

5.6 Results of edgewise compressive load applied to structure . . . . . . . . . 91

A.1 Edgewise strength versus number of layers . . . . . . . . . . . . . 101

A.2 Mesh convergence plot . . . . . . . . . . . . . . . . . 102 


\section{LIST OF EQUATIONS}

2.1 Experimental poisson's ratio of composite facesheet materials . . . . . . . . 34

2.2 Radius of anticlastic curvature of honeycomb core . . . . . . . . . 35

2.3 Poisson's ratio of honeycomb core . . . . . . . . . . . . . . 35

2.4 Ignition mass loss . . . . . . . . . . . . . . . . . . . . 36

3.1 Shear modulus relationship with Young's modulus and Poisson's . . . . . . . . 45

3.2 Ultimate edgewise compressive strength . . . . . . . . . . . . . . . 47

4.1 Governing Equation for displacement of thin plate . . . . . . . . . . . 78

4.2 Grand Vector Equation . . . . . . . . . . . . . . . . 78

4.3 Force Equation for plate under in-plane compression . . . . . . . . . . . 78

4.4 Deflection of a compressed plate . . . . . . . . . . . . 79

5.1 Governing Equation for implicit finite element analysis . . . . . . . . . . . 82 


\section{NOMENCLATURE}

$$
\begin{aligned}
& \varepsilon \quad=\quad \text { strain from strain gage }[\text { in } / \text { in }] \\
& v \quad=\text { Poisson's ratio } \\
& \delta \quad=\operatorname{deflection}[\text { in }] \\
& \sigma_{u l t}=\text { ultimate edgewise compressive strength }[p s i] \\
& c \quad=\text { distance between anticlastic curved honeycomb raised edges for Poisson's ratio tests [in] } \\
& C F \quad=\text { carbon fiber facesheet } \\
& d \quad=\text { honeycomb anticlastic curvature height for Poisson's ratio tests [in] } \\
& D \quad=\quad \text { flexural stiffness }\left[l b f-i n^{2}\right] \\
& E \quad=\text { elastic modulus }[p s i] \\
& G \quad=\quad \text { shear modulus }[p s i] \\
& \text { GF } \quad=\text { glass fiber facesheet } \\
& H B=\text { herringbone hemp fiber facesheet } \\
& K=\text { stiffness of structure } \\
& N=\text { theoretical force under in-plane uniaxial compression } \\
& P_{\max }=\max \text { force prior to failure }[l b f] \\
& P W \quad=\text { plain weave hemp fiber facesheet } \\
& R_{a} \quad=\text { radius of anticlastic curvature of honeycomb for honeycomb Poisson's ratio tests [in] } \\
& R_{c} \quad=\text { radius of cylinder that honeycomb was bent around for honeycomb Poisson's ratio tests [in] } \\
& t_{f s}=\text { thickness of single facesheet }[\mathrm{in}] \\
& U=\text { transverse shear rigidity }[l b f] \\
& w \quad=\quad \text { sandwich width }[i n]
\end{aligned}
$$




$$
\begin{aligned}
& \text { Subscripts \& Superscripts } \\
& c=\text { core } \\
& f s \quad=\text { facesheet } \\
& l=\text { longitudinal } \\
& \max =\operatorname{maximum} \\
& s \quad=\text { shear } \\
& t=\text { transverse } \\
& \text { ult }=\text { ultimate }
\end{aligned}
$$




\section{Chapter 1 \\ INTRODUCTION}

The following sections will include a brief background of the composite materials used in this experiment. They include: pre-preg materials (carbon fiber and fiberglass), biocomposite material (hemp), and Aramid fiber honeycomb core (Nomex). Types of composites and manufacturing techniques will be defined in the initial sections. Characteristics of composite sandwich structures will be discussed in the latter half as well as reasons why compressive behaviors of composite sandwiches must be investigated. Lastly, previous works and the objective of this work will be described at the end of the chapter.

\subsection{Composites Overview}

Composite materials are rapidly becoming the material of choice in many fields of engineering, especially Aerospace Engineering. This is due to the demand for lightweight materials with increased performance characteristics. All composite materials have high strength-to-weight characteristics and can be manufactured to fit the structural needs of any design without compromising strength.

\subsubsection{Introduction to Composites}

The word composite is defined as a combination of various parts or elements to create one standalone structure. The history of composite materials has been a part of man's technology that dates back to the 1500's B.C. when early Egyptians used straw to reinforce mud bricks. [1] This same concept is what makes up the composite materials of today. The 
mud used in ancient times is considered a matrix just like epoxy is considered a matrix. The straw used is considered a fiber that is laid within the matrix. Today, any kind of carbon fiber, fiber glass, or other fibrous materials is used in the same manner to the straw.

Composite materials did not technologically advance for many centuries, until the birth of plastics were introduced in the early 20th century. [2] Many new advances in composites began in the 1950's when better plastic resins were used to reinforce fibers such as glass to make fiberglass. Carbon fiber was also developed in the 1970's but fiberglass was the predominant composite in use through the 1980's until advanced carbon fiber was introduced to the aircraft industry, where it started to replace metal throughout industry. The evolving change from metal to composites has shown to be beneficial in many aspects including higher strength-to-weight ratio and corrosion resistance. But, the composites industry is still growing and learning how to focus research around renewable energy.

Recently, bio-composites have been a topic of interest for the automotive industry due to the demand for "greener" manufacturing processes. Bio-composites include such fibers as hemp, bamboo, kenaf, jute, and many other renewable plants. In fact, the world's most Eco-friendly car, the Kestrel, made entirely of hemp composite went into production in 2013 in Canada. The entire body of the car is made from an impact-resistant hemp biocomposite and is run off an electric battery, making it completely bio-degradable and safe for the environment. Another major car company, Lotus, has also started to delve into the hemp industry as well, by making a version of their Lotus Elise using hemp body panels. These two cars seen in Figure 1.1 a and 1.1b are proof that hemp bio-composites are on the rise and started to be taken serious for the world's need of creating a "greener" environment.

Even though all bio-composites present renewable qualities, the issue at hand is the fact that natural materials may not outperform current materials in industry. However, with proper research, natural materials may hold stronger than other materials in certain structural loading aspects. In order to accomplish this goal, unorthodox research must expand to weigh the advantages and disadvantages of both materials. 


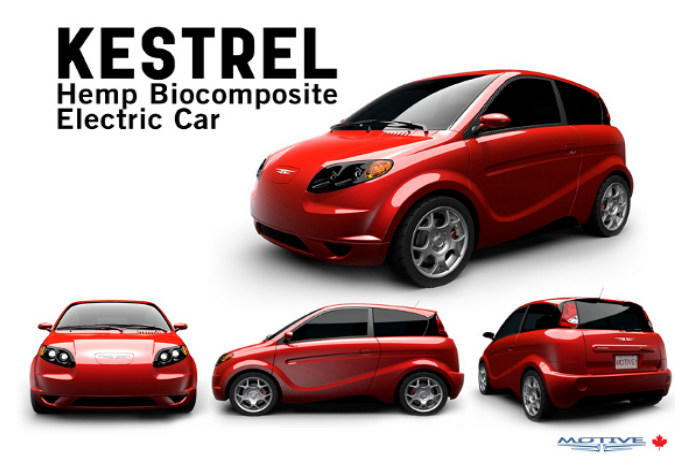

(a) World's most eco-friendly car [3]

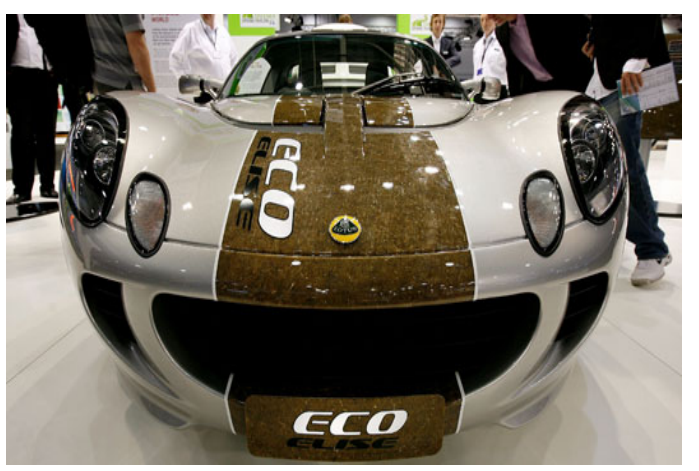

(b) Hemp version of a Lotus Elise [4]

Figure 1.1: Eco-friendly hemp composite cars

With today's fibrous materials, composite structures have evolved a long way from the old mud and straw method. Today, composites are non-homogeneous materials, meaning that they can exhibit many improved characteristics such as increased strength, stiffness, fatigue life, corrosion resistance, and even thermal insulation in any specified fiber direction.

A composite material is defined as the combination of two or more materials to create a superior material. In industry, composite materials are defined as three types, including, fibrous, laminate, and particulate. Fibrous composites include common materials like carbon fiber reinforced polymers (CFRP), glass-fiber reinforced polymers (GFRP), and even Aluminum. This can include any kind of sandwich beam with a low density core and a fibrous sheet on top and bottom of the beam. Within the aerospace industry, two of the main concerns for design are, minimizing weight and maximizing strength. The recent increase in consumer environmental awareness, along with increased commercial desire to use natural materials, has led to new innovations that are predominantly used as a replacement for conventional synthetic petroleum based composites systems.

Traditional composite materials like CFRP use the cellulose taken from petroleum to create the polymer. Although this method proves to create very strong and lightweight materials, there is another way to create material using the cellulose from different plant material. One of the greatest cellulose producers on Earth is hemp (85\% cellulose) and 
being that it is non-toxic and biodegradable, hemp may hold as a viable replacement for petroleum based plastics.[5] Any natural fiber can be developed into a thin fabric similar to dry carbon fiber and when it is impregnated with resin, it cures just like any pre-preg composite does. Three main categories of natural fiber composites consists of the natural fiber serving as a filler in commodity thermoplastics; composites where longer fibers enhanced with and other additives attain additional strength and toughness in thermoplastics; and composites where natural fibers are used with thermosetting resins as designed elements within engineered components.[6] In parallel to these developments there have been many advances in biodegradable polymers, both thermoplastic and thermosetting in nature. Composites using natural fibers and bio-based resins are poised to see explosive development within the next ten years.[6]

\subsubsection{Types of Materials}

\subsubsection{Composite Materials}

Fibrous composites consist of any kind of brittle fiber embedded in a ductile matrix such as CFRP or GFRP. The matrix usually carries the tensile load first but also yields first. Then the fiber carries the tensile load until fracture. The fiber can be any length or orientation laid within the matrix and different combinations can produce different yield strengths.

Particulate composites are similar to short fibrous composites but much more extreme. They are made of particles scattered throughout a matrix such as concrete. An example of fibrous and particulate composite can be seen in Figure 1.2a

Laminate composites are a combination of multiple layers of fibrous or particulate composites that usually create one orthotropic laminate sheet.[9] This can also be combined with a low density core to create a laminate composite sandwich as seen in Figure 1.2b. This combination will be investigated throughout this study. 


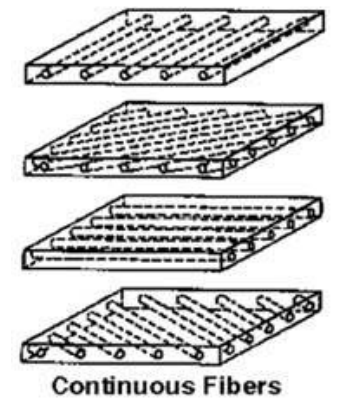

(a) Fibrous and particulate composites [7]

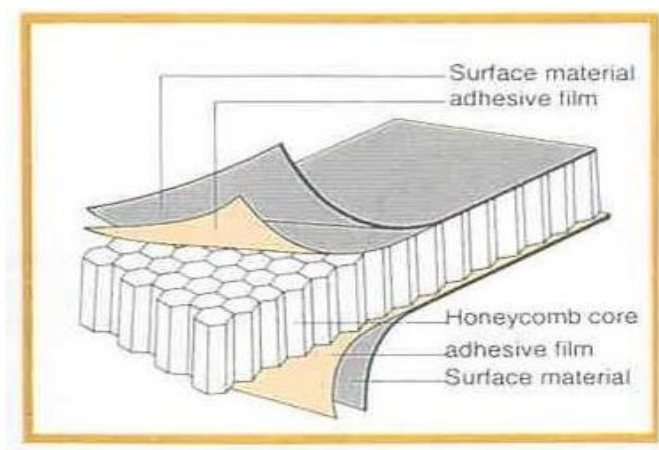

(b) Composite sandwich example [8]

Figure 1.2: Types of composites

\subsubsection{Bio-Composite Materials}

All of the composite materials mentioned above are lightweight and high strength but are not the most optimal materials when considering environmental concern. Petroleumbased composites are produced using fossil fuels, which are non-renewable resources that release harmful pollutants into the atmosphere during production disposal. Bio-composites on the other-hand may be a viable alternative as they are made solely of renewable resources. In order to produce a usable bio-composite like hemp fabric or bio-resin used for composites, one must go through a lengthy process of cultivating to produce the desired weave, fabric thickness or adhesive properties needed to perform similar to pre-preg composites. The beauty of using a natural material like hemp for composites is the unnecessary need to use harmful herbicides and pesticides; hemp is planted in dense crops not allowing sun light to penetrates seen in Figure 1.3, which reduces weed growth by 95\%, eliminating the need for herbicides. [10]

No pesticides are needed due to the inherent properties contained in the plant itself. Hemp is an ideal rotational crop due to its long taproot structure that helps retain topsoil, while also replenishing soil quality

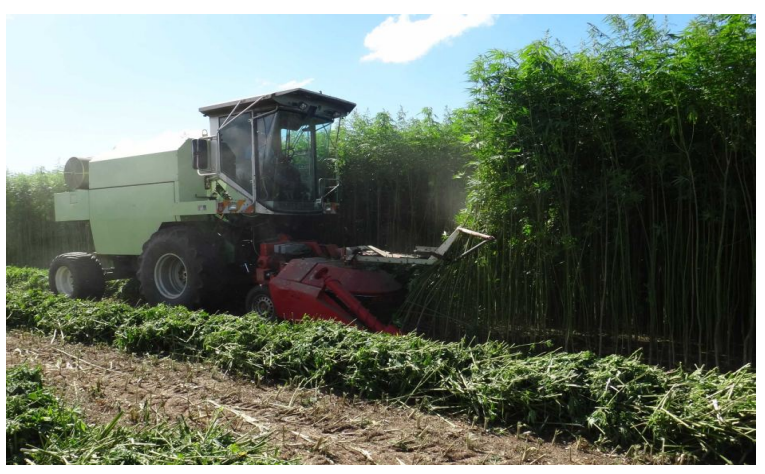

5 Figure 1.3: Industrial hemp farming [11] 
due to the natural leaf composting that regenerates vital elements in the soil. [10]

There are many uses of the hemp plant as seen in Figure 1.4 , but the unique inherent characteristics of the fiber of hemp have the additional ability to suppress the growth of harmful bacteria and fungi, making it the ideal "fiber for our future", especially within the bio-composite structures

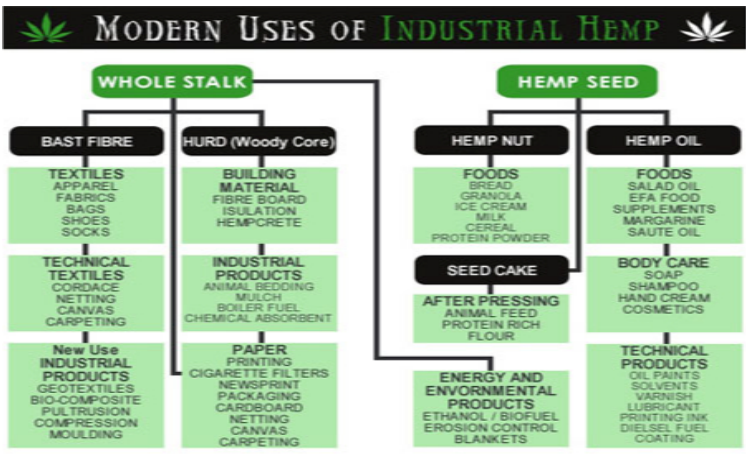

Figure 1.4: The uses of industrial hemp [12] aspect. [10]

\subsubsection{Manufacturing Techniques}

There are currently four different types of layups that are most commonly used in industry. The first method, also the oldest method, is known as the "wet-layup" or "hand-layup" technique, which involves taking dry fibers and mixing in resin by hand, before curing. Advantages include low cost, simple process, no machines needed for curing, no stringent curing cycles. Disadvantages include inconsistencies in fiber-to-resin ratio, and damage to fibers can occur during resin integration.[13]

The second method and most used method nowadays is known as a tape layup or "prepreg" layup, which is a composite that has had the resin pre-impregnated into the fibers when it is initially created. This process can be automated or non-automated. The pre-preg sheet is cut and stacked layer by layer. The orientation of the fiber matters in this scenario to ensure symmetry and to prevent warping. The advantages of pre-preg include a consistent fiber-to-resin ratio, which allows for the strongest part possible when cured. Disadvantages of pre-preg include high material costs, very specific curing cycles and expensive machines for curing (autoclaves or heat presses), and storage at temperatures for the pre-preg close to zero degrees Fahrenheit to ensure the epoxy resin does not cure before desired.[13] 
The third method is known as resin infusion or vacuum assisted transfer-molding system (VARTM). This method uses a vacuum to pull resin across a composite part, while also infusing the fibers with the resin. This can also be used for compression molding. Advantages include a balance between quality and cost, potentially minimal damage to fibers due to any handling of the fibers, and fairly consistent fiber-to-resin ratio. Disadvantages include, limited working time because it is reliant on the resin-curing rate. Big parts tend to prove troublesome with fiber-to resin ratio inconsistencies. This method is a happy medium between wet-layup and pre-preg; it's quick, not as costly as pre-preg and better fiber-to-resin ratios as wet-layup.

The last main method is known as filament winding, where fibers and resin are tensionwound together over a mold or mandrel and, after curing, the mold or mandrel is removed. This process is usually used for composite tubing. It is relatively new and has had many improvements since its inception.

As the integration of composite materials, specifically in military aircraft, increased from the 1960's onward, improvements in fibers and matrix materials resulted in carbon fiber reinforced plastics (CFRP) composites. With improved mechanical properties, CFRP replaced the more conventional titanium alloys and aluminum for primary aircraft structures. The main advantages of CFRP include complex shape manufacture, improved fatigue life, design optimization, reduction in excess material, significant part mass reduction and improved corrosion resistance.[14] The disadvantages include high material and processing costs, susceptibility to impact damage, more advanced repairs and inspections, and size effects on strength. Innovation is paramount in making composites as affordable as, or as close to the affordability of, the conventional material counterparts. 


\subsection{Composite Sandwich Overview}

The American Society for Testing and Materials (ASTM) defines a sandwich composite as a laminated composite facesheet that is bonded to a core material.(ASTM C274 - 07 Standard Terminology of Structural Sandwich Constructions) [15]

Sandwich structures utilize each of the constituent material properties. The thin facesheets have a high stiffness, and when combined with a low-density core, give a sandwich structure a high stiffness-to-weight ratio when compared with a facesheet plate of the same weight as seen in Figure 1.5. This is an ideal characteristic for aerospace structures.

The basic concept of a sandwich struc-

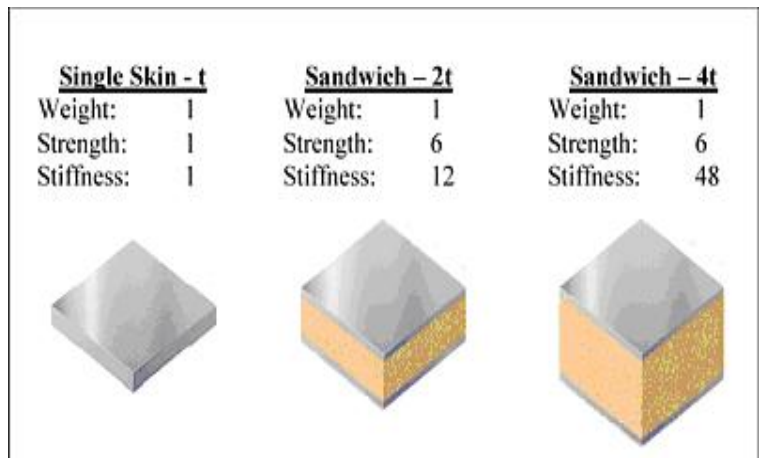

Figure 1.5: Composite sandwich advantage [16]

ture is that the facesheets carry the in-plane and bending loads while the core carries the shear loads.

\subsubsection{Facesheets}

The facesheet (skin) can be comprised of many different fibrous materials that have an epoxy matrix interlaid. The facesheets are generally thin, high density, high tensile strength material. Facesheets are mostly identical in material and thickness and they primarily resist the in-plane and bending loads of the composite sandwich. The facesheets should be thick enough to withstand the tensile, compressive and shear stresses and are generally stronger in tension and compression when compared to the low density core material.

A facesheet must have a matrix along with the fibers and generally the matrix is some sort of epoxy resin. The most widely used is an unsaturated polyester or vinyl ester thermosetting resin. The mechanical properties of the resin depend on both the resin chemical 
and curing chemical. Curing is completed by a certain schedule, which involves heating and keeping the resin to one or more levels of temperature for a prescribed amount of time. If this is not carried out properly, the facesheet will either be overcooked and brittle or undercooked and malleable, thus making the facesheet useless.

\subsubsection{Cores}

The core of a sandwich structure can almost be any material or architecture, but in general they are classified in four types; foam or solid core, honeycomb core, web core and corrugated or truss core. The core is usually very lightweight such as aramid fiber, aluminum or foam. In industry, most sandwich structures consist of a core material that is generally thicker than the facesheet and is made of a low-density, low performing material. The core should be thick enough and have a sufficient shear modulus to prevent overall buckling and crimping of the sandwich under load.

Nowadays, a common core to use in a composite sandwich is a Nomex honeycomb core due to its ability to prevent buckling of the thin skins by providing the right amount of shear strength to do so. Honeycomb cores are also very lightweight, easy to work with, and fairly fatigue resistant.

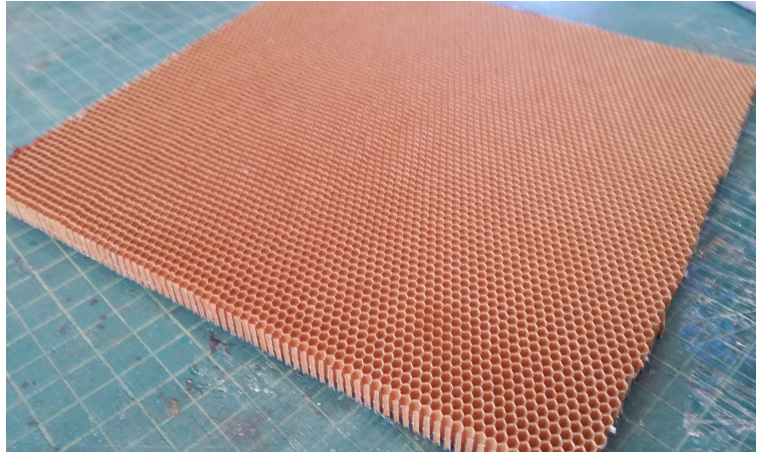

Figure 1.6: Nomex honeycomb

A Nomex honeycomb structure, which is made up of aramid paper is similar to the cross section of a beehive as seen in Figure 1.6. The strips of aramid paper are laid in such a way to create two ribbon directions. The "ribbon" direction is also known as the longitudinal direction, and $90^{\circ}$ to the longitudinal is known as the transverse direction. 


\subsubsection{Advantages and Disadvantages of Composite Sandwiches}

As mentioned above, composite sandwich advantages in the aerospace industry are; the ability to create strong, lightweight structures that can be used in place of aluminum or steel. Also, composite sandwiches are proving to be fatigue and corrosive resistant which is very beneficial in the aerospace industry.

Recently, composite sandwiches are becoming the popular choice for construction of strong, lightweight structures, but one of the main concerns or disadvantages in building them is, the face-to-core connection. There are different opinions in industry on the correct way to create a composite sandwich. One option is to cure the facesheet first, separately from the core, and then bond the facesheet to the core with an adhesive. Another option is to cure the facesheet with the adhesive and the core all as one sandwich. The problem with the latter is if the adhesive material has a different curing cycle than the facesheet material, this process will not work. But, no matter which process is chosen, if the bond of the facesheet to the core is not sufficient for the type of loading, then the sandwich will fail

due to delamination. Even with the assistance from adhesive materials, it is still an area of focus in creating sandwich composites. If delamination does occur, any compressive load on the structure will be concentrated at that delamination area. This will create buckling in the facesheets and catastrophic failure will occur.

Another disadvantage of using composite sandwiches is that the core is susceptible to absorb moisture easily which leads to corrosion within the core. This can be prevented with a sealant around the edges of the sandwich, but if this is overlooked, moisture will propagate and failure will occur.

\subsubsection{Edgewise Compressive Behavior of Composite Sandwiches}

In general, in-plane loading causes buckling of a structure. In-plane loading of a composite sandwich structure is very important to investigate because different failure modes 
can arise from loading such a structure. Compressive properties, collapse modes and crushing characteristics of various types of composite sandwich panels are all dependent on the facesheet and the core used. Under edgewise compressive load, sandwich panels tend to collapse in the different modes as seen in Figure 1.7

According to ASTM C364, there are acceptable failures and an unacceptable failure when testing. The unacceptable failure is known as an "end" failure which is caused by bearing stress between the fixture and the specimen. The first accept-

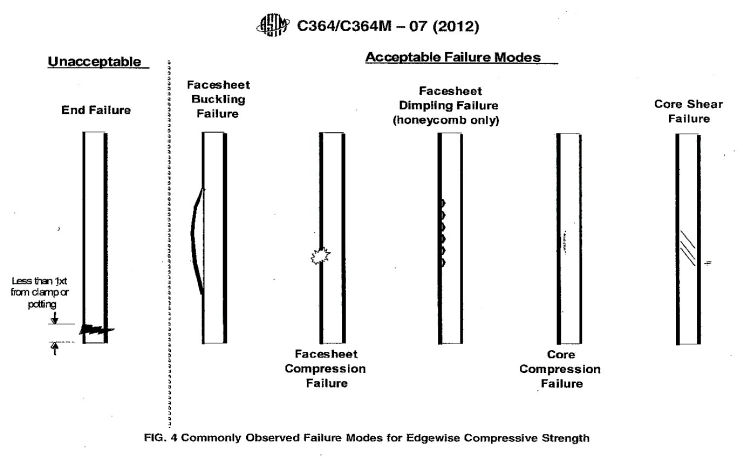
able failure mode is facesheet buckling fail- Figure 1.7: ASTM C364 failure modes of ure which can cause delamination of the composite sandwiches [17] facesheet from the core. Mode two is facesheet compression failure. The third mode is a facesheet dimpling failure which usually only happens with honeycomb. The fourth and fifth modes are, core compression failure and core shear failure, respectively. These failures would generally tend to happen if the core is significantly weaker than the facesheet. Overall, facesheet buckling or "delamination" is the most probable mode of collapse. The most important factor that determines the collapse mode and the overall crushing response of a sandwich panel under edgewise compression is the properties of the core and facesheet-tocore bonding.

\subsubsection{Applications of Composite Sandwiches}

The use of composites is in high demand in the aerospace industry due to favorable mechanical properties that carbon fiber and other composites alike prove to have. The use of sandwich composites is also becoming very popular due to the fact that a sandwich panel is very lightweight and has increased stiffness when compared to the facesheet and core as standalone structures. The industry norm has been aluminum for many years but 
now composites are taking over as the preferred choice of material in industry. Not only are composites being used and researched, but bio-composite materials are also on the rise due to their biodegradable properties.[18] Composites have many different applications throughout many different industries.

In aerospace applications, various honeycomb core sandwich structures were used for space shuttle constructions and are also used for both military and commercial aircraft. The U.S. Navy and the Royal Swedish Navy has used honeycomb sandwich bulkheads to reduce the weight of the ship and to withstand underwater explosions for more than 20 years.[19] Moreover, locomotives are designed in order to resist the pressure waves occurring during the crossing of two high-speed trains in tunnels. More recently, sandwich constructions are commonly used in civil engineering projects such as bridge decks, wall and roof claddings for buildings because of their low cost and thermal performance.[19] Also, rail cars for rapid transit trains, buses, sailboats, racing boats, racing cars, snow skis, water skis and canoes are all employing sandwich constructions.[19] Also, the auto industry has many uses for composites due to the fact that it decreases weight and adds strength which increases fuel consumption. The auto industry has also started implementing the bio-composite material, hemp, into the body panels as mentioned in an earlier section. This not only reduces raw material cost but still maintains good mechanical characteristics.

Lastly, composite materials have a main presence in the aircraft industry. Sandwich composites are starting to be implemented into the interior seat shells, floor and ceiling panels, interior cargo compartments, and even the engine cowls as seen on the new Boeing 787 in Figure 1.8. Not only are sandwich composites being used but laminate composites make up most of the new aircraft wings, fuselage, and empennage. With that being said; steel, aluminum, and titanium only play a small roll in the material selection of the aircraft as can also be seen in Figure 1.8.

Weight savings is always a huge benefit in the aircraft industry and if there is a way for bio-composites to be implemented in place of petroleum based composites, then not only 


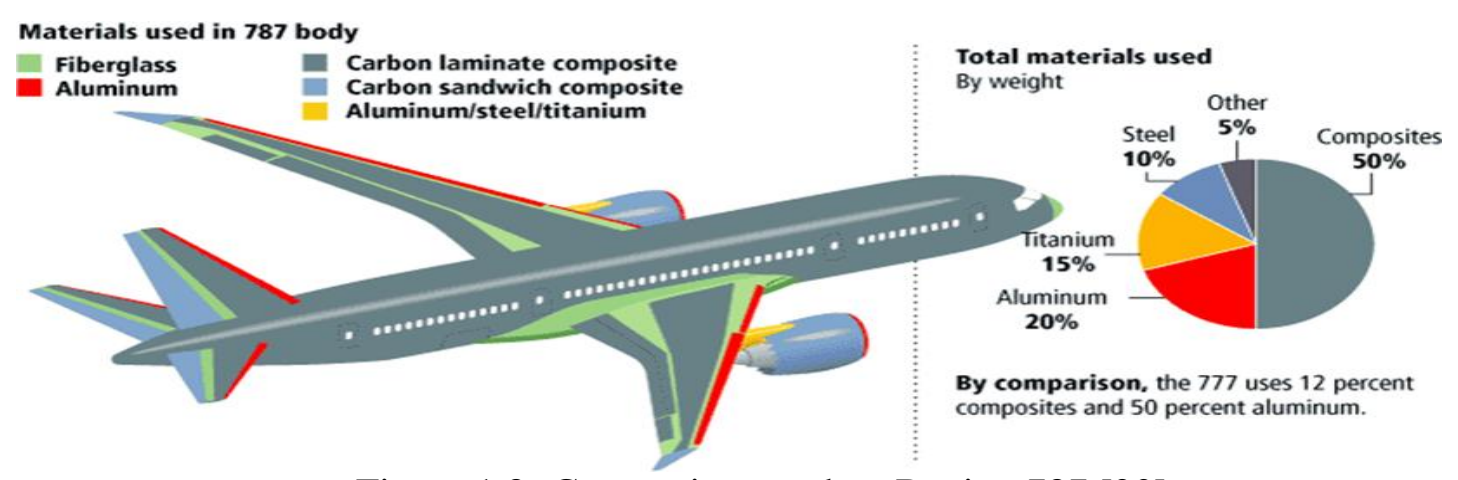

Figure 1.8: Composites used on Boeing 787 [20]

will there be weight decrease and similar strength, but there will be a biodegradable and sustainable aspect of using the natural material.

\subsection{Previous Research of Edgewise Compression of Composite Sandwiches}

To help finding the correct test procedures and materials, previous work on similar research is very beneficial to reference. By examining previous research, time and money can be saved to make sure not to repeat any failing or useless tests.

Throughout this study, edgewise compression of composite sandwiches will solely be investigated. In the edgewise compression test, facesheets are the main load carrying members. The core materials increase the strength of the system by coupling the facesheets to each other and increasing the buckling capacity. The failure mode of edgewise compression testing is one of the main concerns for a structural designer, and by having an idea of how different facesheets and cores fail, an ideal combination can be developed.

One of the main failure concerns when testing a composite sandwich is delamination of facesheet to core. Even with an adhesive in between the two, delamination can still occur. According to a study conducted by İzmir Institute of Technology in Turkey, facesheet buckling within the sandwich panel initiated with the delamination of the core and facesheets at the edge of the panels in contact with the cross-heads. Failure occurred due to shear force at the interface between the core and the facesheet laminate; on the compression side of the 
core. On the opposite side that is under tension, the core remained perfectly bonded to the facesheet.[19]

According to M K Khan [21], The behavior of honeycomb sandwich panels under compressive loads, against out-of-plane axis which is the strongest axis under different a kind of support and against edgewise configuration, has been investigated by many researchers analytically or experimentally. Hoff and Mautner [22] studied the edgewise compression mode and investigated the buckling of sandwich panels. Birman [23] gave a solution based on simultaneous wrinkling of both facings during edgewise compressive mode. Edgewise compressive tests were performed to find the difference in strength of the sandwich panel when compressive loading is applied to the in-plane direction. The purpose of the test was to investigate the difference in strength with respect to core thickness and facing type of the sandwich panels and to predict the expected failure mode that a sandwich panel can withstand in this kind of compressive loading.

As mentioned above, there have been many studies conducted on the effects of compressive loading of composite sandwiches. The failure modes seem to be consistent and will be kept in mind throughout this study. Even though there are many studies in the past similar to this study, the combination of facesheet and core vary drastically from study to study. Many experiments in the past have used outdated materials like aluminum or steel. Newer age materials like carbon fiber and fiberglass still need more research to examine the failure modes of different sandwich combinations. In addition, bio-composite materials under compression has not been researched nearly as much as other materials, if at all. Throughout this study, the bio-composite, hemp will be investigated and compared with the pre-preg materials, carbon fiber and fiberglass. 


\subsection{Main Objective and Scope of Study}

The objective of this study was to determine failure modes of two different types of hemp, fiberglass, and carbon fiber facesheets and discuss strength-to-weight ratio of the different sandwich panels.

The goal of this research is to provide experimental and theoretical analysis by consecutively increasing the amount of layers of two types of hemp, fiberglass and carbon fiber facesheets creating sandwich panels using Nomex honeycomb core which will be tested under an edgewise-compressive loading condition according to ASTM C364. The Nomex honeycomb core will be kept constant. Throughout this study the effect of the failure mode will be carefully examined. Strength-to-weight ratio and the deflection at a constant 1000 pound load will be compared as well.

After all initial testing of carbon fiber, fiberglass and hemp are completed separately, a combination of the two best performing facesheets will be embedded into the same sandwich to create a hybrid sandwich. The goal of this procedure is to see how well the two materials perform when they are mixed. This hybrid sandwich may potentially create a composite sandwich that utilizes the tensile strength and compressive resistance of each material to create a superior sandwich composite panel.

The rest of this study will delve into the manufacturing and testing processes performed for each sandwich design, the experimental results of each test, and the comparisons of experimental and numerical analyses. Chapter 2 explains the specimen manufacturing methods used to construct each composite sandwich and the testing procedures used for material property testing. The edgewise compression testing procedure will be described as well. Chapter 3 will present the experimental results obtained for the material properties testing and for the edgewise compression testing. The experimental failure modes will also be examined and discussed for each sandwich design. Chapter 4 will discuss the theoretical analysis used to predict the deflection created during the edgewise compression testing. 
Chapter 5 will discuss the Finite Element Analysis used to predict the deflection values created during testing. In Chapter 6, all experimental, theoretical, and analytical values will be compared. Chapter 7 will conclude the study and present ideas for future considerations. 


\section{Chapter 2 \\ MANUFACTURING AND TESTING PROCEDURES}

This chapter will discuss the specimen manufacturing and testing procedures. There are some general guidelines that must be followed when preparing and testing composite specimens. First, this chapter will discuss the facesheets, core, adhesives and the layup method chosen. The second part of this chapter will also discuss the procedures taken to generate mechanical properties of each material used throughout the experiment.

\subsection{Composite Sandwich Design and Materials Used}

A composite sandwich structure is composed of two laminate composite facesheet materials that are placed on each side of the core material. The composite sandwich design that will be created and tested throughout this study was chosen according to ASTM C364, with the dimensions of the sandwich being, a 4 inch width by a 3 inch height and a constant honeycomb core of 0.375 inch thick. Each specimen was constructed with the same core and dimensions. The variation in sandwich design occurs with the amount of facesheets used. Each material used for the facesheets will have a symmetrical design, being that the core is in the middle of the facesheets (or "layers") and the layers will be placed on top and bottom of the core. The different combinations being tested will include; 2 layers, 4 layers, 6 layers, and 8 layers for the single materials of carbon fiber, fiberglass, and two different types of hemp. When creating the hybrid combination, a 4 layer and an 8 layer combination will be investigated while changing the outer facesheet for each combination. 


\subsubsection{Facesheets}

Two of the four materials used for the facesheets were pre-preg materials; carbon fiber and fiberglass. The pre-preg materials had to be stored in the Cal Poly Aerospace Structures freezer so that curing did not occur before intended. The two different hemp fibers used were dry fiber cloth material which could be kept at room temperature.

The pre-preg carbon fiber material used in the composite sandwich structure was Hexcel's pre-impregnated bi-weave. This was designed and manufactured with Hexply AGP280$5 \mathrm{H}$ fibers and an 8552 epoxy matrix.

The fiberglass pre-preg which was a slight variation of a typical fiberglass composite material. This material is called Texalium and it is a $2 / 2$ twill weave (two fibers woven in one direction for every two fibers woven in the perpendicular direction) fiberglass that has a proprietary finish and a thin coating of $99.99 \%$ pure aluminum, which is approximately 200 angstroms thick. Its designation is NB308T 7725 Texalium.

The hemp fabrics used were B601 Natural Canvas, Plain Weave and D118DKBR Dark Brown Split Herringbone Weave, shown in Figure 2.1a, 2.1b and data can be seen in Table 2.1.

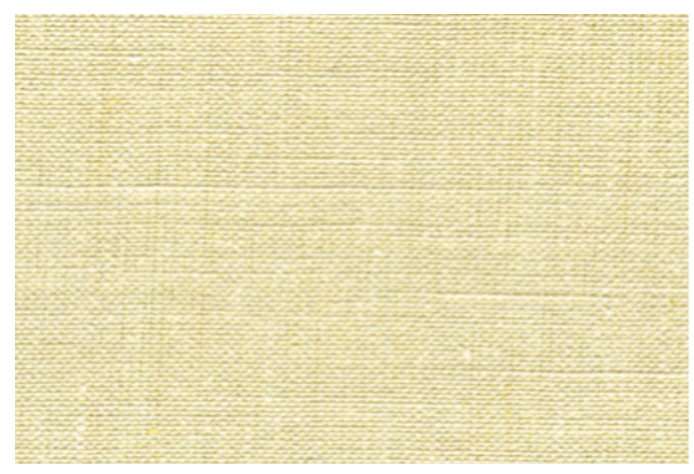

(a) Plain Weave Hemp Fiber

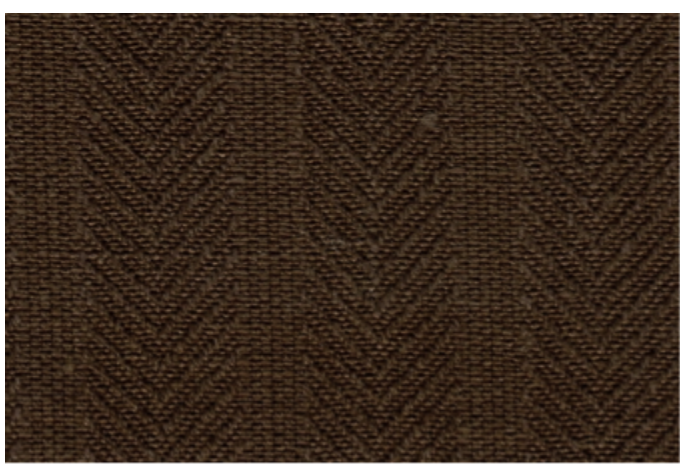

(b) Dark Brown Split Herringbone Weave Hemp Fiber

Figure 2.1: Weaves of hemp fibers used

These hemp fabrics were manufactured by EnviroTextiles and it was combined with an Aeropoxy epoxy composed of PR2032 resin and PH3660 hardener. The PR and PH stand 
Table 2.1: Hemp fabrics used as facesheets

\begin{tabular}{|c|c|c|c|c|}
\hline & $\begin{array}{c}\text { Weight } \\
{[\mathrm{oz}]}\end{array}$ & $\begin{array}{c}\text { Width } \\
{[\mathrm{in}]}\end{array}$ & $\begin{array}{c}\text { Areal } \\
\text { Weight } \\
{\left[\mathrm{g} / \mathrm{m}^{2}\right]}\end{array}$ & $\begin{array}{c}\% \text { Hemp } \\
\text { Fiber }\end{array}$ \\
\hline $\begin{array}{c}\text { Plain Weave } \\
\text { Hemp Fiber }\end{array}$ & 12 & $57 / 58$ & 370 & 100 \\
\hline $\begin{array}{c}\text { HB Weave } \\
\text { Hemp Fiber }\end{array}$ & 16 & $55 / 56$ & 550 & 100 \\
\hline
\end{tabular}

for resin and hardener, respectively, and the numbers are Aeropoxy's description of the type of resin and hardener.

These four materials, used as composite sandwich facesheets, will be compared throughout this study. Once each material is compared individually, the two strongest, lightest materials will be combined to create an optimum hybrid composite sandwich.

\subsubsection{Core}

The core material which is the lowest density material in the sandwich design still plays an important role in the testing of each sandwich. Being that it separates the facesheets and creates a larger moment of inertia of the entire sandwich structure, the overall failure load is greater with a core than without.

The core used in this experiment is a Nomex honeycomb core which is a non-homogeneous, anisotropic material. This means it is not one solid structure and its material characteristics are different in each axis direction. The fibers that make up the cell walls of honeycomb run in one direction along the honeycomb structure (the longitudinal direction). The other axis direction of the honeycomb is called the transverse direction and it runs perpendicular to the fiber orientation. Being that the longitudinal direction is stronger in compression, this orientation will be used and loaded for every sandwich structure. The honeycomb used for this study was a Hexcel HRH-10 (1/8"cell size, 5.0 pounds per cubic foot nominal density). 
Hexcel's HRH honeycomb is composed of hexagonal cells that are made of aramid fiber cell walls coated in a heat-resistant phenolic resin.

\subsubsection{Adhesives}

An adhesive is pertinent in composite sandwich design. An adhesive which is placed between the core and facesheet helps to prevent delamination during testing. In this study, two different adhesive materials were used, due to the low supply of the first adhesive.

The first adhesive used was a 3M AF 163-2OST WT 0.03 which is a thermosetting modified epoxy structural adhesive that comes in film form.

The second adhesive that was used for the latter half of the experiment was an epoxy film made by Hexcel that was designated as 8552 RFI A1030/B430. It is made of the same epoxy used in the carbon fiber pre-preg facesheet material but comes as a non-reinforced epoxy film.

Both adhesives were compared in a separate test using the same sandwich design. They were tested under the same loading conditions and proved to be similar in quality. Carbon fiber and honeycomb composite sandwich structures were manufactured with the Hexcel 8552 adhesive and the four-point bending strength and stiffness of that sandwich were compared. The results of this side experiment are shown in Figure 2.2 and show a $2.98 \%$ difference in maximum loading between the two adhesives. The stiffness of each sandwich is the same regardless of adhesive used. These results showed that the adhesive used was not going to compromise any future tests and the Hexcel 8552 adhesive would be used in place of the $3 \mathrm{M}$ adhesive.

\subsection{Specimen Manufacturing}

Each pre-preg specimen was manufactured using the non-automated tape layup and each hemp specimen was manufactured using the "wet" layup technique. All specimen 


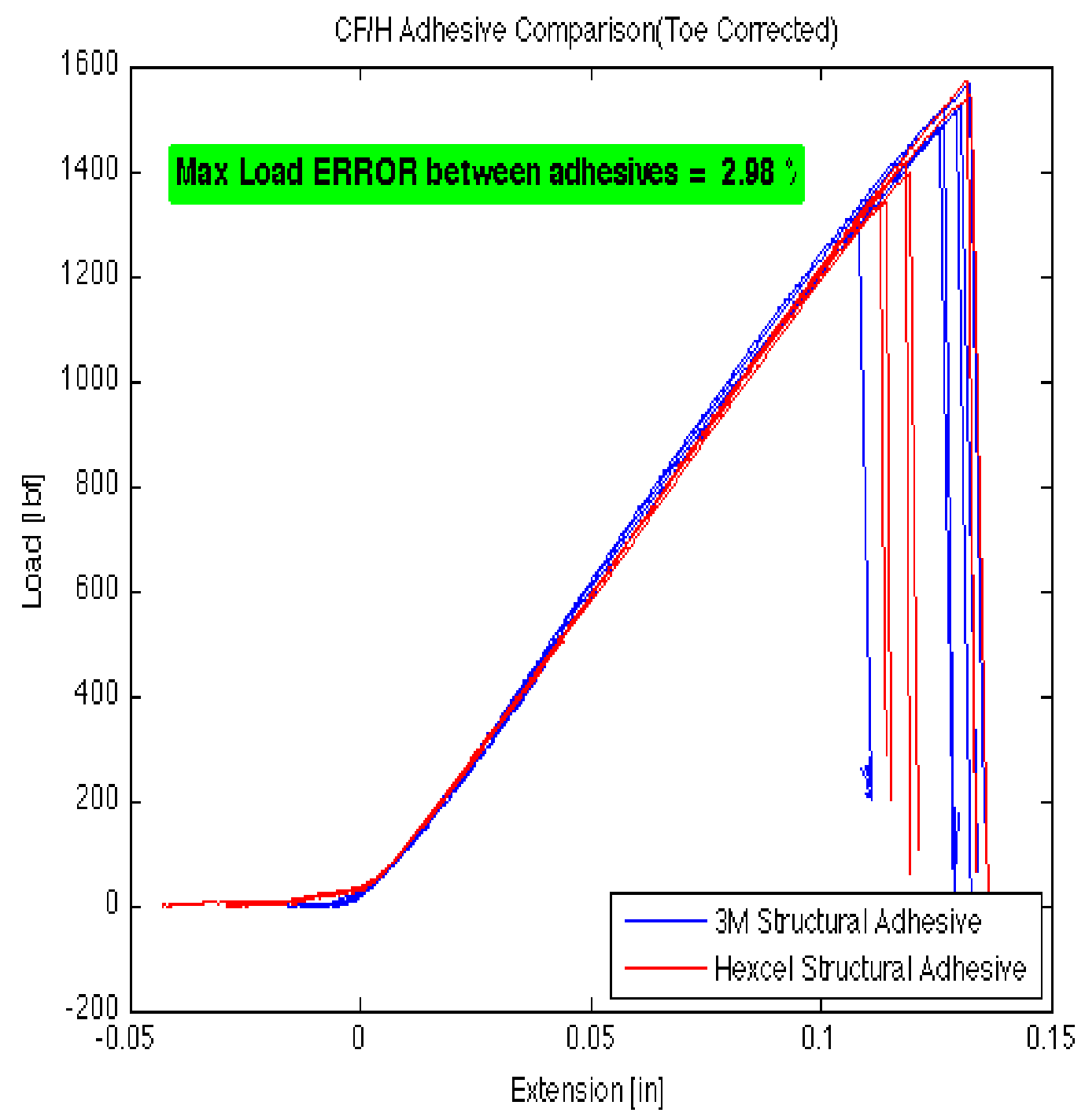

Figure 2.2: Comparison of bending strength and stiffness of carbon fiber/honeycomb composite sandwiches manufactured with the two different adhesive materials 
were cured in the composite heat press located in the Cal Poly Aerospace Structures Laboratory. The raw materials were cut to 10 inch by 10 inch squares and layered in a symmetric composite sandwich orientation with the core in the middle. The pre-preg materials used; carbon fiber and fiberglass, were assembled by hand using the non-automated tape method. This method requires the pre-preg to be taken out of the freezer and once it is at room temperature, it can be layered like stickers on top of each other. This method does not require any mixing of epoxy or vacuum bagging. On the other-hand, the hemp had to be assembled using the "wet" hand layup technique. This required a precise amount of epoxy resin and hardener to be mixed and spread throughout the dry fiber sheets. Care was taken to assure not to put to much epoxy or to little throughout the facesheets, as this would affect the way it cured and affect the overall specimen during testing. Once the specimen were cured in the heat press, they were cut using a diamond tile saw to a precise 4 inch by 3 inch dimension. Care was taken during this process because any imperfection would affect the test as each specimen was loaded on its edge.

\subsubsection{Layup Methods}

Even though the specimen were created to be the exact same dimension, the layup method did vary depending on whether or not it was pre-preg or dry fiber. Two methods were used throughout this experiment: The non-automated tape method for the pre-preg material, and the wet layup technique for the hemp fibers.

\subsubsection{Non-Automated Tape Layup}

The carbon fiber and glass fiber pre-preg materials came from the manufacturer as a bulk roll of material that had to be cut into individual 10 inch by 10 inch squares.

This method was very simple and only required scissors to cut the material off the bulk roll, then a rolling pin was used to assure all the air was compressed out from in between the individual plies. 


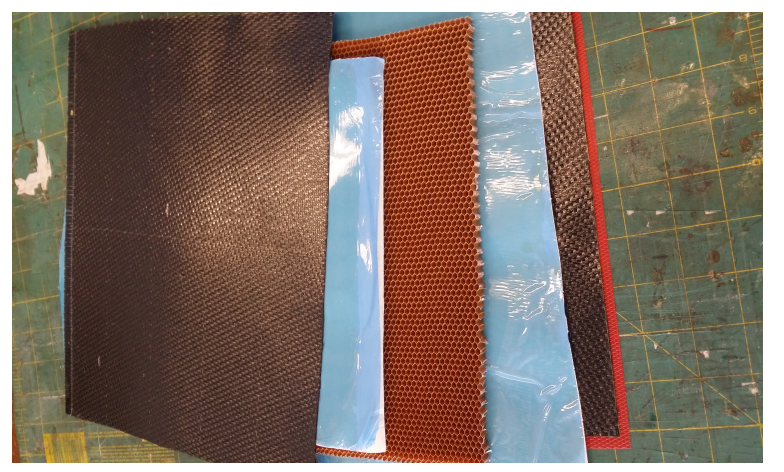

Figure 2.3: Non-automated tape layup of carbon fiber

These pre-assembled parts for carbon fiber are shown in Figure 2.3. The same process of assembling was used for the glass fiber.

\subsubsection{Wet Layup Technique}

The composite sandwiches constructed with the hemp fibers needed a different method of layup because it came from the manufacturer as a roll of dry fabric with no epoxy matrix impregnated in it. So using the wet layup technique, these specimen required a couple more steps to assure it cured similar to the pre-preg sandwiches.

The first step of this process was to cut the hemp fabric into squares similar to the pre-preg material as shown in Figure 2.4. The next step in the wet layup method was to mix the correct amount of resin and hardener to assure every square inch of the facesheets was properly soaked with the epoxy mixture. Using the 100:27 ratio of resin to hardener as indicated by Aeropoxy datasheets, and by testing the amount of epoxy to saturate one square inch of material, we discovered that 0.25 grams com-

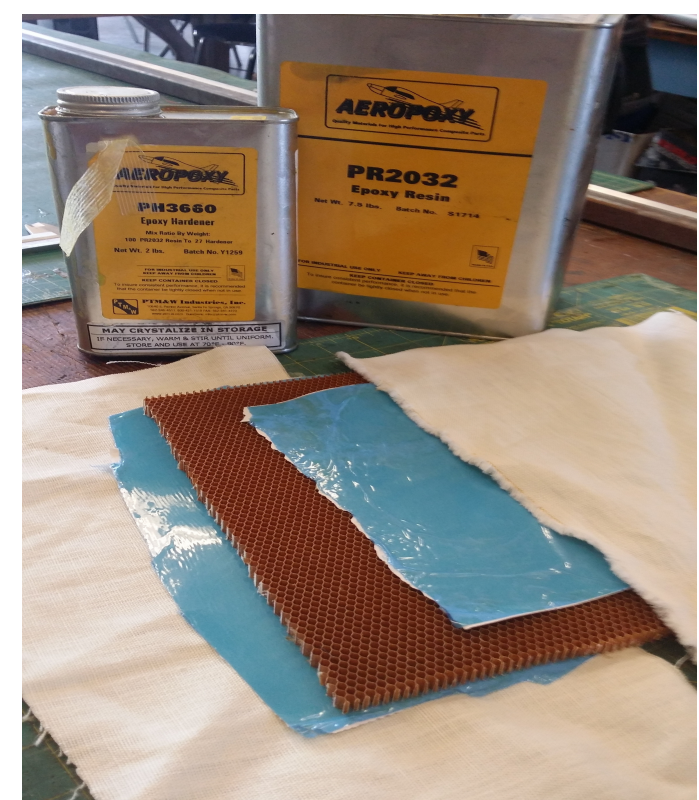

Figure 2.4: Aeropoxy resin and hardener with dry hemp fiber, adhesive, and honeycomb core

pletely saturated the material. So, the mixture of Aeropoxy was weighed out to roughly 250 grams of resin and hardener combined per 10 inch by 10 inch square of hemp fabric and poured onto the hemp facesheets. 
After each hemp facesheet was covered thoroughly with the epoxy mixture, the facesheets were laid on each side of the honeycomb core, making sure that the adhesive sheet was also applied in between the facesheets and core. After this process was completed, the same process of manufacturing to the pre-preg non-automated tape layup was completed.

\subsubsection{Curing and Post-Curing Process}

All specimen were cured in the heat press located in the Cal Poly Aerospace Structures lab using a non-porous sheet on top and bottom of the sandwiches to ensure resin was not leaked out during pressurization. The heat press, shown in Figure 2.5, has two metal plates that are each 12 inch by 12 inch squares.

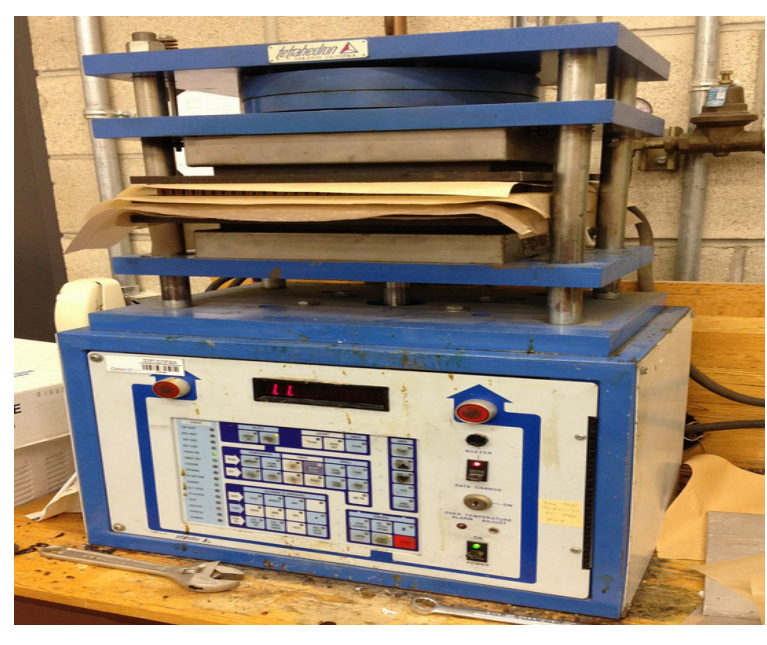

Figure 2.5: Cal Poly Aerospace Structures lab heat press

The sheets of non-porous material separating the sandwiches from the metal plates also helped give the composite sandwich a clean finish after it cured.

Each cure cycle used in the heat press was based on the manufacturer's recommended cure schedules of the epoxy matrix used in each composite material. The Hexcel 8552 epoxy system in the carbon fiber pre-preg facesheets had a suggested curing cycle on its data sheet. The cycle consisted of an initial ramp up to $225^{\circ} \mathrm{F}$ where it was held for an hour. Following that hour, the temperature ramped up again to $350^{\circ} \mathrm{F}$ and stayed there for two hours.[28] Finally, a ramp down in temperature occurred at $145^{\circ} \mathrm{F}$. A constant force of $300 \mathrm{lbf}$ was held on the carbon fiber sandwiches throughout the cure cycle as well.

The hemp composite sandwiches cured based on the Aeropoxy cure cycle which was held at $120^{\circ} \mathrm{F}$ for 12 hours. A constant force of $100 \mathrm{lbf}$ was held on the sandwiches through- 
out the process. The glass fiber composite suggested a one hour cure cycle at $250^{\circ} \mathrm{F}$ with a $100 \mathrm{lbf}$ constant force.

The carbon fiber, glass and hemp fiber cure cycles are shown in Figure 2.6a, 2.6b, and 2.6c, respectively.

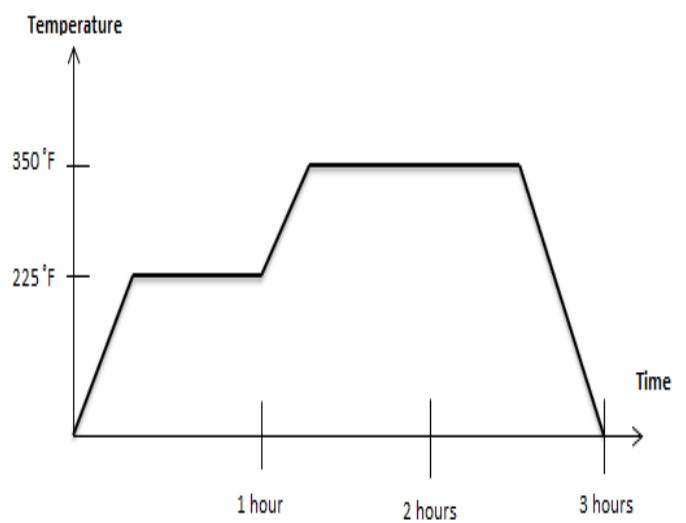

(a) Carbon fiber pre-preg cure cycle

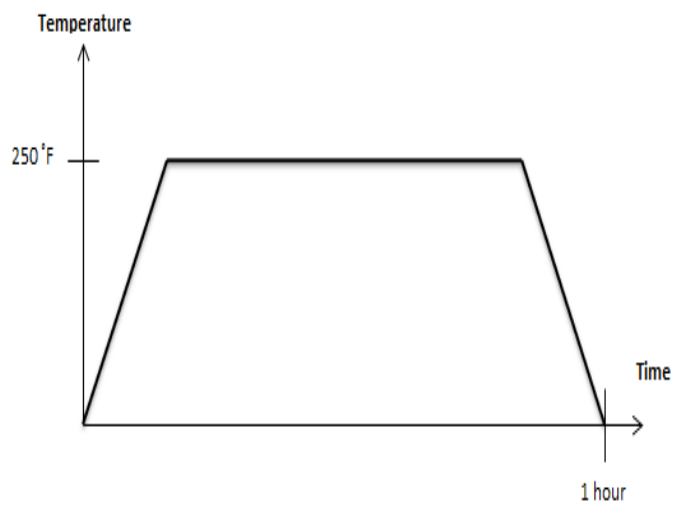

(b) Glass fiber pre-preg cure cycle

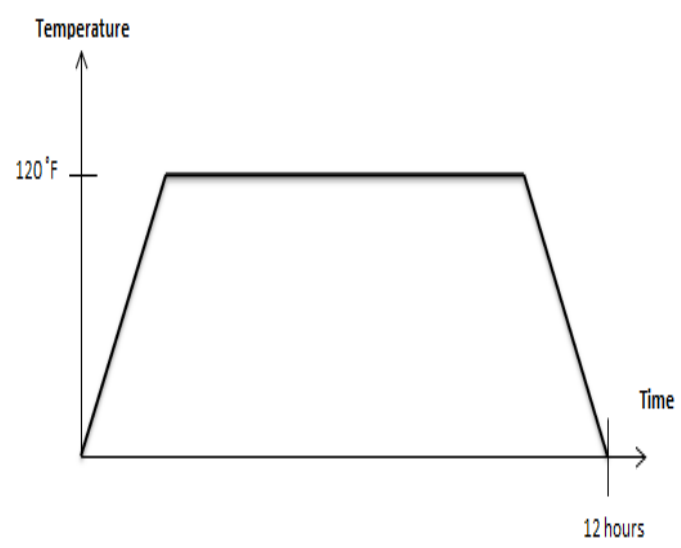

(c) Both hemp weaves cure cycles based on Aeropoxy epoxy

Figure 2.6: Cure cycles of each composite sandwich

Once the sandwich plates were finished curing, each plate had to be cut down to the five (4 inch by 3 inch) test specimens using a diamond tile saw. To accurately cut each specimen out of 10 inch by 10 inch the plate, lines were drawn with a sharpie and straight edge on the cured plates to designate where each sandwich should be cut out. The fully cured and cut individual sandwich specimen are shown in Figure 2.7. 


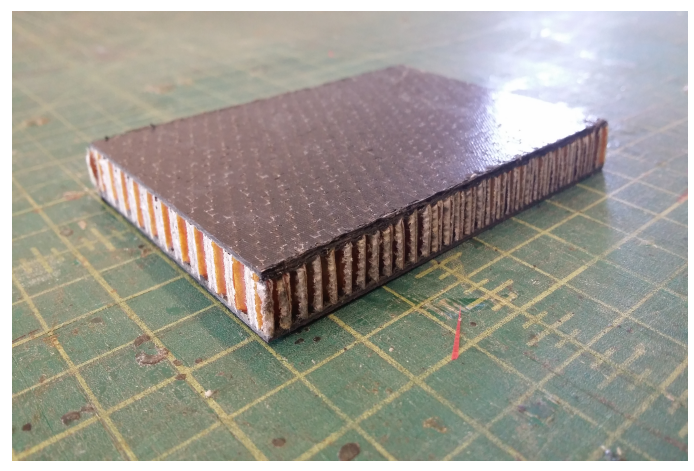

(a) Carbon fiber sandwich fully cured

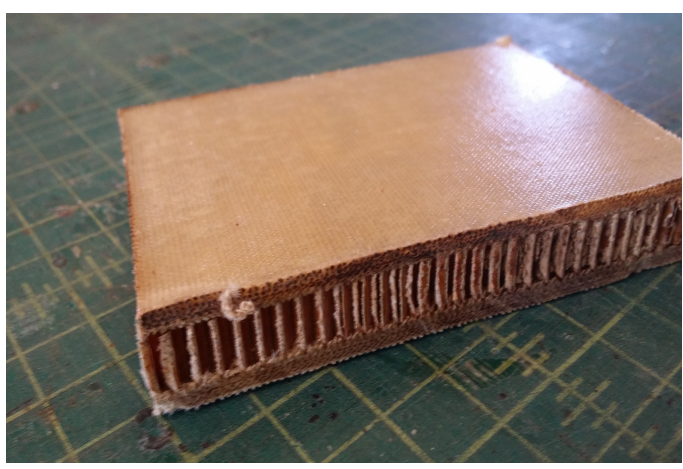

(b) Plain weave hemp sandwich fully cured

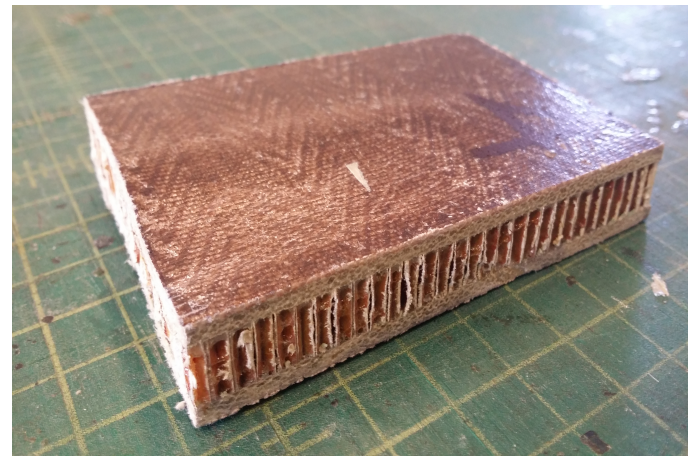

(c) Herringbone weave hemp sandwich fully cured

Figure 2.7: Fully cured and cut sandwich specimen

\subsubsection{Issues Faced During Hybrid Manufacturing}

After trial and error, the best way found to create a hybrid sandwich was to cure the carbon fiber facesheets by themselves first. Then, when they were done curing, the hemp was laid either on the outside or the inside face of the sandwich using the wet layup technique and cured again with the core sandwiched in the middle. This was all cured as one sandwich, which allowed the hemp to cure without the carbon fiber being affected. The successful hybrid sandwich under load without delamination can be seen in Figure 2.8

The carbon fiber has a higher curing temperature so there was no worry of creating a brittle carbon fiber facesheet. Unfortunately, not all hybrid sandwiches were successful during testing and most had a problem with delamination, especially the ones created with carbon fiber as the outer face. The sandwiches with carbon fiber as the outer facesheet had a higher temperature resistance than the epoxy used for the hemp, so the epoxy used on 


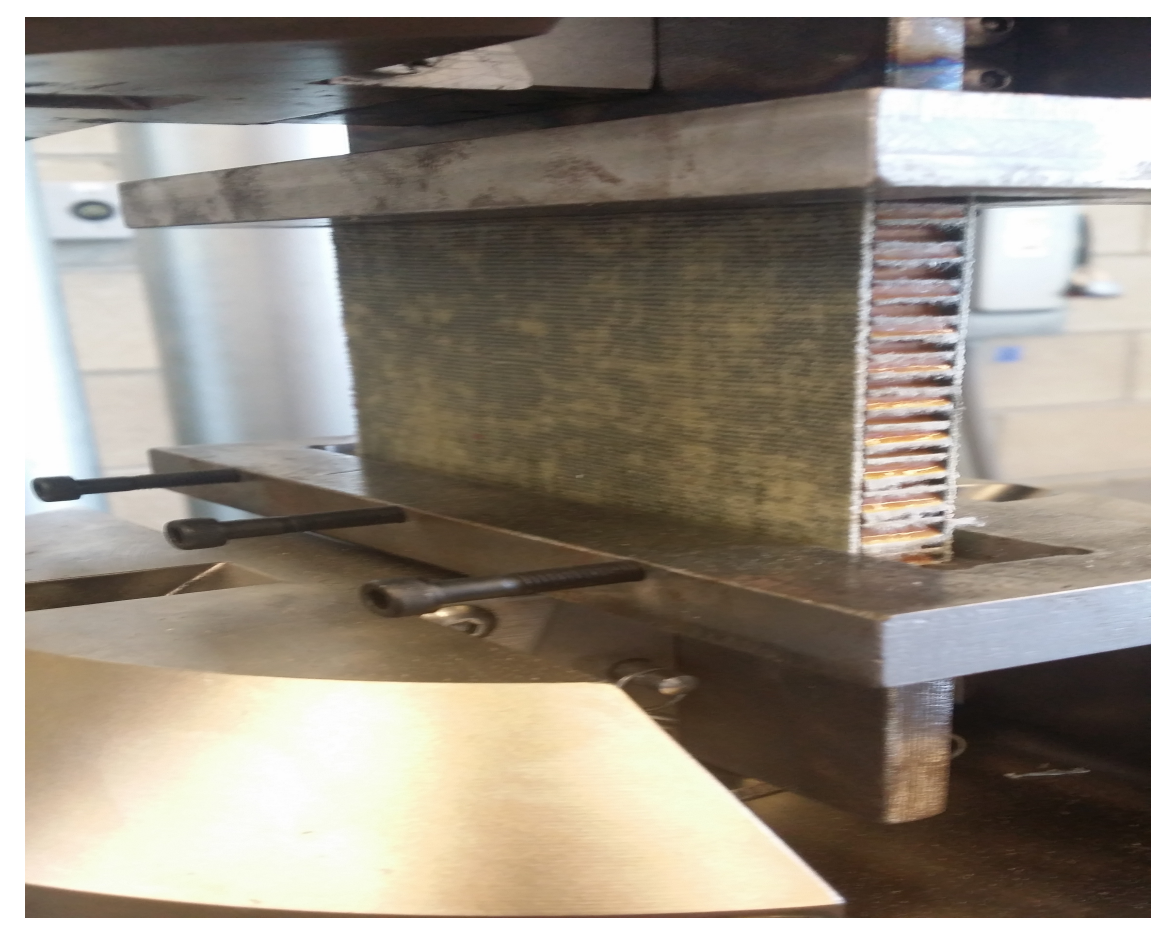

Figure 2.8: Hybrid sandwich with hemp outer face

the inner facesheet became brittle when cured above its glass transition temperature, thus creating a poor bond to the core. The problem of delamination can be seen in Figure 2.9. 


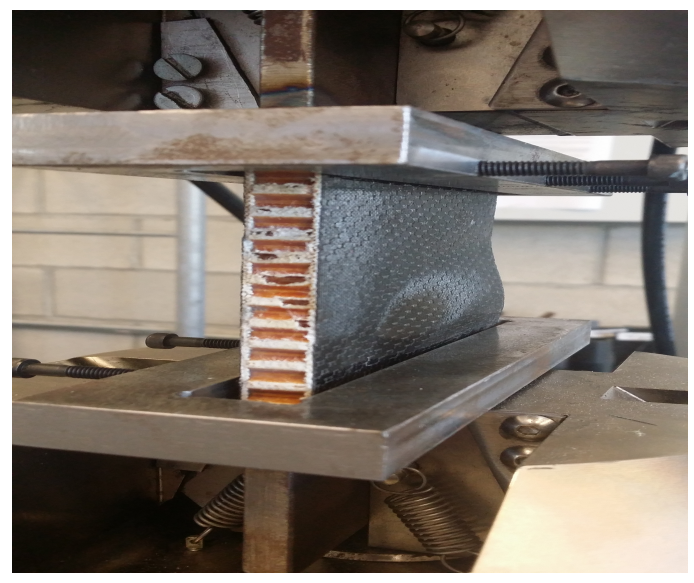

(a) Carbon fiber outer face separating from inner face of hemp

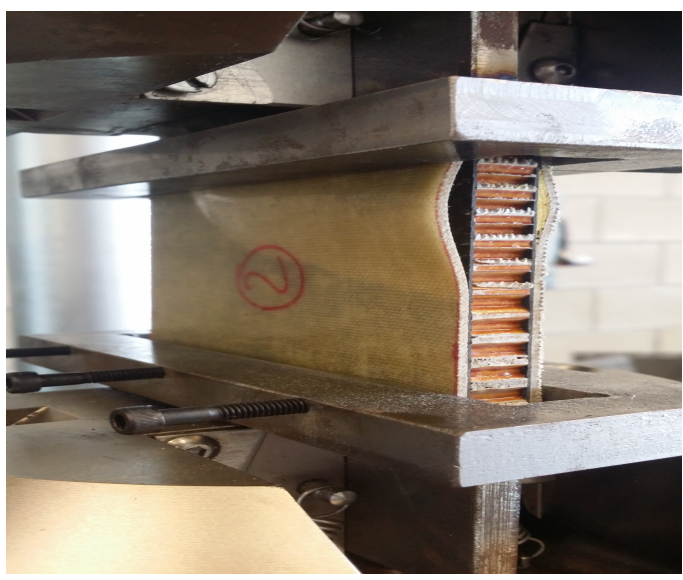

(b) Hemp outer face separating from inner face of carbon fiber

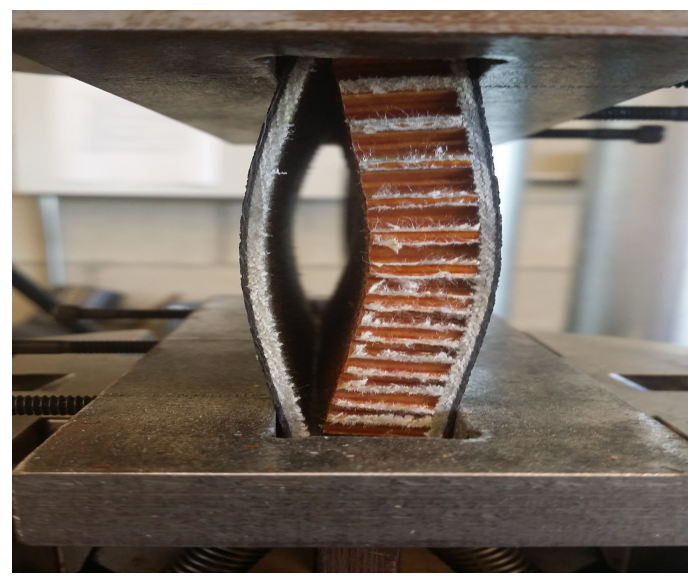

(c) Carbon fiber outer face with complete delamination from core

Figure 2.9: Problem of delamination between facesheet materials in hybrid sandwiches

\subsection{Mechanical Properties Testing of Composite Sandwich Constituent Materials}

To obtain the mechanical properties, composite laminate materials were made the same as the sandwiches but without the core and made with a thickness of 0.1 inch, which was suggested by the ASTM standards for a bi-weave composite. With all of the composite laminates cut into their correct dimensions for each test, the mechanical properties of each material were found through three different tests on an Instron 8801 machine: compressive, tensile, and strain gage assisted tensile tests. These tests all followed ASTM standards. The carbon fiber pre-preg was the only material that had a datasheet with enough material properties data from the manufacturer to compare the accuracy of the each test's findings. 
Carbon fiber was tested and analyzed first for each experiment to ensure the Instron was producing acceptable results.

\subsubsection{Preparing Specimen}

After curing the test specimens, they needed to be properly prepared for testing. This preparation entailed placing aluminum tabs at the ends of the test specimen to ensure no grip damage was done to the test specimen and to ensure no "slipping" during the test. The wedge grip test fixtures apply a lot of pressure during placement within the grips and the only way to get a proper mechanical characteristic from the test is to place tabs at the ends of the specimen so that the failure occurs somewhere near the middle of the specimen. The aluminum tabs were cut to the length and width suggested by the ASTM for each test. After being cut, a file was used to scratch the surface of the tab, allowing the surface to be rougher which allowed for better bonding strength when the tabs were bonded to each specimen.

For each tab, a $3 \mathrm{M}$ two part structural adhesive paste (1614A and 1614B) was used as the bonding material. Figure 2.10 shows an example of a test strip with the aluminum tabs bonded on it. Once all of the tabs were covered in adhesive and placed on the specimens, the adhesive was cured

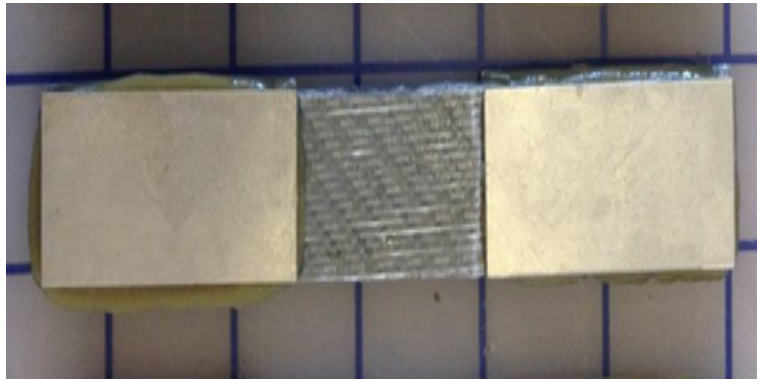

Figure 2.10: Specimen with aluminum tabs bonded in the heat press. The adhesive cure cycle was $150^{\circ} \mathrm{F}$ for 1 hour with $100 \mathrm{lbf}$ of constant force. After the adhesive fully cured, the specimen were completely ready for testing. Six of these test strips were made for each material for the compressive and tensile tests. One of the tensile strips was used as a Poisson's ratio test specimen and it had to undergo one more preparation step before testing, which is described in the next section. 


\subsubsection{Strain Gage Application for Poisson's Ratio Tests}

After the aluminum tabs were placed on the test specimen, the addition of lateral strain gages where adhered on to the specimen to obtain transverse strain readings for Poisson's ratio calculations. Acetone was used to wipe down the surface of the test strip so that the specimen was clean of all dirt and debris. After cleaning, a piece of Scotch tape was laid on top of the strain gage, making sure that the top surface of the strain gage was touching the tape. The tape, with the strain gage connected, was then laid down on the test specimen in the exact position and orientation that was necessary for the test. This position and orientation can be seen in Figure 2.11.

Then one end of the tape was lifted off of the test specimen, lifting the strain gage with it as well. While the bottom surface of the strain gage was exposed, a blue Vishay 200 Catalyst-C M-bond adhesive was brushed onto it. With the strain gage covered in the catalyst and still lifted up, the other part of the M-bond 200 adhesive is applied to the surface of the test

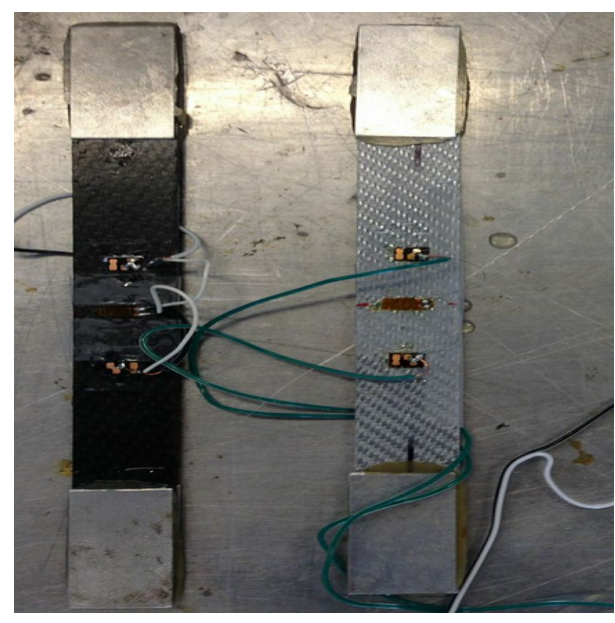

Figure 2.11: Poisson's ratio specimen with strain gages specimen directly below the strain gage.

After the bond adhesive was brushed onto the strain gage, the tape was then reapplied to the surface of the specimen and the chemical reaction began. Curing occurred immediately and the strain gage was in place for the soldering of the wires to the terminals. The wiring is shown in Figure 2.11. Once each wire had been soldered to each strain gage terminal on the test specimen, an M-Line rosin solvent and then an M-Coat A air-drying polyurethane coating was brushed on top of the soldered areas of the strain gages to create a 
protective barrier on the wiring. After this protective barrier was applied, the test specimen were ready for testing.

\subsubsection{Tensile Testing Procedure (ASTM D3039)}

The test method used to find tensile material characteristics was ASTM D3039. [24] The tensile test specimens had ASTM suggested dimensions of a 1.0 inch width by a 10.0 inches height with a thickness of 0.1 inch.

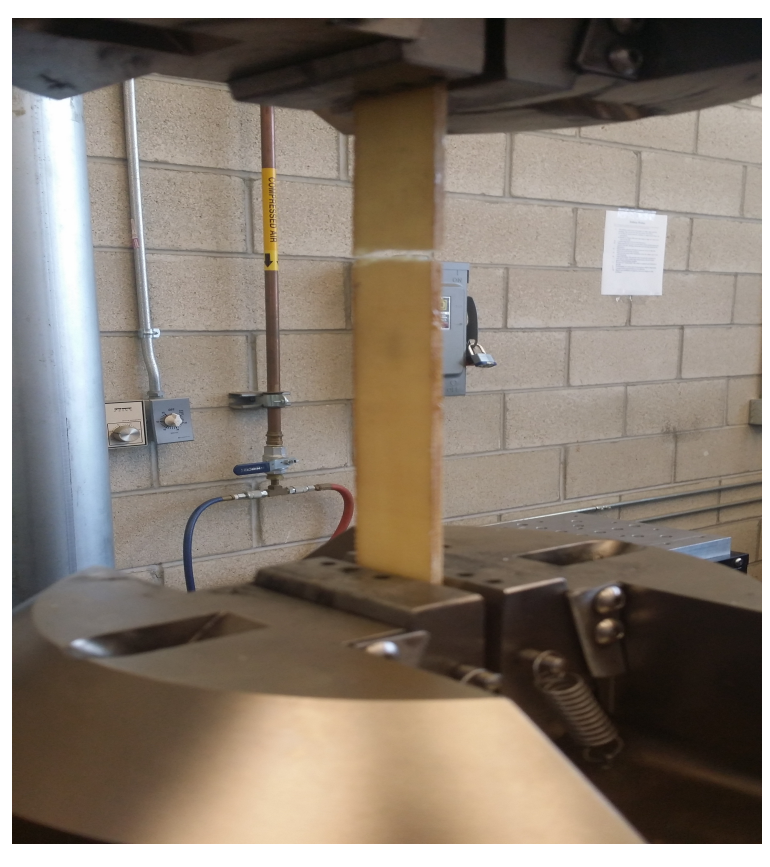

Figure 2.12: Hemp specimen under tensile characteristic test
The ASTM standard did specify a tab length of 2.5 inches, but due to the 2 inch Instron wedge grips, 2 inch tabs were used instead. The pulling motion of the tensile test can be seen in Figure 2.12. A rate of 0.05 inches per minute was used as recommended by the ASTM standard. The specimen were loaded until the load dropped to $40 \%$ of its maximum. The raw data from the test was outputted and analyzed in MATLAB, which is presented in Chapter 3.1.1. 


\subsubsection{Compressive Testing Procedure (ASTM D3410)}

The test method used to find compressive characteristics of each facesheet material was ASTM D3410. [25] The gage length recommended by the ASTM for this test was 0.5-1.5 inch. So, a specimen with height of 5.5 inch was created due to the necessity of having to bond tabs to the ends. The width was 1.0 inch and thickness was 0.1 inch. Again, because the Instron grips were 2.0 inches deep and the only ones available to the Cal Poly Aerospace Structures lab, the aluminum tabs were cut to be 2 inches long instead of 2.5 inches. Therefore, the gage length came to be 1.5 inch.

Once the tabs were attached on the specimens, they were individually placed into the wedge grips, as seen in Figure 2.13. Like the tensile test, ASTM recommended a compression rate of 0.05 inches per minute, but this time, an increasing compressive load was applied. The test stopped when the strip fully failed and the

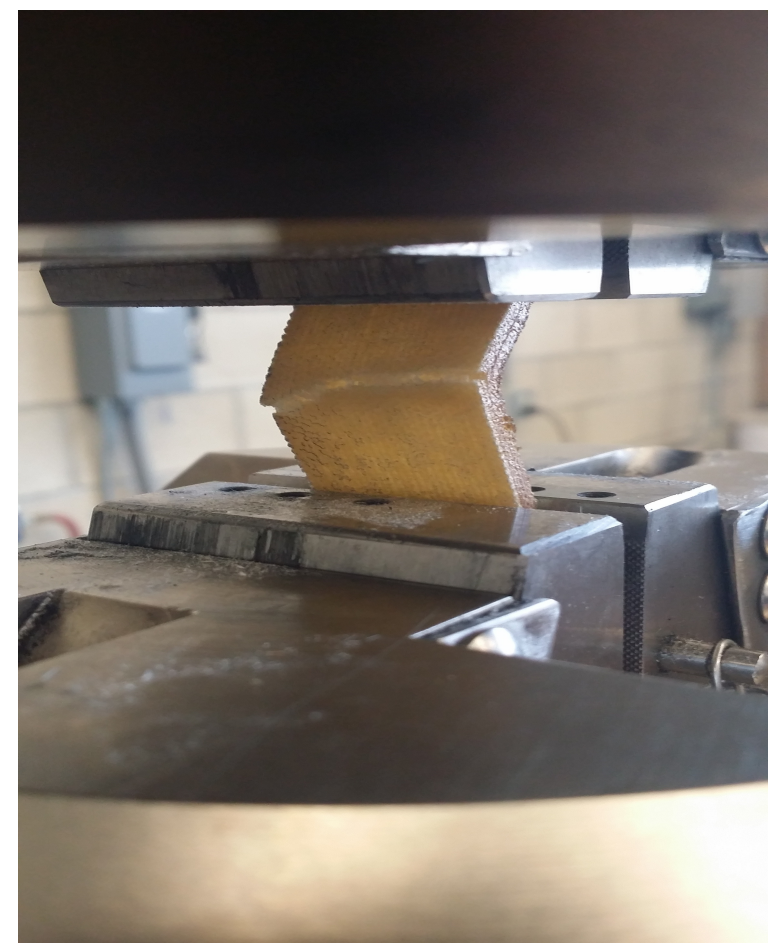

Figure 2.13: Hemp specimen under compressive characteristic test load dropped to below $40 \%$ of the maximum load. The Instron data was collected after the specimen failed and analyzed in MATLAB for the characteristics which are presented in Chapter 3.1.2. 


\subsubsection{Poisson's Ratio Testing Procedure (ASTM E132)}

The Instron machine in accordance with ASTM E132 was the test method used to find the Poisson's ratio of each facesheet material. [26]

The dimensions of the test specimen as recommended by the ASTM are a length of at least five times larger than the width, a gage length seven times larger than the width, and a width larger than the thickness.[26] Each of these requirements are met with the tensile test strips created in the previous section.

The rate of increase of the test fixture was 0.05 inches per minute like the tensile test but the test was stopped before failure for the purpose of keeping the strain gages intact. The transverse and longitudinal strain data was collected from this test and was used to obtain a proper Poisson's ratio. The collection of this data came from a Measurements Group strain indicator box, National Instruments USB-6229 DAQ device, a LabView code written by a Cal Poly student named, Ross Gregoriev, and the Bluehill 2 program which was pre-programmed using the Instron machine. The strain gage indicator can be seen in Figure 2.14.

The wires extruding away from the strain gage setup on each test specimen run to the strain indicator box which is setup in a quarter bridge circuit with the USB DAQ device. These transverse strain readings were then sent to the LabView code, which converted the data into units of millistrain and outputted it to a .csv file with the load in units of pounds force.

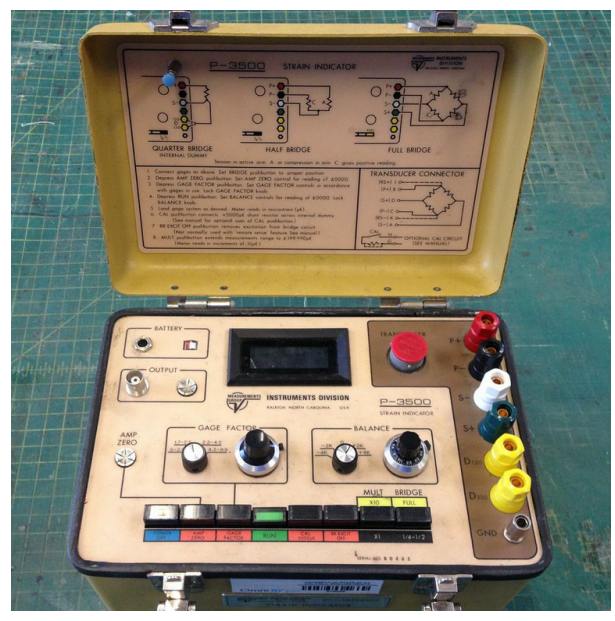

Figure 2.14: Strain indicator used with a quarter bridge circuit

The calculation of Poisson's ratio, according to the ASTM standard, is the slope of the transverse strain vs. load (from LabView) divided by the slope of the longitudinal strain vs. 
load (from Bluehill). The equation for Poisson's ratio from the ASTM is shown below in Eq. ( 2.1).

$$
\mathrm{V}=\frac{\frac{d \varepsilon_{t}}{d P}}{\frac{d \varepsilon_{l}}{d P}}
$$

$\varepsilon_{t}$ and $\varepsilon_{l}$ are the strains in the transverse and longitudinal directions, respectively and $\mathrm{P}$ is the loading throughout the test.

\subsubsection{Poisson's Ratio Testing of Honeycomb Core (ASTM D6790)}

Nomex honeycomb was a special case to try and find the Poisson's ratio. The traditional way of attaching strain gages was not possible for the honeycomb due to its porous structure, so an unconventional way of finding the Poisson's ratio was investigated, called Anticlastic Curvature test.

For this, ASTM D6790 was used to find the honeycomb's Poisson's ratio.[27] When an anticlastic material is bent about one axis, bending will also occur about the perpendicular in-plane axis. An example of this can be seen in Figure 2.15.

To find the radii necessary, the ASTM suggests bending a 12 inch by 12 inch sample of the honeycomb core around a recommended 24 inch diameter cylinder. When the honeycomb is bent around the outside of the cylinder, anticlastic curvature occurs and the sides of the honeycomb not being held down by fingers like in Figure 2.15 raise up. As seen in Figure 2.16 a straight edge was placed on top of the lifted edges of the honeycomb to measure how high

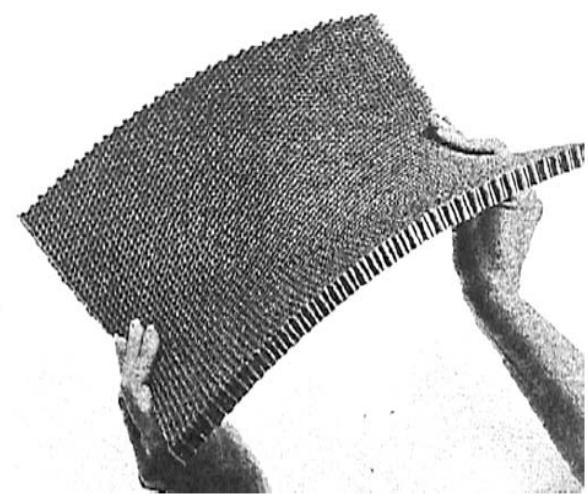

Figure 2.15: Example of anticlastic curvature with a honeycomb core[27]

the sides of the honeycomb lift up. Another measurement was taken as well, and this was the distance between the two sides when lifted. Originally they would be 12 inches apart, 
but due to anticlastic curvature this distance decreased. With these two values, the radius of anticlastic curvature can be found using Eq.( 2.2). The Poisson's ratio of the honeycomb can then be found using this result and the radius of the cylinder using Eq.( 2.3) below.

$$
\begin{gathered}
R_{a}=\frac{4 d^{2}+c^{2}}{8 d} \\
v=\frac{R_{c}}{R_{a}}
\end{gathered}
$$

Where $\mathrm{d}$ is the height of the anticlastic curvature, $\mathrm{c}$ is the length between the raised edges, and $R_{a}$ and $R_{c}$ are the radii of anticlastic curvature and the cylinder, respectively. The results from this testing will be described in the next chapter.

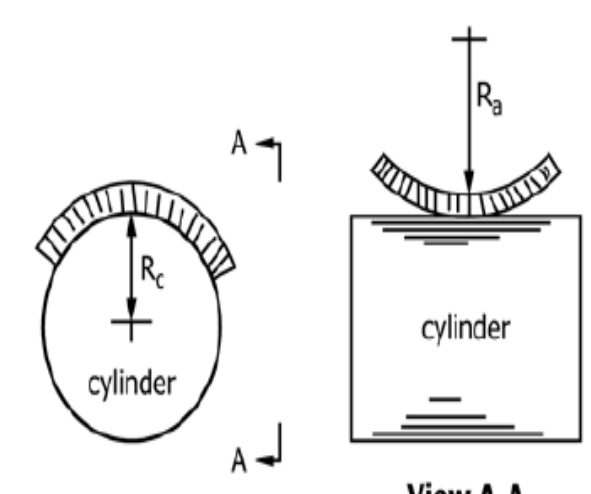

View A-A

$R_{C}=$ cylinder radius $\quad R_{a}=$ anticlastic radius

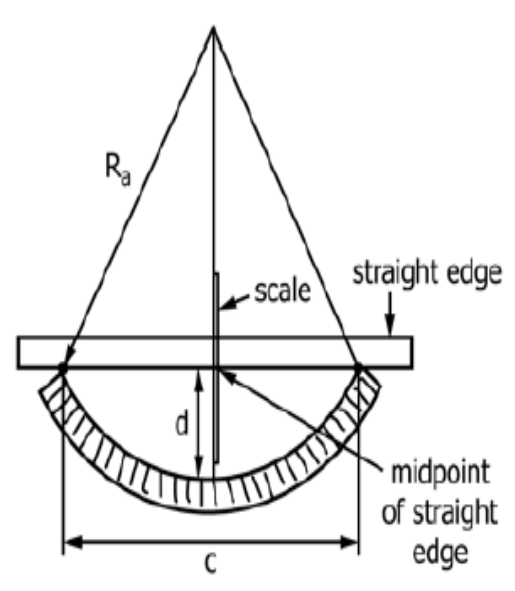

Measurements

Figure 2.16: How to calculate Poisson's ratio of honeycomb using anticlastic curvature [27] 


\subsubsection{Facesheet Fiber Volume Fraction Calculation (ASTM D2584)}

In order to determine the quality of a composite, a fiber volume calculation must be made. This test shows how much the epoxy in a pre-preg material has degraded over time. Usually there will be some loss of epoxy when curing the specimen, but if the material is expired or is not kept in the freezer, there will be some degradation of the material, therefore losing the mechanical characteristics that the company had initially intended it to have when they released it with the data sheet.

This simple test places the cured specimen in a furnace until the epoxy is burned off, while keeping the fibers in tact. The difference of weights from before burning the specimen to after burning it is evaluated using Eq.(2.4), which can be found in ASTM D2584.

$$
\text { Ignitionloss, weight } \%=\frac{W_{1}-W_{2}}{W_{1}} * 100
$$

\subsection{Composite Sandwich Experimental Testing}

As mentioned before, the composite sandwich test specimen were cut into 4 inch wide by 3 inch tall specimen and were ready to be tested. With four different combinations of facesheets, and the same core, all specimen were to undergo the same edgewise compression test using an Instron 8801. But, according to ASTM C364 [17], a steel fixture was needed to place the specimen into in order to properly test. A custom steel fixture shown in Figure 2.17 had to be fashioned before any testing could start.

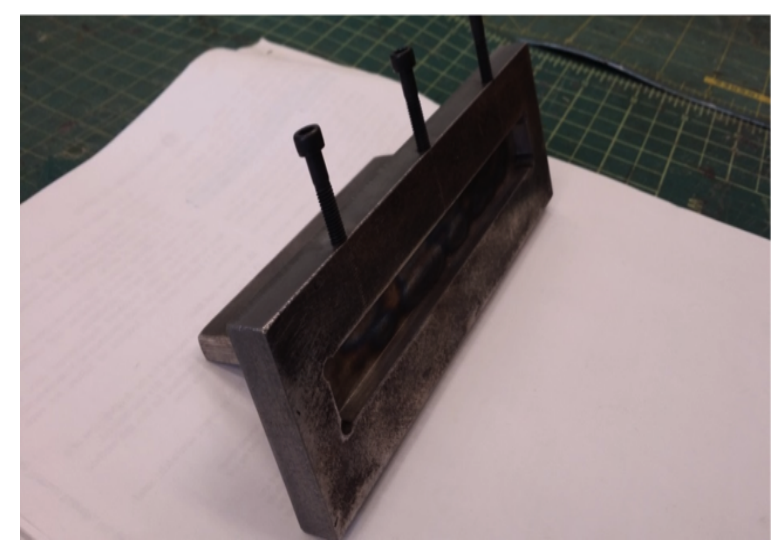

Figure 2.17: Custom steel fixture 
The steel fixture was utilized throughout the testing in this experiment. The rest of Chapter 2 will describe how the edgewise compression testing procedure was setup and performed.

\subsubsection{Instron Machine setup for Edgewise Compression}

In addition to using the Instron 8801 machine, a custom fixture was needed for proper edgewise compression testing of a composite sandwich structure and can be seen loaded into the Instron machine in Figure 2.18. Any unintended loading eccentricities would cause premature failure, so the steel fixture was made sure to be made completely flat. This fixture was made to fit within the Instron wedge grips. The fixture also had slots for the composite sandwich

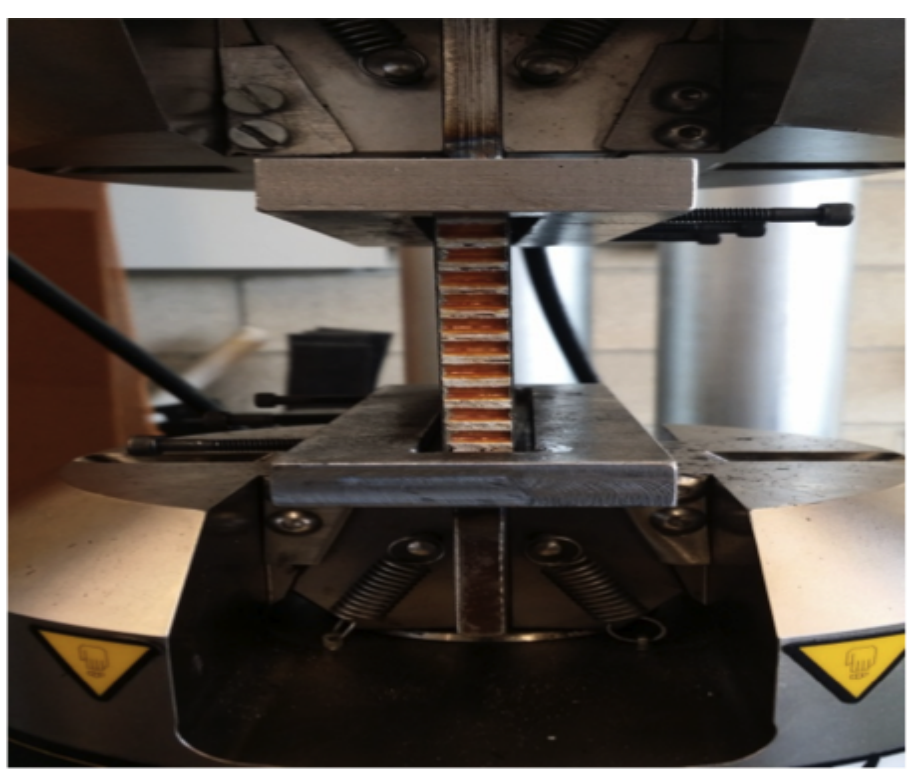

Figure 2.18: Fixture loaded in Instron to slide right into so that no slippage would occur during testing, as also shown in Figure 2.18 .

\subsubsection{Edgewise Compression Testing Procedure (ASTM C364)}

The significance of ASTM C364 is the edgewise compressive strength of short sandwich construction specimen. This provides a basis for judging the load-carrying capacity of the construction in terms of developed facing stress.

This test method consists of subjecting a sandwich panel to monotonically increasing compressive force parallel to the plane of its faces. The force is transmitted to the panel through either clamped or bonded end supports. Stress and strength are reported in terms of the nominal cross-sectional area of the two facesheets, rather than total sandwich panel thickness. [17] 
The test consisted of at least five specimen per test condition. The recommended dimensions of the specimen were indicated by ASTM C364. The recommended length or "height" was to be less than or equal to 8 times the thickness, so a 3 inch length was used because the core used was 0.375 inch thick and each facesheet was 0.025 inches. The recommended width indicated was supposed to be greater than 2 times the thickness, so a 4 inch width was utilized. Both chosen dimensions fell within the range allowed and was utilized throughout the entire experiment. The suggested standard head displacement rate was to be $0.50 \mathrm{~mm} / \mathrm{min}$ or $0.020 \mathrm{inch} / \mathrm{min}$.

Because failure mode is a concern when dealing with sandwich composites, the failure mode of each specimen was recorded and analyzed. The data recording recommended by ASTM C364 was force versus head displacement at a sampling rate of 5 to 10 data recordings per second. Upon data analysis, the ultimate edgewise strength was calculated using Eq.( 3.2) and reported to three significant figures. Results of the testing are explained in depth in later chapters. 


\section{Chapter 3 \\ EXPERIMENTAL TESTING RESULTS AND DISCUSSION}

The results from all experimental testing will be presented in this chapter. The different moduli from the mechanical characteristic testing will be described for all facesheet materials and honeycomb core. The edgewise compressive results of each of the composite sandwiches will also be explained and the failure modes of each sandwich combination will be analyzed and compared. Finally, two optimal facesheets in terms of weight and performance will also be combined to create a hybrid sandwich. This will be tested in a similar manner and be compared to the individual materials to see if there is any added benefit to combine materials in a single sandwich.

\subsection{Material Properties Testing}

The main purpose of testing the materials used in this study was to obtain the material properties for use in theoretical and numerical analysis. It is necessary to obtain our own values in the lab so that we can compare to the given data-sheet values. And in the case of the hemp material used, which does not have any material properties given, we must develop our own values for these materials. The values for compressive and tensile material properties given in the manufacturer's data-sheets for pre-preg material does not always accurately represent the actual properties at time of testing. When a material is expired, or has not been stored at an optimal temperature, the material properties can change from the time of manufacture. The material property results obtained, not only help understand how the specimen behave during experimental testing, but also help with the theoretical and numerical calculations. 


\subsubsection{Tensile Testing Results}

Tensile strength and modulus are important values used to define the strength of the material. Typically composite laminates are stronger in tension than in compression due to the nature of the fiber-matrix structure. But, if loaded in a certain direction, the fibers may be only under a tensile force and the tensile modulus is important to know so that failure predictions can be estimated. Some composite laminates orient the fibers in all directions, so directional loading is not that big of an issue. Even though composite fibers usually fail first in compression, it is still important to know the overall tensile strength of the material when conducting experimental testing.

This study tested carbon fiber, plain weave hemp, herringbone (HB) hemp, and glass fiber composite materials for tensile strengths to gain a better understanding of how strong each material was and what load a typical specimen would fail. The results of each tensile test are shown in Table 3.1.

Table 3.1: Tensile moduli and strengths of each facesheet material used

\begin{tabular}{|c|c|c|c|c|}
\hline & $\begin{array}{l}\text { Carbon } \\
\text { Fiber }\end{array}$ & $\begin{array}{c}\text { Plain } \\
\text { Weave } \\
\text { Hemp } \\
\text { Fiber }\end{array}$ & $\begin{array}{c}\text { HB } \\
\text { Weave } \\
\text { Hemp } \\
\text { Fiber }\end{array}$ & $\begin{array}{l}\text { Glass } \\
\text { Fiber }\end{array}$ \\
\hline $\begin{array}{c}\text { Tensile Modulus } \\
{[\mathrm{psi}]}\end{array}$ & $\begin{array}{c}9.82 \mathrm{E} 6 \\
+/-0.2 \mathrm{E} 6\end{array}$ & $\begin{array}{c}1.22 \mathrm{E} 6 \\
+/-0.1 \mathrm{E} 6\end{array}$ & $\begin{array}{c}1.82 \mathrm{E} 6 \\
+/-0.1 E 6\end{array}$ & $\begin{array}{c}2.33 \mathrm{E} 6 \\
+/-0.1 \mathrm{E} 6\end{array}$ \\
\hline $\begin{array}{c}\text { Tensile Strength } \\
{[\mathrm{psi}]}\end{array}$ & $\begin{array}{c}9.1 \mathrm{E} 4 \\
+/-0.2 \mathrm{E} 4\end{array}$ & $\begin{array}{c}1.4 \mathrm{E} 4 \\
+/-0.1 E 4\end{array}$ & $\begin{array}{c}1.6 \mathrm{E} 4 \\
+/-0.1 E 4\end{array}$ & $\begin{array}{c}4.0 \mathrm{E} 4 \\
+/-0.2 \mathrm{E} 4\end{array}$ \\
\hline
\end{tabular}

The carbon fiber pre-preg, was by far the stiffest material between the four cases, making it the best material in a tensile loading case. The two hemp materials were the lowest of them all, but had the most extension, which makes them the must ductile materials. Being more ductile could be an advantage for compression testing, which will be explained in a later section. The glass fiber was a little stiffer than hemp but still more ductile than carbon fiber probably due to the small amount of aluminum in the weave. 
Each of these materials failed in a similar manner during the tensile testing. The fracture was very close to the middle of the specimen and can be seen in Figure 3.1.

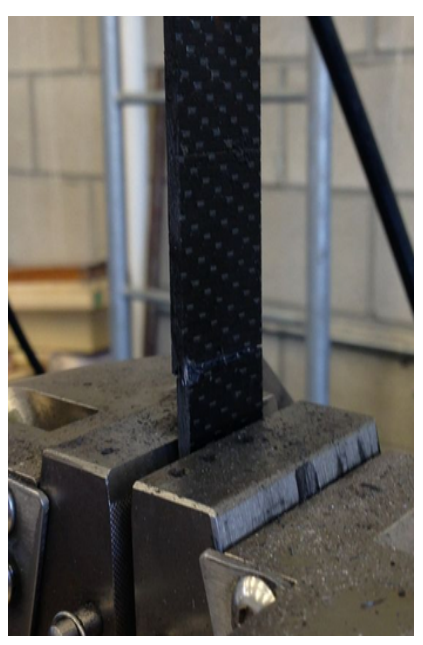

(a) Carbon fiber failure

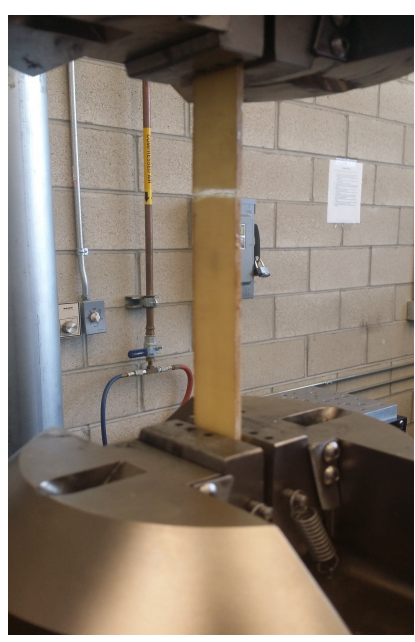

(b) Plain Weave Hemp failure

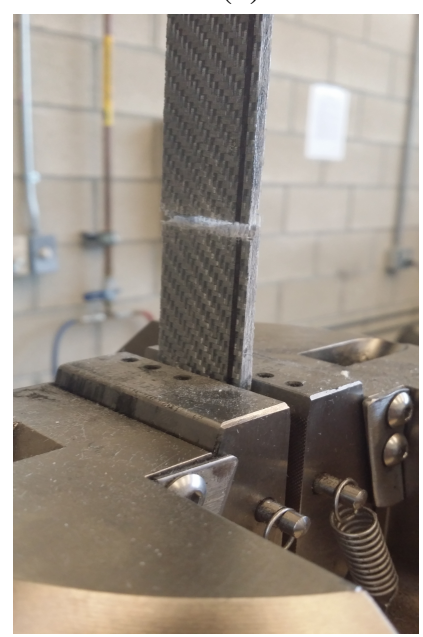

(c) Glass fiber failure

Figure 3.1: Tensile testing failures of facesheet materials 


\subsubsection{Compressive Testing Results}

Typically a composite material is stronger in tension than in compression, so the compressive properties are important to know and understand because a structure is only as strong as it's weakest link and usually a composite material will fail in compression before it fails in tension. Since the main analysis of this experiment is edgewise compression of composite sandwiches, it is imperative to fully grasp the compressive properties of each material.

This will give a better judgement of how the composite sandwiches will fail and what to expect when they fail. The compressive moduli and strengths of each facesheet material are shown in Table 3.2.

Table 3.2: Compressive moduli and strengths of each facesheet material used

\begin{tabular}{|c|c|c|c|c|}
\hline & $\begin{array}{l}\text { Carbon } \\
\text { Fiber }\end{array}$ & $\begin{array}{c}\text { Plain } \\
\text { Weave } \\
\text { Hemp } \\
\text { Fiber }\end{array}$ & $\begin{array}{c}\text { HB } \\
\text { Weave } \\
\text { Hemp } \\
\text { Fiber }\end{array}$ & $\begin{array}{l}\text { Glass } \\
\text { Fiber }\end{array}$ \\
\hline $\begin{array}{l}\text { Compressive } \\
\text { Modulus [psi] }\end{array}$ & $\begin{array}{c}6.41 \mathrm{E} 6 \\
+/-0.1 E 6\end{array}$ & $\begin{array}{c}0.86 \mathrm{E} 6 \\
+/-0.1 E 6\end{array}$ & $\begin{array}{c}1.1 \mathrm{E} 6 \\
+/-0.1 \mathrm{E} 6\end{array}$ & $\begin{array}{c}1.87 \mathrm{E} 6 \\
+/-0.1 \mathrm{E} 6\end{array}$ \\
\hline $\begin{array}{c}\text { Compressive } \\
\text { Strength [psi] }\end{array}$ & $\begin{array}{c}4.3 \mathrm{E} 4 \\
+/-0.3 E 4\end{array}$ & $\begin{array}{c}0.7 \mathrm{E} 4 \\
+/-0.1 E 4\end{array}$ & $\begin{array}{c}0.9 \mathrm{E} 4 \\
+/-0.1 E 4\end{array}$ & $\begin{array}{c}2.3 \mathrm{E} 4 \\
+/-0.1 E 4\end{array}$ \\
\hline
\end{tabular}

Again, carbon fiber is the stiffer and stronger material than the rest as was the case for the tensile test. The hemp fibers did not outperform any material but was able to withstand the most extension again. Both the carbon fiber and glass fiber seemed to be brittle and fail in an unconventional micro-buckling manner which caused fiber fracture, instead of buckling at the center of the test specimen like the hemp did. This probably is because of the ductile properties of hemp as was seen in the tensile testing. The failure modes of the compression testing specimen can be seen in Figure 3.2 


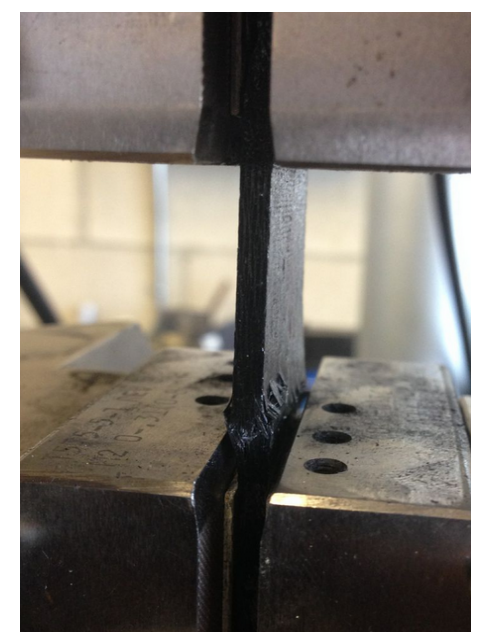

(a) Carbon fiber failure

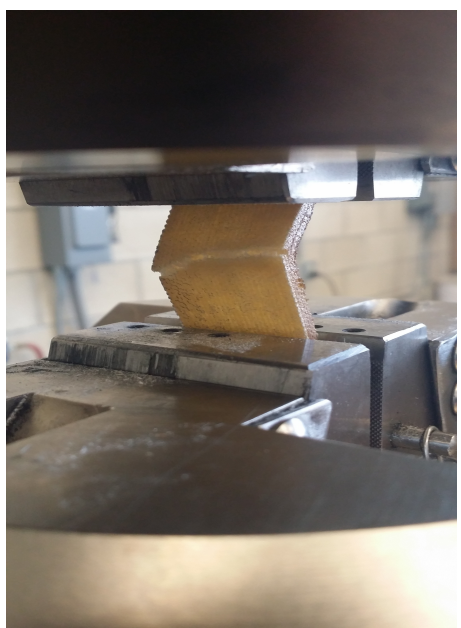

(b) Plain Weave Hemp failure

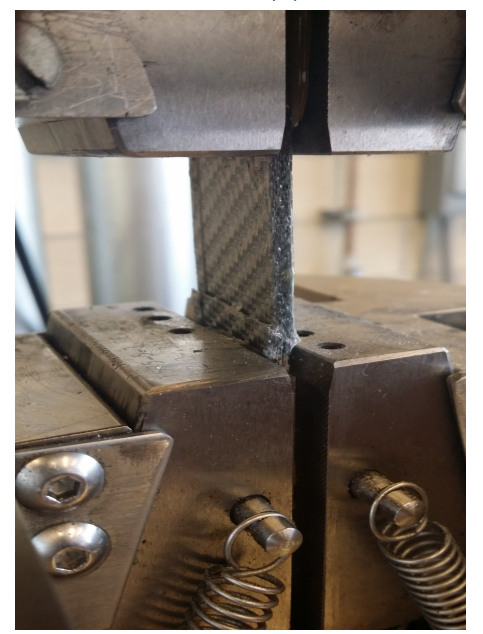

(c) Glass fiber failure

Figure 3.2: Compressive testing failures of facesheet materials

\subsubsection{Poisson's Ratio Testing Results}

The Poisson's ratio testing was not taken until failure like the compressive and tensile tests so the analysis of the results is not on the maximum loadings of each material but on the longitudinal and transverse strain relationships with the load instead. The transverse strains found using the LabView code were in units of millistrain so all of these values were converted to units of strain (inch per inch) to match the longitudinal data before analysis was done. As mentioned in the last chapter, Poisson's ratio for each material was calculated using the slopes of the transverse and longitudinal strain and load relationships. These 
plots show that the longitudinal strains always had a higher slope when plotted against loads which leads to Poisson's ratio values less than one. The final Poisson's ratio values calculated from these plots for carbon, hemp, and glass fibers were 0.0125, 0.248, 0.216, and 0.122 , respectively. These values, like the tensile and compressive test were considered to be the same in both the transverse and longitudinal directions for carbon, hemp, and glass fiber materials.

\subsubsection{Honeycomb Poisson's Ratio Testing Results}

The honeycomb core material had a datasheet that gave all the necessary values for theoretical and numerical analysis. The only value not given by the datasheets was the Poisson's ratio. Therefore, ASTM D6790 was utilized to test for the Poisson's ratio value. The test was done for both the longitudinal and transverse directions. After completing the ASTM standard, the value for the longitudinal Poisson's ratio was 0.81 and the value for the transverse direction was 0.41 . These values were used to determine the tensile modulus for each direction. All material properties are shown in Table 3.3.

Table 3.3: Honeycomb material properties

\begin{tabular}{|c|c|c|}
\hline & $\begin{array}{c}\text { Honeycomb } \\
\text { (Longitudinal) }\end{array}$ & $\begin{array}{c}\text { Honeycomb } \\
\text { (Transverse) }\end{array}$ \\
\hline Density [lbf $/ \mathrm{ft}^{3}$ ] & 5.0 & 5.0 \\
\hline $\begin{array}{c}\text { Tensile Modulus } \\
\text { [psi] }\end{array}$ & $3.8 \mathrm{E} 4$ & $1.6 \mathrm{E} 4$ \\
\hline Poisson's Ratio & 0.81 & 0.41 \\
\hline Shear Modulus [psi] & $1.04 \mathrm{E} 4$ & $5.8 \mathrm{E} 3$ \\
\hline
\end{tabular}

From these findings, for all composite sandwiches created throughout the experiment, it was chosen to position the honeycomb in the longitudinal direction in the direction of loading for the edgewise compressive testing due to its higher Poisson's ratio and Shear modulus. 


\subsubsection{Shear Moduli of Facesheet Materials}

By finding the Poisson's ratio of the facesheet material, the shear modulus can be calculated using the Young's modulus $\left(E_{12}\right)$ and Eq.( 3.1$)$. This value determines how strong a material is under a shearing load. It is important for theoretical and numerical analysis because under a compressive load the specimen experience a high shearing force between the core and facesheet. The shear modulus can reveal a lot about how the specimen will behave and fail under a load.

$$
G_{12}=\frac{E_{12}}{2\left(1+v_{12}\right)}
$$

Using this equation and the results from tensile testing, the carbon fiber shear modulus

was calculated to be 4.85E6, plain weave hemp modulus was 4.89E5, herringbone weave hemp modulus was 6.69E5, and glass fiber modulus was 1.04E6. All moduli pertain to longitudinal and transverse material directions because of the bi-weave characteristics of the facesheets.

\subsubsection{Fiber Volume Fractions for Facesheet Materials}

After placing the specimen in a crucible as seen in Figure 3.3a, the epoxy burned away just leaving the fibers behind as seen in Figure $3.3 \mathrm{~b}$.

Once the fibers were left without epoxy, they were weighed. The values were recorded and used to calculate the experimental fiber volume percentages. They were compared to the theoretical percentages that are given by the manufacturer. With the pre-preg material, degradation is always an important aspect to keep in mind so that the mechanical characteristic values are accurate. With the bio-composite material used, the fiber volume percentages are not given due to the fact that the wet-layup technique is used to manufacture the composites. Therefore, theoretically there is no degradation because the epoxy is not pre-impregnated into it. In Table 3.4 below, the fiber volume percentages from ig- 


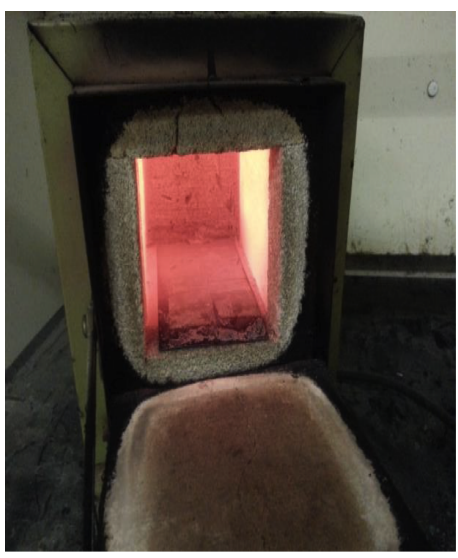

(a) Crucible used to burn off epoxy

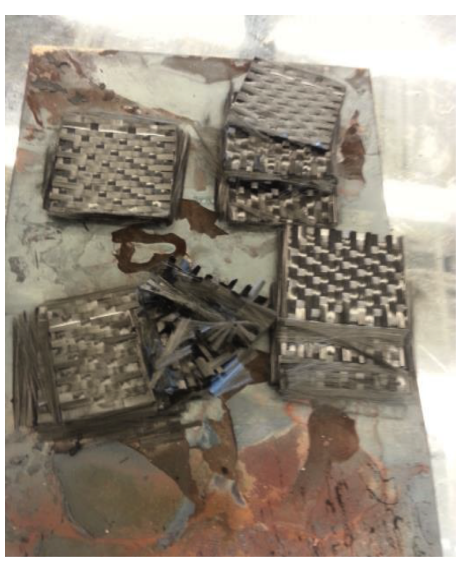

(b) Carbon fiber after epoxy burned off

Figure 3.3: Fiber volume fraction materials

nition loss are compared and show that there was not much epoxy lost in the process of manufacturing.

Table 3.4: Fiber volume percentages from ignition loss

\begin{tabular}{|c|c|c|c|c|}
\hline & $\begin{array}{c}\text { Carbon } \\
\text { Fiber }\end{array}$ & $\begin{array}{c}\text { Plain } \\
\text { Weave } \\
\text { Hemp } \\
\text { Fiber }\end{array}$ & $\begin{array}{c}\text { HB } \\
\text { Weave } \\
\text { Hemp } \\
\text { Fiber }\end{array}$ & $\begin{array}{c}\text { Glass } \\
\text { Fiber }\end{array}$ \\
\hline $\begin{array}{c}\text { Ignition Loss } \\
\text { Volume [\%] }\end{array}$ & $57.8 \%$ & $32.9 \%$ & $42.5 \%$ & $60.1 \%$ \\
\hline $\begin{array}{c}\text { Datasheet Fiber } \\
\text { Volume [\%] }\end{array}$ & $55.3 \%$ & $\mathrm{n} / \mathrm{a}$ & $\mathrm{n} / \mathrm{a}$ & $55.3 \%$ \\
\hline Error [\%] & $4.5 \%$ & $\mathrm{n} / \mathrm{a}$ & $\mathrm{n} / \mathrm{a}$ & $8.5 \%$ \\
\hline
\end{tabular}

\subsubsection{Summary of Material Properties Testing}

Overall, from the material property testing that occurred, it was found that carbon fiber facesheets have a significantly higher strength than the other three facesheet materials. The hemp materials have a higher tolerance for deflection without failure. The glass fiber material characteristics are in the middle of these other fibers. These attributes will continue to show when the facesheets are bonded to the core and the sandwich specimen are tested 
under a compressive load. When testing under a compressive load, failure analysis will be closely monitored. So, having a higher strength may not be a desired attribute if its deflection produces an unstable failure. In the case of the hemp facesheets, an ability to deflect more may produce a stable failure, which is desired in compressive testing. All edgewise compressive testing results of the sandwich composites will be explained in the next section.

\subsection{Edgewise Compressive Testing Results and Discussion}

This section covers the edgewise compressive experimental results for all sandwich composite specimen. The comparisons of results are shown for a better understanding of how each facesheet reacts to a compressive load when bonded to a honeycomb core. In accordance with the goal of the experiment, the ultimate edgewise-compressive strength was calculated using Eq.( 3.2) after the specimen failed.

$$
\left[\sigma_{u l t}=\frac{P_{\max }}{w\left(2 * t_{f s}\right)}\right]
$$

Where, $\sigma_{\text {ult }}$ is the ultimate edgewise-compressive strength [psi], $\mathrm{P}_{\max }$ is the max force

prior to failure [lbs], $w$ is the width of the specimen [in], and $t_{f s}$ is the thickness of a single facesheet [in]. The acceptable failure modes according to ASTM C364 are shown in Figure 3.4 and help to indicate what the material is undergoing during the testing process.

During this experiment, three types of the failure were apparent (facesheet buckling or delamination, face compression, and end failure). The failure mode was found to not change in each specimen case by increasing layers. 


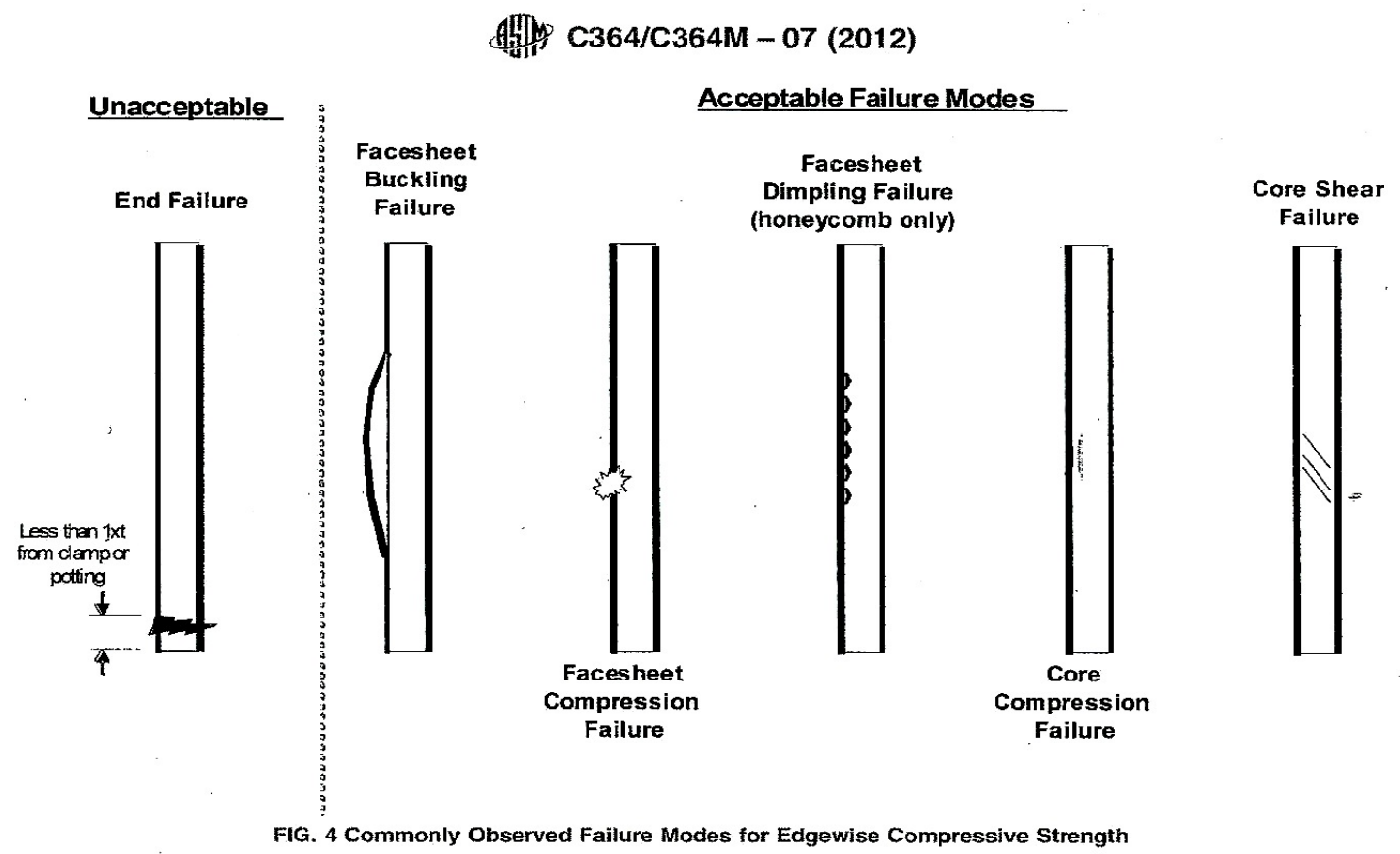

Figure 3.4: ASTM C364 failure modes of composite sandwiches [17]

\subsubsection{Carbon Fiber Facesheet Sandwiches}

The experimental results of carbon fiber sandwiches showed a general increase in max load prior to failure as layers were added to the sandwich configuration. The loads ranged from $1942 \mathrm{lbf}$ for the $1 \mathrm{X} 1$ layer combination to $9826 \mathrm{lbf}$ for the $4 \mathrm{X} 4$ layer combination as shown in Table 3.5. In order to accurately compare the deflection of all specimen, a load of $1000 \mathrm{lbf}$ was chosen because all specimen were able to reach that value. The carbon fiber sandwiches showed a slight decrease of deflection as each layer was added, and ranged from 0.0023 inch to 0.0015 inch. This slight decrease was expected due to the nature of carbon fiber and the high stiffness that was noticed during the mechanical testing of the fiber. As for the ultimate edgewise compressive strength, carbon fiber showed a range of 13 ksi to $65 \mathrm{ksi}$. This is an important metric when comparing to the other material sandwiches and will be discussed more in a later section of this chapter.

The average experimental results of carbon fiber sandwiches can be seen graphically in Figure 3.5. The general trend showed a long unsteady trek to failure. Even though the 
Table 3.5: Edgewise-compressive results for carbon fiber facesheet sandwiches

\begin{tabular}{|c|c|c|c|}
\hline & $\begin{array}{c}\text { Max load prior to } \\
\text { failure [lbf] }\end{array}$ & $\begin{array}{c}\text { Deflection at 1000 } \\
\text { lbf [in] }\end{array}$ & $\begin{array}{c}\text { Ultimate Edgewise } \\
\text { Compressive } \\
\text { Strength [ksi] }\end{array}$ \\
\hline \multirow{2}{*}{ 1X1 Layer } & 1942.35 & 0.0023 & 13.11 \\
$+/-112.3$ & $+/-0.0013$ & $+/-1.42$ \\
\hline \multirow{2}{*}{ 2X2 Layers } & 3619.42 & 0.0021 & 24.33 \\
& $+/-279.3$ & $+/-0.0033$ & $+/-3.54$ \\
\hline \multirow{2}{*}{ 3X3 Layers } & 6231.70 & 0.0019 & 41.79 \\
& $+/-692.4$ & $+/-0.0021$ & $+/-4.75$ \\
\hline \multirow{2}{*}{ 4X4 Layers } & 9826.40 & 0.0018 & 65.81 \\
& $+/-309.2$ & $+/-0.0039$ & $+/-14.98$ \\
\hline
\end{tabular}

carbon fiber sandwiches were able to reach a high max load, the plot shows an unpredictable failure for each layer combination. The fact that each specimen was not a predictable failure makes carbon fiber a hesitant choice to use for edgewise compressive purposes. Even though it is a stiff and strong material in tension, as previously shown from the mechanical testing, compression testing was not it's strong suit. Failure analysis will be discussed more in depth later in this chapter as well. 


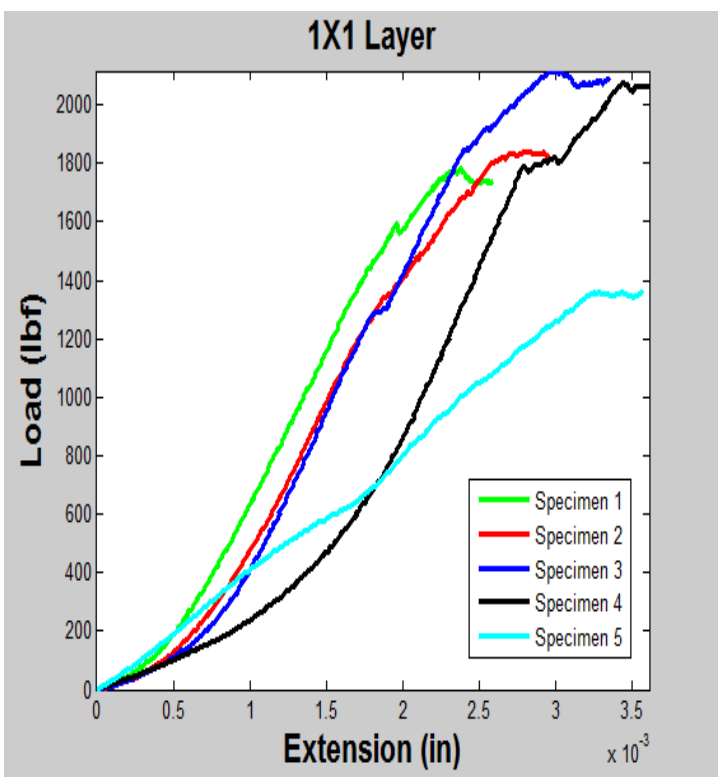

(a) 1X1 Layer-carbon fiber

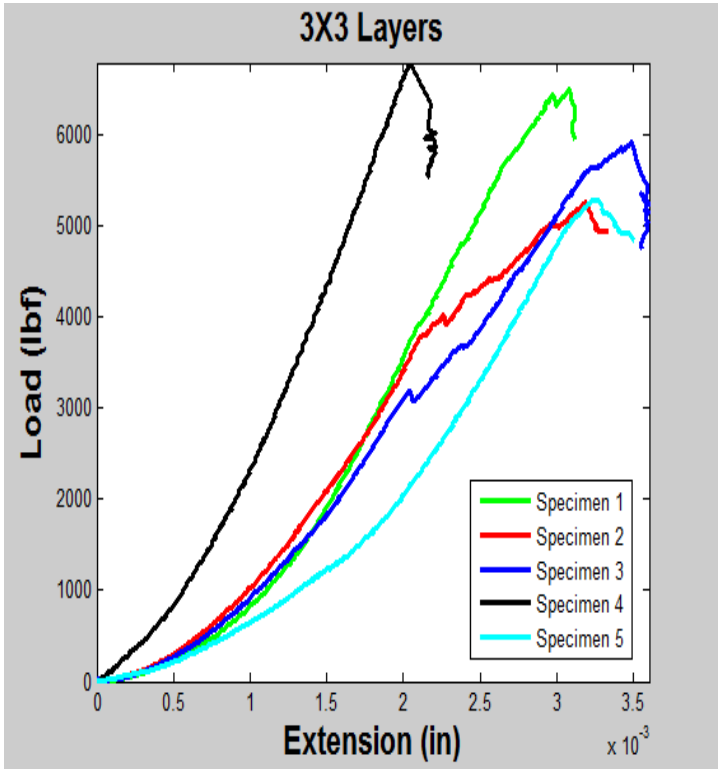

(c) 3X3 Layers-carbon fiber

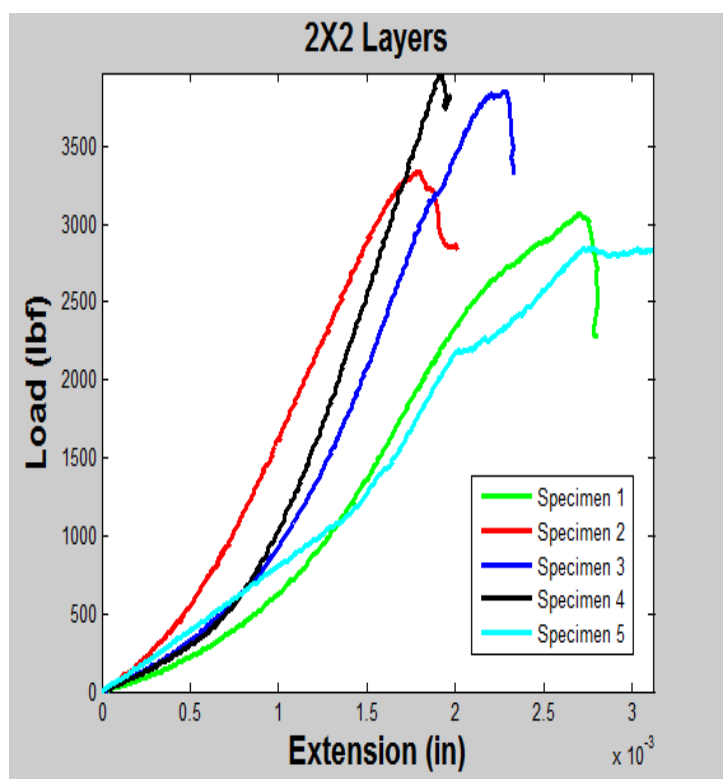

(b) 2X2 Layers-carbon fiber

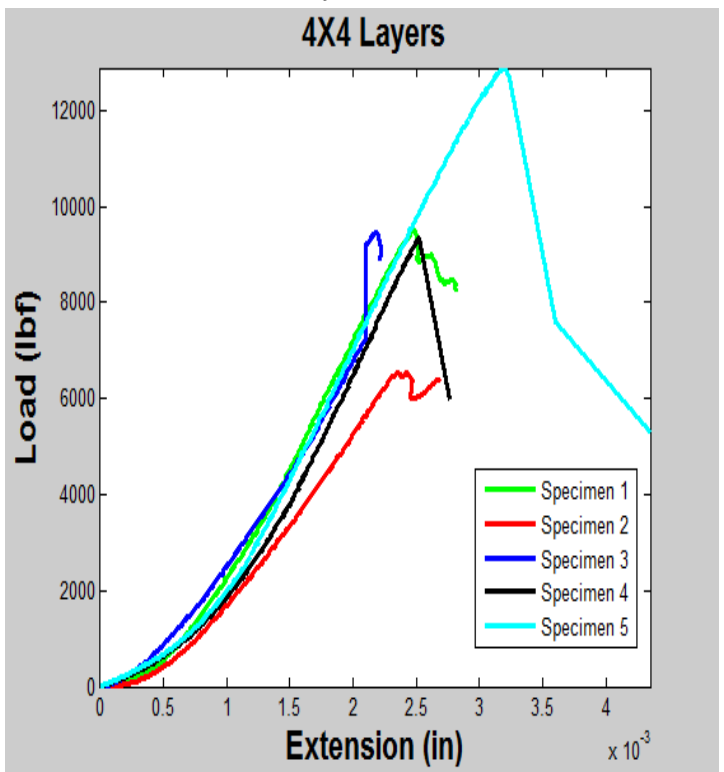

(d) 4X4 Layers-carbon fiber

Figure 3.5: Edgewise-compressive testing of carbon fiber facesheet sandwiches 


\subsubsection{Plain Weave Hemp Facesheet Sandwiches}

The experimental results of the plain weave hemp sandwiches showed a general increase in max load prior to failure as layers were added to the sandwich configuration, similar to carbon fiber. The loads ranged from $2025 \mathrm{lbf}$ for the $1 \mathrm{X} 1$ layer combination to $8403 \mathrm{lbf}$ for the $4 \mathrm{X} 4$ layer combination as shown in Table 3.6. The deflection at a load of $1000 \mathrm{lbf}$ for the plain weave hemp sandwiches showed a slight decrease of deflection as each layer was added, and ranged from 0.054 inch to 0.028 inch. This was nearly double the extension that carbon fiber underwent. This high extension was expected due to the nature of hemp and the high ductility that was noticed during the mechanical testing. As for the ultimate edgewise compressive strength, plain weave hemp showed a range from 13 ksi to $56 \mathrm{ksi}$, which was very similar to carbon fiber edgewise strength.

Table 3.6: Edgewise-compressive results for plain weave hemp facesheet sandwiches

\begin{tabular}{|c|c|c|c|}
\hline & $\begin{array}{c}\text { Max load prior to } \\
\text { failure [lbf] }\end{array}$ & $\begin{array}{c}\text { Deflection at 1000 } \\
\text { lbf [in] }\end{array}$ & $\begin{array}{c}\text { Ultimate Edgewise } \\
\text { Compressive } \\
\text { Strength [ksi] }\end{array}$ \\
\hline \multirow{2}{*}{ 1X1 Layer } & 2025.53 & 0.054 & 13.85 \\
& $+/-273.61$ & $+/-0.012$ & $+/-1.33$ \\
\hline \multirow{2}{*}{ 2X2 Layers } & 3599.19 & 0.041 & 24.95 \\
& $+/-587.39$ & $+/-0.006$ & $+/-5.53$ \\
\hline \multirow{2}{*}{ 3X3 Layers } & 5071.69 & 0.033 & 34.83 \\
& $+/-180.1$ & $+/-0.036$ & $+/-3.38$ \\
\hline \multirow{2}{*}{ 4X4 Layers } & 8403.36 & 0.028 & 56.14 \\
& $+/-282.46$ & $+/-0.027$ & $+/-5.61$ \\
\hline
\end{tabular}

The average experimental results of plain weave hemp sandwiches can be seen graphically in Figure 3.6. The general trend for all specimen showed a smooth trek to failure. In contrast to the carbon fiber sandwiches, the plain weave hemp sandwiches showed a predictable failure for each layer combination. Each sandwich slowly extended and reached it's peak then failed, and drastically reduced to a minimal load after failure. Having a predictable failure is ideal when dealing with compressive loads on structures. When de- 
signing, it is much easier to build within tolerance by knowing when a failure is going to occur.

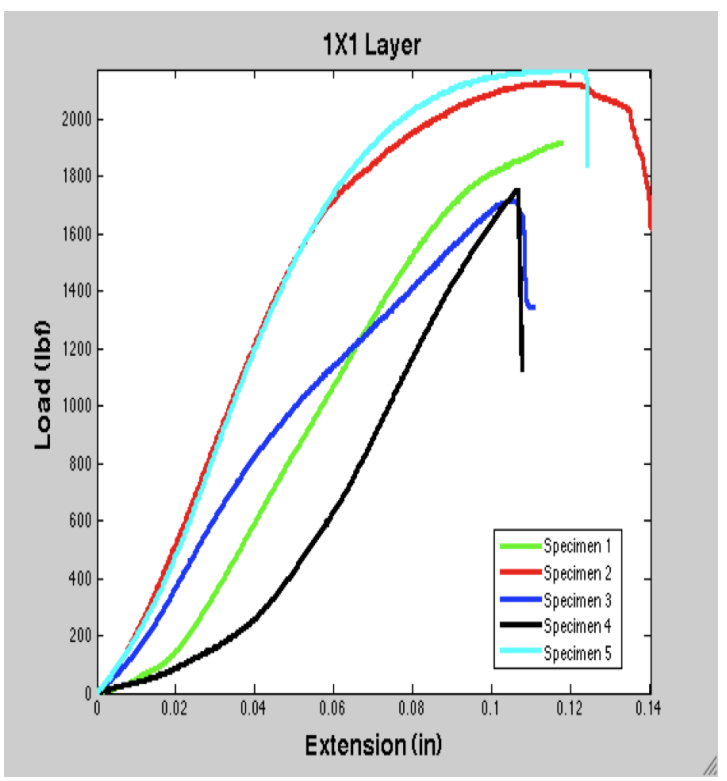

(a) 1X1 Layer-plain weave hemp

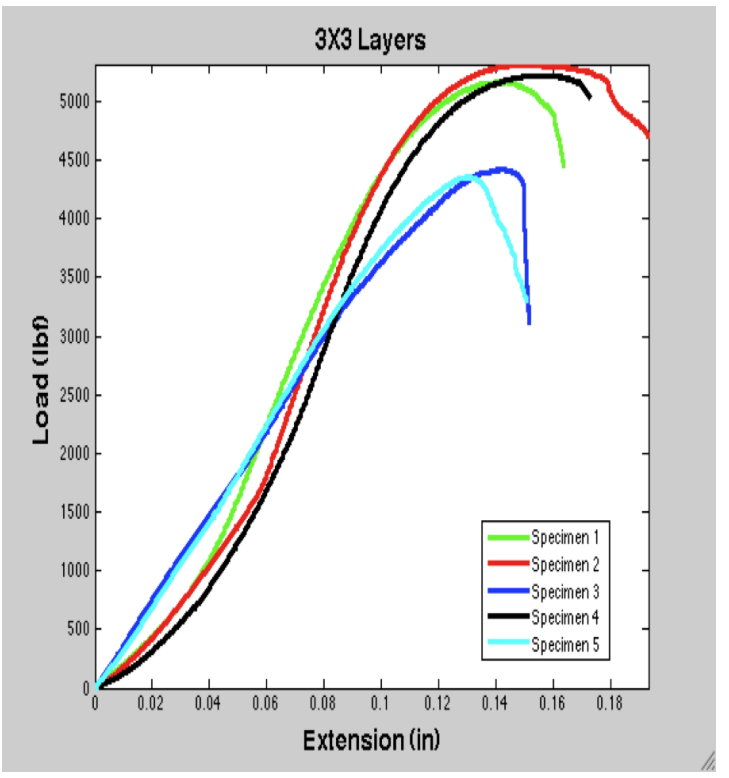

(c) 3X3 Layers-plain weave hemp

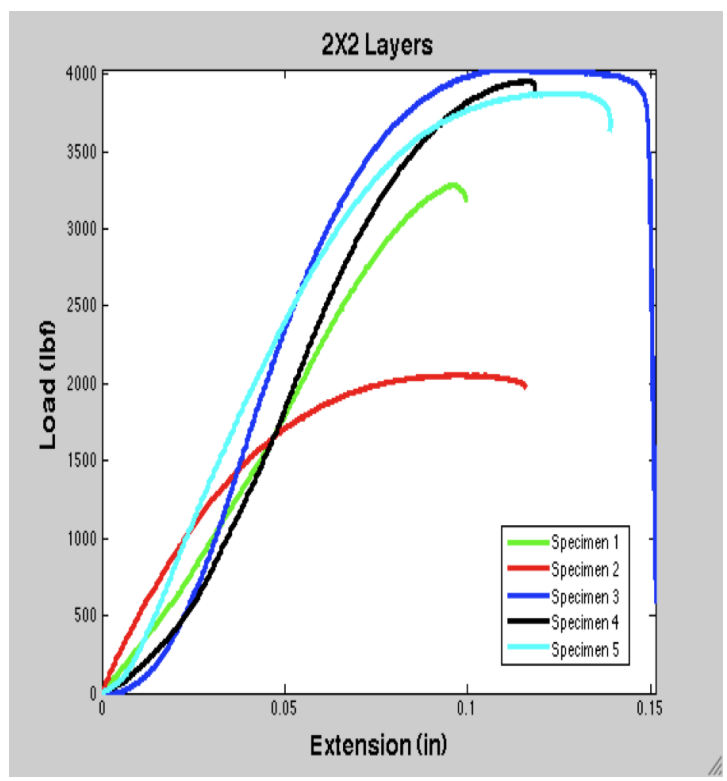

(b) 2X2 Layers-plain weave hemp

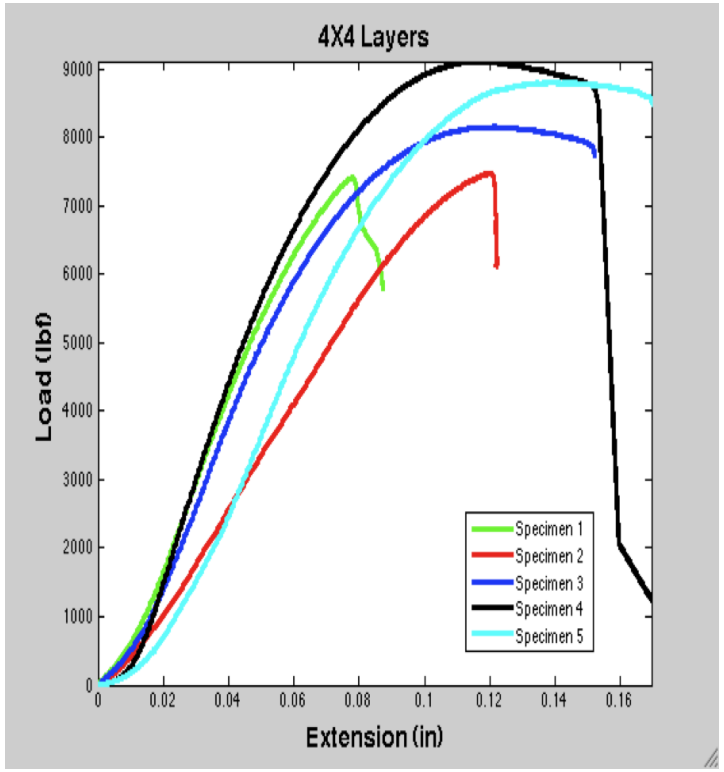

(d) 4X4 Layers-plain weave hemp

Figure 3.6: Edgewise-compressive testing of plain weave hemp facesheet sandwiches 


\subsubsection{Herringbone Weave Hemp Facesheet Sandwiches}

The experimental results of the herringbone weave hemp sandwiches showed a general increase in max load prior to failure as layers were added to the sandwich configuration. The loads ranged from $2873 \mathrm{lbf}$ for the $1 \mathrm{X} 1$ layer combination to $9012 \mathrm{lbf}$ for the $4 \mathrm{X} 4$ layer combination as shown in Table 3.7. The deflection at a load of $1000 \mathrm{lbf}$ for the herringbone weave hemp sandwiches showed a slight decrease of deflection as each layer was added, and ranged from 0.044 inch to 0.030 inch. This was similar deflection to the plain weave hemp, but due to the thickness of the herringbone hemp, it was a little stiffer in nature than the plain weave hemp, and therefore did not extend as much. Again, this extension was expected due to the nature of hemp and the high ductility that was noticed during the mechanical testing. The ultimate edgewise compressive strength for herringbone hemp was a range from about $10 \mathrm{ksi}$ to $30 \mathrm{ksi}$, which was much lower than carbon fiber and plain weave hemp. This was mainly due to the thickness of each facesheet.

Table 3.7: Edgewise-compressive results for herringbone hemp facesheet sandwiches

\begin{tabular}{|c|c|c|c|}
\hline & $\begin{array}{c}\text { Max load prior to } \\
\text { failure [lbf] }\end{array}$ & $\begin{array}{c}\text { Deflection at 1000 } \\
\text { lbf [in] }\end{array}$ & $\begin{array}{c}\text { Ultimate Edgewise } \\
\text { Compressive } \\
\text { Strength [ksi] }\end{array}$ \\
\hline \multirow{2}{*}{ 1X1 Layer } & 2873.06 & 0.044 & 9.77 \\
& $+/-859.78$ & $+/-0.025$ & $+/-1.83$ \\
\hline \multirow{2}{*}{ 2X2 Layers } & 5044.71 & 0.041 & 17.20 \\
& $+/-1026.1$ & $+/-0.022$ & $+/-3.56$ \\
\hline \multirow{2}{*}{ 3X3 Layers } & 7978.47 & 0.031 & 27.18 \\
& $+/-1439.18$ & $+/-0.02$ & $+/-1.18$ \\
\hline \multirow{2}{*}{ 4X4 Layers } & 9012.59 & 0.030 & 29.88 \\
& $+/-2142.89$ & $+/-0.03$ & $+/-4.19$ \\
\hline
\end{tabular}


The average experimental results of herringbone hemp sandwiches can be seen graphically in Figure 3.7. The general trend for all specimen showed a smooth trek to failure, just like plain weave hemp did. Each sandwich slowly extended and reached it's peak then failed, and drastically reduced to a minimal load after failure.

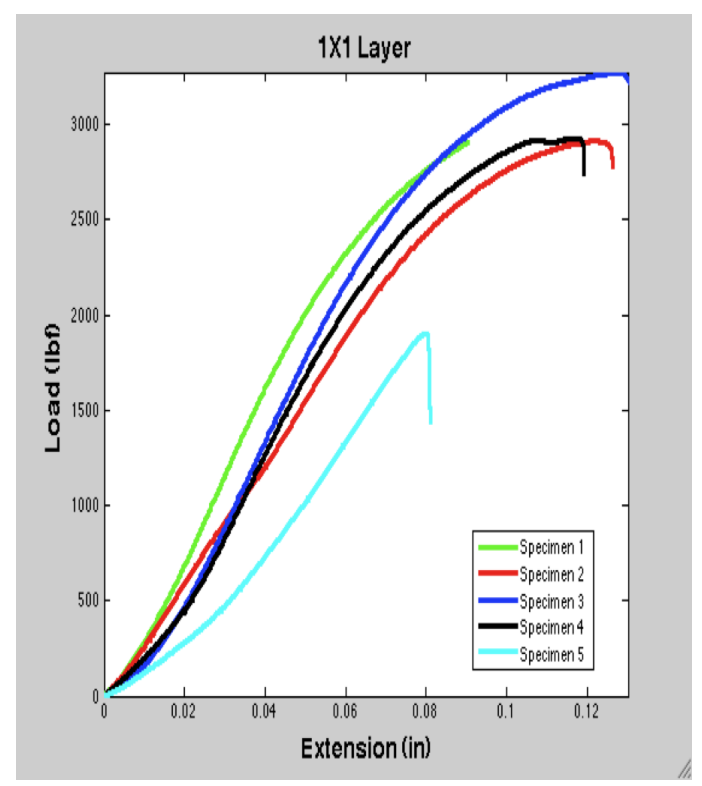

(a) 1X1 Layer-herringbone weave hemp

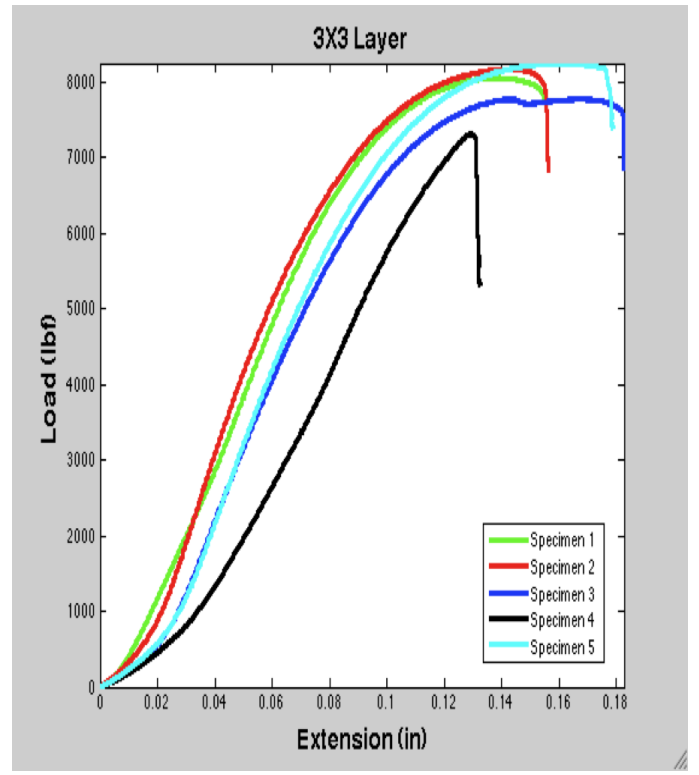

(c) 3X3 Layers-herringbone weave hemp

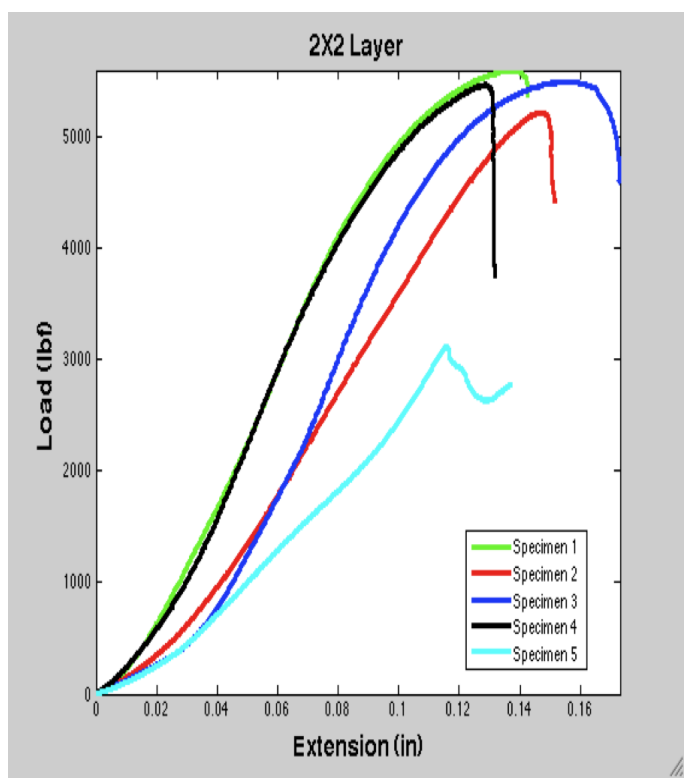

(b) $2 \mathrm{X} 2$ Layers-herringbone weave hemp

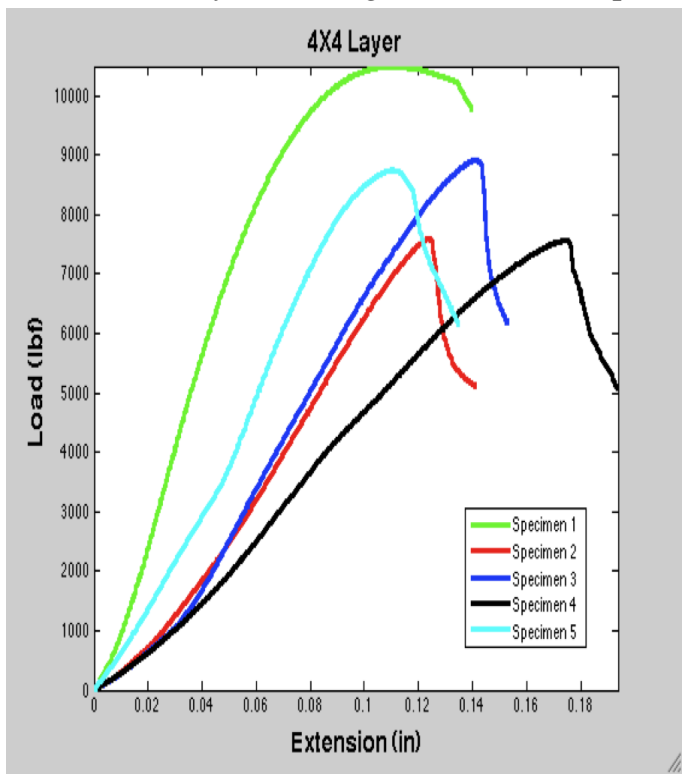

(d) 4X4 Layers-herringbone weave hemp

Figure 3.7: Edgewise-compressive testing of herringbone hemp facesheet sandwiches 


\subsubsection{Glass Fiber (Texalium) Facesheet Sandwiches}

The experimental results of carbon fiber sandwiches showed a general increase in max load prior to failure as layers were added to the sandwich configuration. The loads ranged from $1247 \mathrm{lbf}$ for the $1 \mathrm{X} 1$ layer combination to $9339 \mathrm{lbf}$ for the $4 \mathrm{X} 4$ layer combination as shown in Table 3.8. At a load of $1000 \mathrm{lbf}$ the glass fiber sandwiches showed a slight decrease of deflection as each layer was added, and ranged from 0.024 inch to 0.010 inch. This slight decrease was expected, just like carbon fiber, and is due to the high stiffness of glass fiber. As for the ultimate edgewise compressive strength, glass fiber showed a similar but lower range to carbon fiber, and was calculated to $8.37 \mathrm{ksi}$ for $1 \mathrm{X} 1$ layer and $63.11 \mathrm{ksi}$ for the $4 \mathrm{X} 4$ layer.

Table 3.8: Edgewise-compressive results for glass fiber facesheet sandwiches

\begin{tabular}{|c|c|c|c|}
\hline & $\begin{array}{c}\text { Max load prior to } \\
\text { failure [lbf] }\end{array}$ & $\begin{array}{c}\text { Deflection at 1000 } \\
\text { lbf [in] }\end{array}$ & $\begin{array}{c}\text { Ultimate Edgewise } \\
\text { Compressive } \\
\text { Strength [ksi] }\end{array}$ \\
\hline \multirow{2}{*}{ 1X1 Layer } & 1247.10 & 0.024 & 8.37 \\
& $+/-103.54$ & $+/-0.006$ & $+/-1.52$ \\
\hline \multirow{2}{*}{ 2X2 Layers } & 4286.20 & 0.015 & 28.86 \\
& $+/-266.40$ & $+/-0.013$ & $+/-3.89$ \\
\hline \multirow{2}{*}{ 3X3 Layers } & 5272.30 & 0.011 & 35.50 \\
& $+/-1281.40$ & $+/-0.006$ & $+/-4.85$ \\
\hline \multirow{2}{*}{ 4X4 Layers } & 9339.10 & 0.010 & 63.11 \\
& $+/-1683.63$ & $+/-0.0056$ & $+/-7.88$ \\
\hline
\end{tabular}


The average experimental results of glass fiber sandwiches can be seen graphically in Figure 3.8. The general trend showed a similar long unsteady trek to failure as was seen for the carbon fiber.

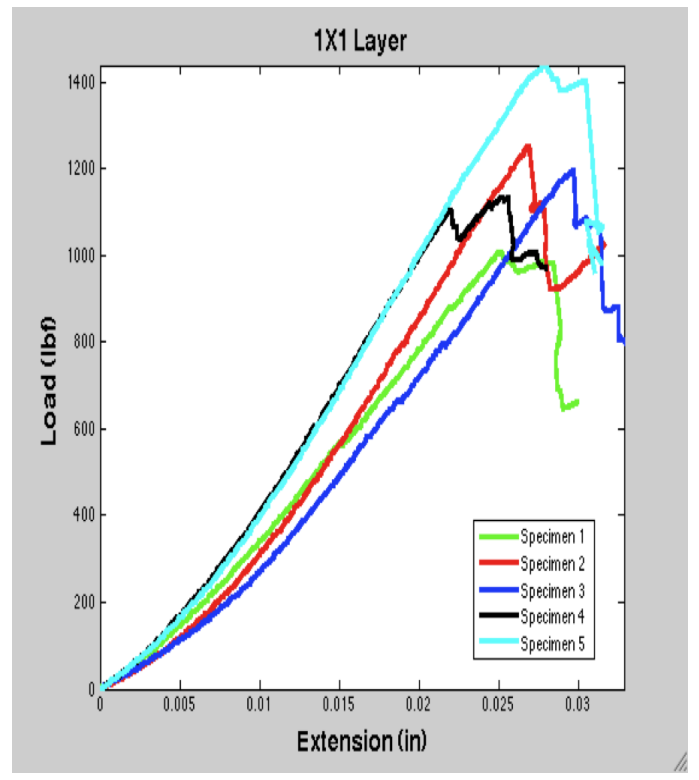

(a) 1X1 Layer-glass fiber

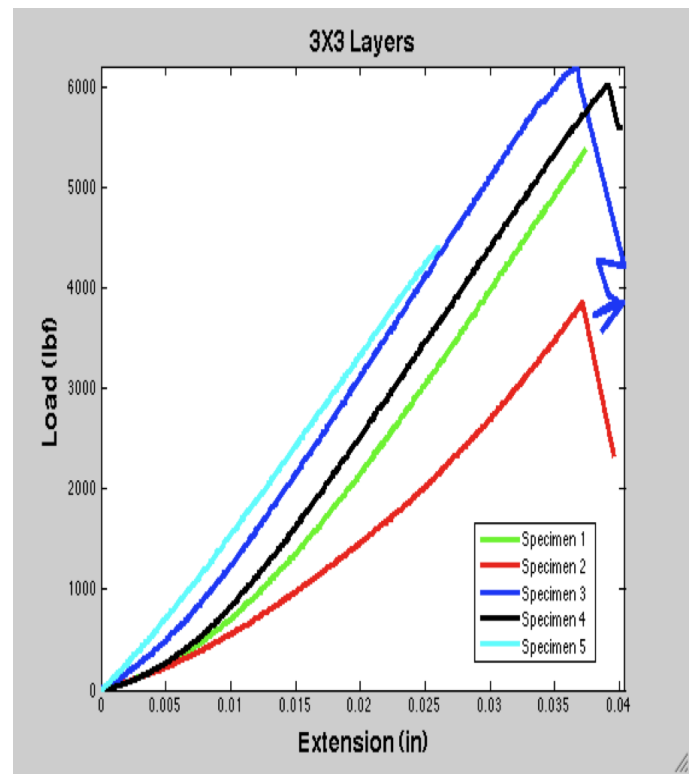

(c) 3X3 Layers-glass fiber

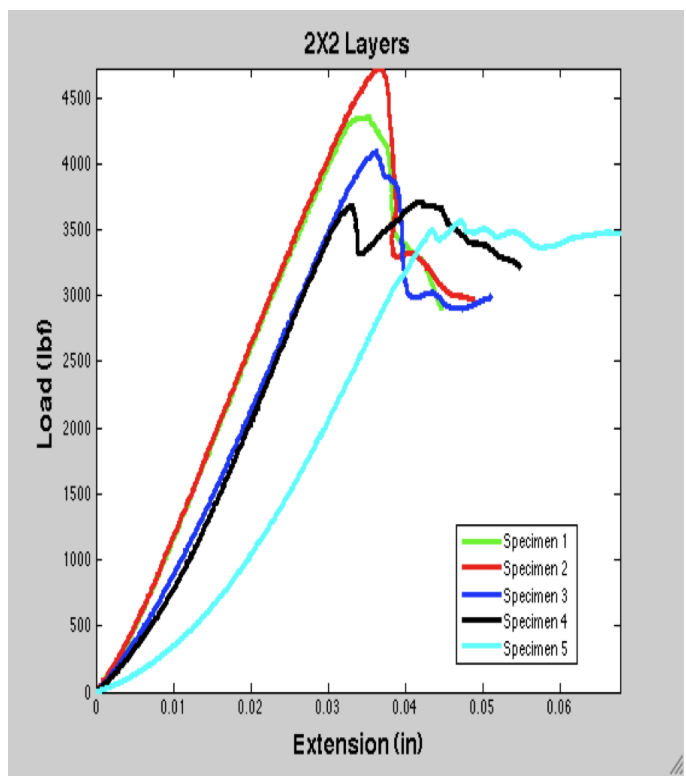

(b) 2X2 Layers-glass fiber

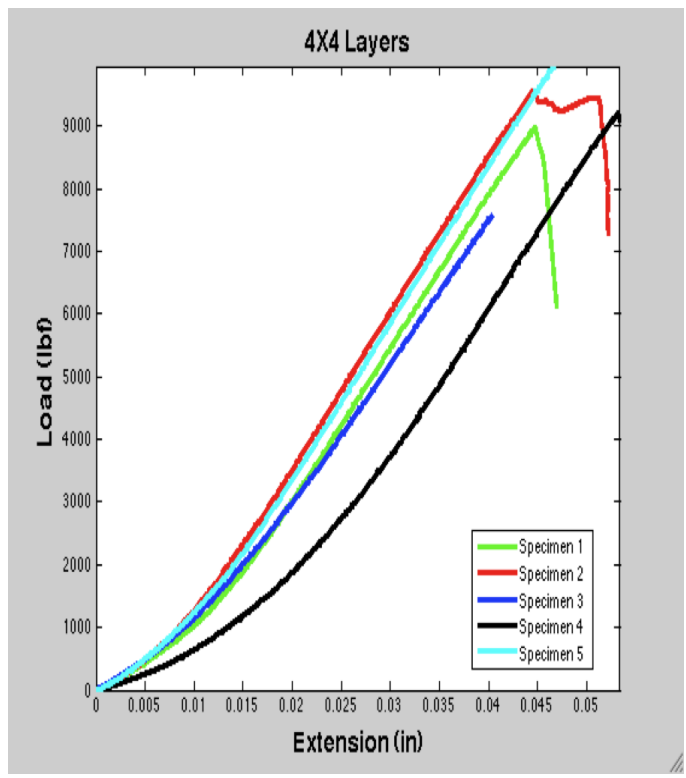

(d) 4X4 Layers-glass fiber

Figure 3.8: Edgewise-compressive testing of glass fiber facesheet sandwiches 


\subsubsection{Individual to Hybrid Facesheets}

By individually testing each material in the previous section, the results revealed which materials were best to choose for the hybrid composite sandwich. The two pre-preg composites; carbon and glass (texalium), presented similar edgewise-compressive results and weights but due to the overall strength of carbon fiber being a bit superior and the fact that delamination was not an issue, carbon fiber was chosen over the glass fiber to use in the hybrid sandwich.

The two bio-materials; plain weave hemp and herringbone weave hemp tested similar to each other as well. Even though the overall max load obtained was higher in the herringbone weave hemp, the plain weave hemp was calculated to have a higher edgewisecompressive strength for each layer added. In addition, the plain weave hemp was significantly lighter in weight so plain weave hemp was chosen to use in the hybrid sandwich.

The goal of the hybrid composite is to create a strong, lightweight composite that can utilize the best qualities of bio-materials (ductile/sustainable) and pre-preg materials (stiff/lightweight).

In order to keep symmetry consistent within the sandwich composites created, the hybrid composites tested consisted of two different layer counts created two different ways. The amount of layers used were two carbon and two hemp (2X2), and four carbon and four hemp (4X4). The same honeycomb core was utilized to keep consistency. The battle of creating these sandwiches is figuring out how to bond the two different materials within the same sandwich because they each have two different curing cycles. The two different ways that were tested is by trying to bond the hemp layers to the core first and having the carbon layers on the outer face of the sandwich. The other way of creating the hybrid sandwich is by bonding the carbon layers to the core first and having the hemp layers on the outer face. In order to create a proper composite, the cure cycle of the carbon fiber pre-preg and the 
resin used for the hemp had to be carefully thought out and planned in order to allow for proper curing. 


\subsubsection{Hybrid Sandwiches}

As stated in the previous section, there was a major problem of delamination between each opposing facesheet and between the core and facesheet. This problem of delamination can be the cause of lower edgewise-compressive results because the specimen were not able to reach their max potential. All results for the hybrid specimen can be seen in Table 3.9.

Table 3.9: Edgewise-compressive results for hybrid sandwiches

\begin{tabular}{|c|c|c|c|}
\hline & $\begin{array}{c}\text { Max load prior to } \\
\text { failure [lbf] }\end{array}$ & $\begin{array}{c}\text { Deflection at } \\
\text { 1000lbf [in] }\end{array}$ & $\begin{array}{c}\text { Ultimate Edgewise } \\
\text { Compressive } \\
\text { Strength [ksi] }\end{array}$ \\
\hline $\begin{array}{c}\text { 2X2 Layers CF outer } \\
\text { face }\end{array}$ & 2630.80 & 0.014 & 18.05 \\
$+/-658.65$ & $+/-0.009$ & $+/-1.74$ \\
\hline 2X2 Layers Hemp & 3103.90 & 0.015 & 20.69 \\
outer face & $+/-195.36$ & $+/-0.009$ & $+/-4.88$ \\
\hline 4X4 Layers CF outer & 7449.80 & 0.013 & 49.67 \\
face & $+/-768.48$ & $+/-0.006$ & $+/-8.92$ \\
\hline 4X4 Layers Hemp & 7804.20 & 0.012 & 52.45 \\
outer face & $+/-1644.04$ & $+/-0.021$ & $+/-10.66$ \\
\hline
\end{tabular}

The average experimental results of the hybrid sandwiches can be seen graphically in Figure 3.9. The general trend for all specimen showed a smooth trek to failure, as was seen with both hemp sandwiches. The interesting thing to note about the hybrid sandwiches is how little and smooth they deflected while undergoing a significant load. The delamination may have caused a premature failure and the panels may have deflected more if allowed to. But, in any case, the results show a steady, predictable failure which was not the case for the carbon fiber by itself. 


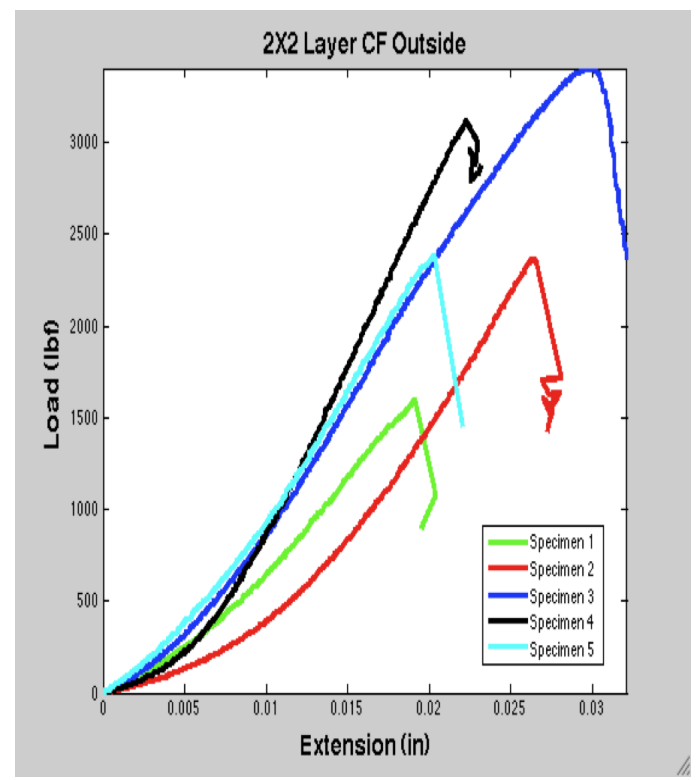

(a) 2X2 Layer-CF outer face

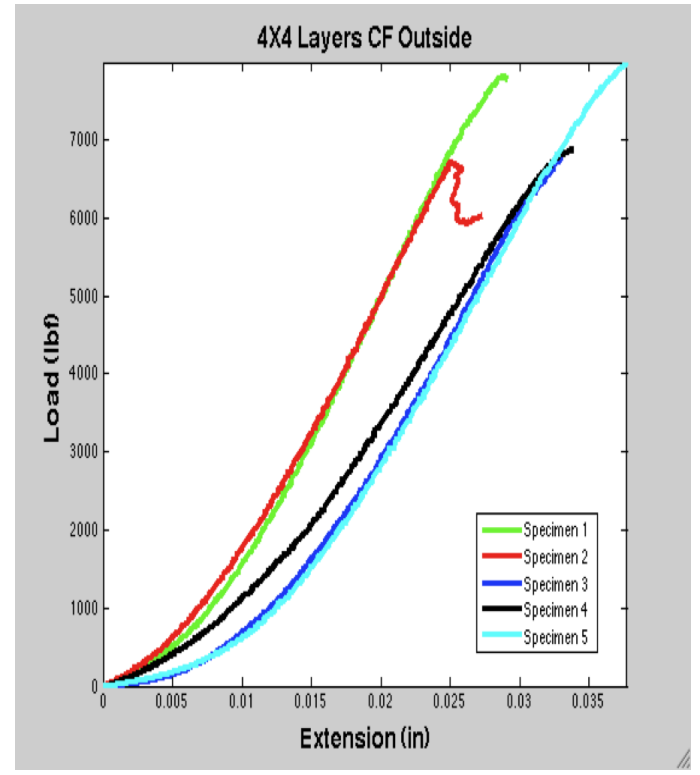

(c) 4X4 Layers-CF outer face

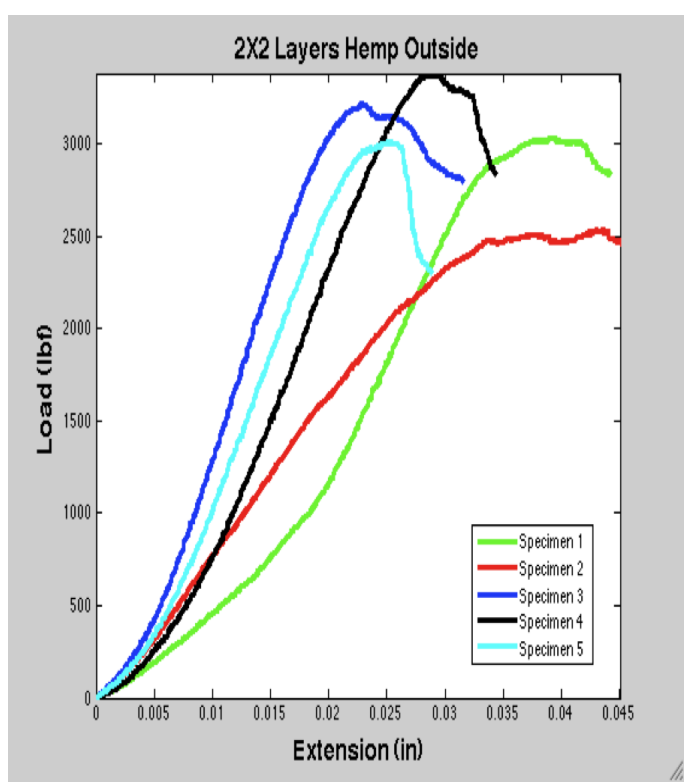

(b) 2X2 Layers-Hemp outer face

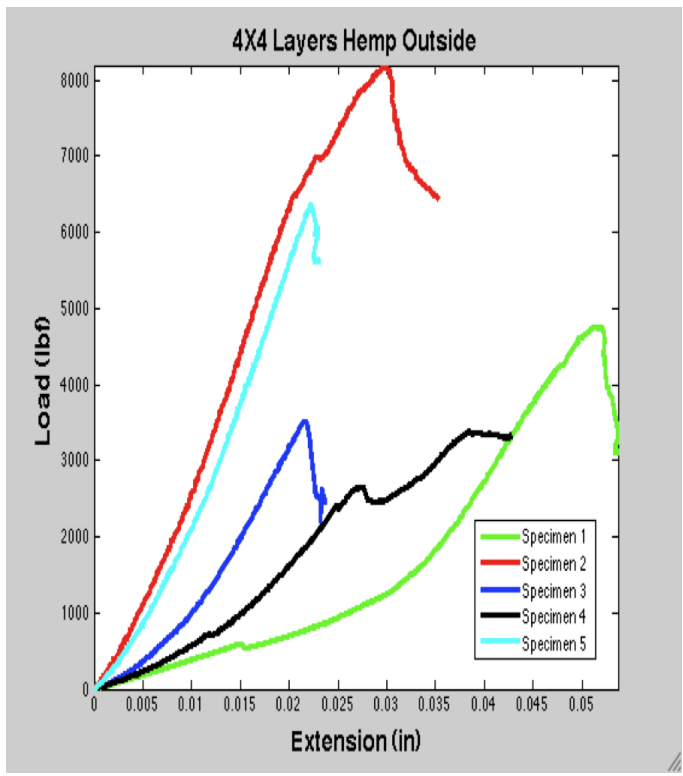

(d) 4X4 Layers-Hemp outer face

Figure 3.9: Edgewise-compressive testing of hybrid facesheet sandwiches

\subsubsection{Comparison of Individual and Hybrid Facesheets}

\subsubsection{Average Strength for Individual Facesheet Materials}

The comparison of edgewise-compressive strength to weight between all sandwich specimen is made in this section to fully understand which facesheet material has the high- 
est strength to weight. In aircraft structures, high strength and low weight is imperative to examine as it determines the most efficient structure.

As seen in Table 3.10 plain weave hemp has the highest edgewise strength for one and two layers, but carbon fiber surpasses all for three and four layers.

Table 3.10: Edgewise-compressive strength comparison for individual facesheet materials

\begin{tabular}{|c|c|c|c|c|}
\hline & $\begin{array}{c}\text { Carbon } \\
\text { Fiber [ksi] }\end{array}$ & $\begin{array}{c}\text { Plain Weave } \\
\text { Hemp [ksi] }\end{array}$ & $\begin{array}{c}\text { Herringbone } \\
\text { Hemp [ksi] }\end{array}$ & $\begin{array}{c}\text { Glass Fiber } \\
{[\mathrm{ksi}]}\end{array}$ \\
\hline \multirow{2}{*}{ 1X1 Layer } & 13.11 & 13.85 & 9.77 & 8.37 \\
& $+/-1.42$ & $+/-1.33$ & $+/-1.83$ & $+/-1.52$ \\
\hline \multirow{2}{*}{ 2X2 Layers } & 24.33 & 24.95 & 17.20 & 28.86 \\
& $+/-3.54$ & $+/-5.53$ & $+/-3.56$ & $+/-3.89$ \\
\hline \multirow{2}{*}{ 3X3 Layers } & 41.79 & 34.83 & 27.18 & 35.50 \\
& $+/-4.75$ & $+/-3.38$ & $+/-1.18$ & $+/-4.85$ \\
\hline \multirow{2}{*}{ 4X4 Layers } & 65.81 & 56.14 & 29.88 & 63.11 \\
& $+/-14.98$ & $+/-5.61$ & $+/-4.19$ & $+/-7.88$ \\
\hline
\end{tabular}

\subsubsection{Average Weight for Individual Facesheet Materials}

As seen in Table 3.11 carbon fiber and glass fiber were the lightest with nearly equal values for each added layer. The plain weave hemp was heavier than both the carbon fiber and glass fiber, but lighter than the herringbone hemp. Both hemp materials are a bit heavier but may strictly be due to the fact that it is not a pre-preg material. 
Table 3.11: Average weight comparison for individual materials

\begin{tabular}{|c|c|c|c|c|}
\hline & $\begin{array}{c}\text { Carbon } \\
\text { Fiber [g] }\end{array}$ & $\begin{array}{c}\text { Plain Weave } \\
\text { Hemp [g] }\end{array}$ & $\begin{array}{c}\text { Herringbone } \\
\text { Hemp [g] }\end{array}$ & $\begin{array}{c}\text { Glass Fiber } \\
{[\mathrm{g}]}\end{array}$ \\
\hline \multirow{2}{*}{ 1X1 Layer } & 15.72 & 20.96 & 25.48 & 15.60 \\
& $+/-0.23$ & $+/-0.57$ & $+/-0.33$ & $+/-0.28$ \\
\hline \multirow{2}{*}{ 2X2 Layers } & 22.40 & 32.20 & 39.44 & 21.76 \\
& $+/-0.51$ & $+/-1.15$ & $+/-0.53$ & $+/-0.48$ \\
\hline \multirow{2}{*}{ 3X3 Layers } & 29.88 & 42.80 & 52.80 & 29.28 \\
& $+/-0.67$ & $+/-0.86$ & $+/-0.69$ & $+/-0.61$ \\
\hline \multirow{2}{*}{ 4X4 Layers } & 36.08 & 57.12 & 70.72 & 35.92 \\
& $+/-0.86$ & $+/-1.62$ & $+/-2.46$ & $+/-0.78$ \\
\hline
\end{tabular}

\subsubsection{Average Strength for Hybrid Facesheet Materials}

As seen in Table 3.12 plain weave hemp on the outer face shows to have the highest edgewise strength for both the $2 \mathrm{X} 2$ layer and the $4 \mathrm{X} 4$ layer. This factor may have been from how well the carbon fiber bonded to the core when it was the inner layer. It did not delaminate as fast and therefore was able to withstand a higher load.

Table 3.12: Edgewise-compressive strength comparison for hybrid sandwiches

\begin{tabular}{|c|c|}
\hline & Average Strengths [ksi] \\
\hline 2X2 Layer-CF outer & 18.05 \\
face & $+/-1.74$ \\
\hline 2X2 Layer-Hemp & 20.69 \\
outer face & $+/-4.88$ \\
\hline 4X4 Layer-CF outer & 49.67 \\
face & $+/-8.92$ \\
\hline 4X4 Layer-Hemp & 52.45 \\
outer face & $+/-10.66$ \\
\hline
\end{tabular}

\subsubsection{Average Weight for Hybrid Sandwiches}

The positive component of the hybrid sandwiches was the average weight when compared to the plain weave hemp and carbon fiber sandwiches. The hybrid sandwiches were 
roughly 8 grams lighter than the plain weave hemp and only 1-2 grams heavier than the carbon fiber for the $2 \mathrm{X} 2$ layers specimen. The $4 \mathrm{X} 4$ layer set was about 7 grams heavier than the carbon fiber and about 12 grams lighter than the plain weave hemp sandwiches. All specific weights can be seen in Table 3.13.

Table 3.13: Average weight comparison for hybrid sandwiches

\begin{tabular}{|c|c|}
\hline & Average Weights [g] \\
\hline 2X2 Layer-CF outer & 23.76 \\
face & $+/-0.43$ \\
\hline 2X2 Layer-Hemp & 24.36 \\
outer face & $+/-0.55$ \\
\hline 4X4 Layer-CF outer & 43.84 \\
face & $+/-0.83$ \\
\hline 4X4 Layer-Hemp & 45.68 \\
outer face & $+/-0.54$ \\
\hline
\end{tabular}

\subsubsection{Strength-to-Weight Results of All Sandwiches}

The general trend of the edgewise-compressive strength-to-weight for all specimen is linear from layer to layer. As shown in the Strength-to-Weight vs. layer plot in Figure 3.10, it can be seen that carbon fiber has the highest strength to weight ratio for every layer except the 2X2 which was the glass fiber. Both carbon fiber and glass fiber were extremely lightweight, which is why they dominate in strength-to-weight. But, these two materials were followed closely by plain weave hemp and both hybrid sandwiches. This can be attributed to the fact that hemp fibers have an excellent buckling capability and can withstand a heavy compressive load.

As seen in Figure A.1 the average edgewise-compression strength is compared per material and plotted against the amount of layers researched. This plot shows that carbon fiber is the dominant material in almost all layer combinations and herringbone hemp fiber has some of the worst results in this comparison. 


\section{Strength-to-Weight}

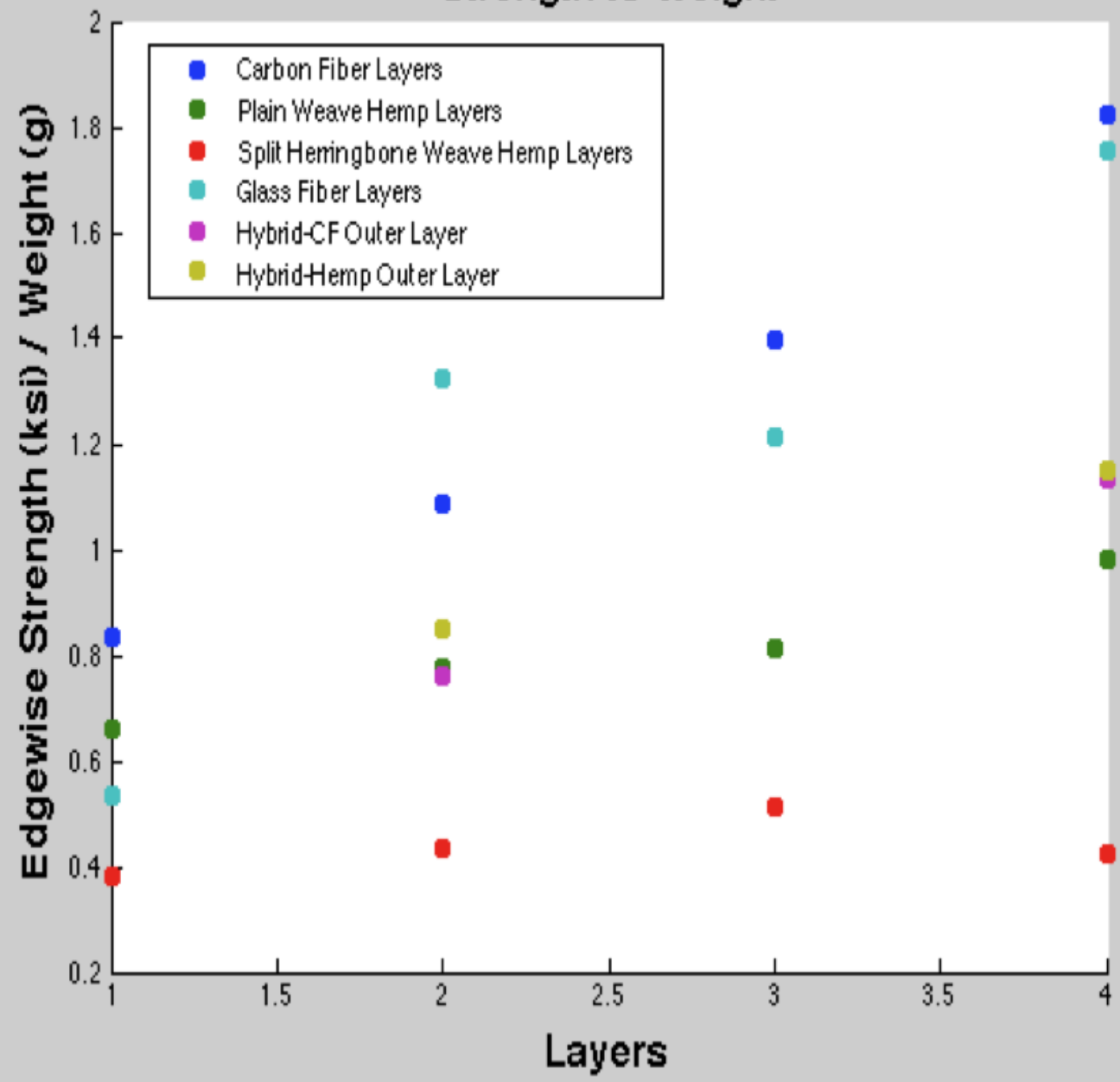

Figure 3.10: Strength-to-Weight vs. number of layers

\subsection{Failure Mode Discussion}

The failure mode of a composite sandwich is very important to investigate as it gives the designer beneficial information about the weak areas of the composite structure. Depending on the type of material used for the facesheet and core, the failure mode can vary for each different sandwich combination created. Especially under a compressive load, failure can be unpredictable and as seen in a previous section, there are six different ways a composite sandwich can fail. Obviously the weakest area of the sandwich will fail first, but can only be discovered with a load applied to the structure. Many times the adhesion region between the core and facesheets for a composite sandwich will fail first. This will be explained for 
the hemp fiber sandwiches in a later section. Failure can occur many ways and whether it is predictable or not is also very important to consider, especially when the composite piece is a main part of a bigger structure. Because mechanical properties are different from material to material, failures are different and important to investigate after testing.

\subsubsection{Carbon Fiber Facesheet Sandwiches}

As seen in the mechanical properties section, carbon fiber was by far the strongest and stiffest facesheet material used in this study. The failure type for carbon fiber was difficult to judge when testing because the facesheets on all specimens were still intact after the load dropped by $40 \%$ of max load. The load versus deflection plot of every carbon fiber sample continually showed a leveling out of load after $P_{\max }$ was achieved. This circumstance indicated end failure caused by bearing stress. Even though this is considered an unacceptable failure by the ASTM standard, each specimen continually failed in this manner and was deemed to be sufficient as a means of failure. The complete failure mode is shown in Table 3.14 .

After adding more layers to the specimen of carbon fiber, each sandwich failed similarly and can be seen in Figure 3.11b. As seen, the carbon fiber sandwiches did not delaminate or buckle at all. The end failure of all specimen can be seen in Figure 3.11 as well. Even though ASTM C364 indicated an unacceptable failure during testing is less than 1xt from clamp, the carbon fiber sandwich continually failed at the top and bottom of the sandwich. After continually testing carbon fiber samples, the failure did not change. This phenomena may be due to the innate brittleness of carbon fiber.

Table 3.14: Edgewise-compressive failure mode for carbon fiber sandwiches

\begin{tabular}{|c|c|}
\hline & Failure Mode \\
\hline Failure Type & End Failure \\
\hline Failure Area & Facesheet Edge \\
\hline Failure Location & Top and Bottom \\
\hline
\end{tabular}




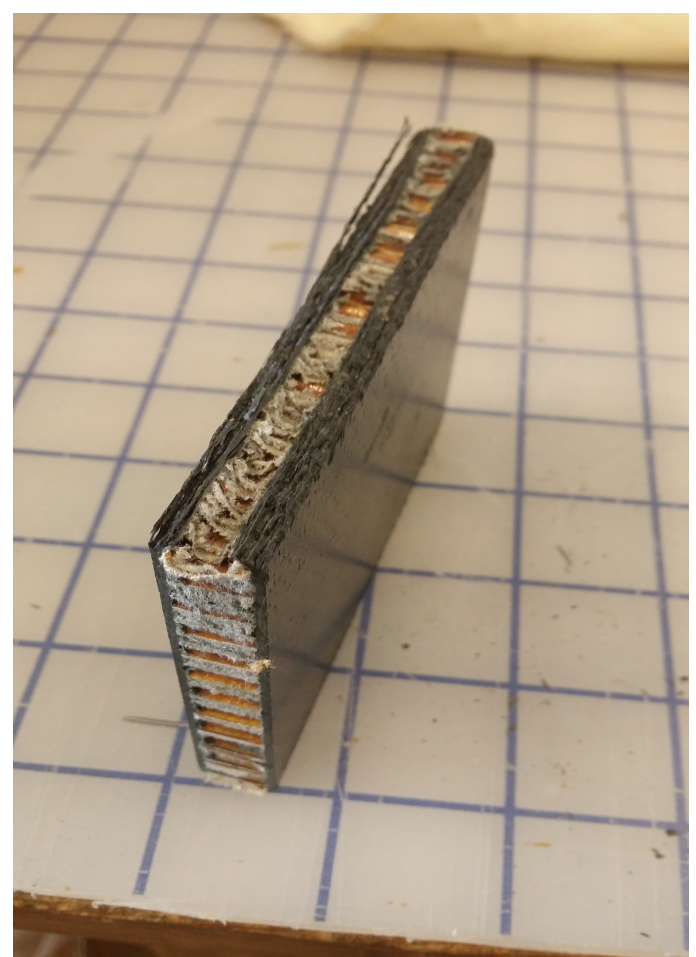

(a) Failure mode of carbon fiber sandwich

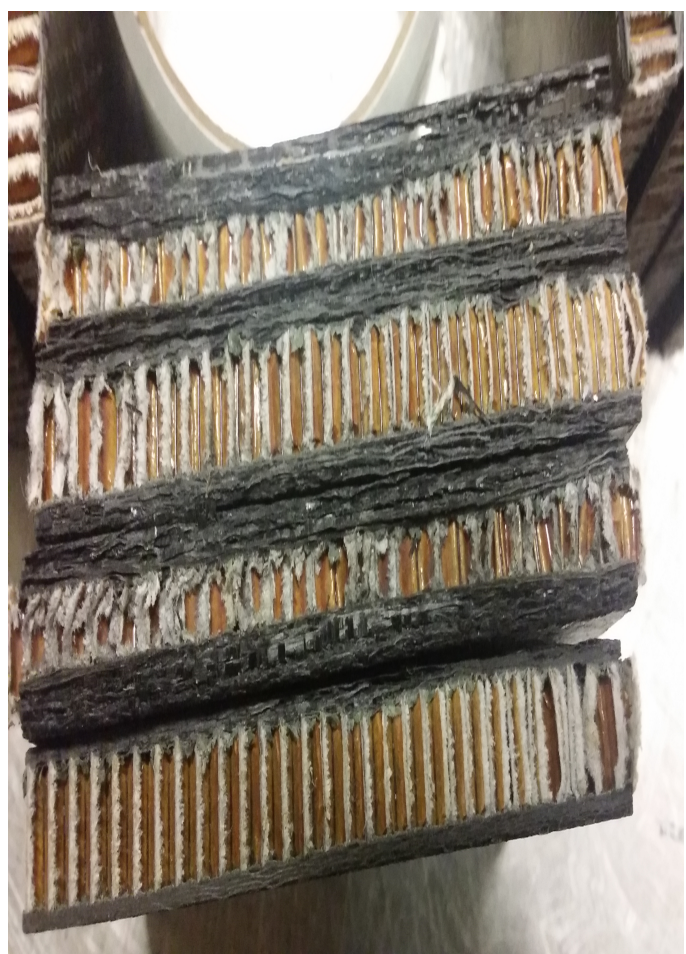

(b) Failure mode of carbon fiber sandwich

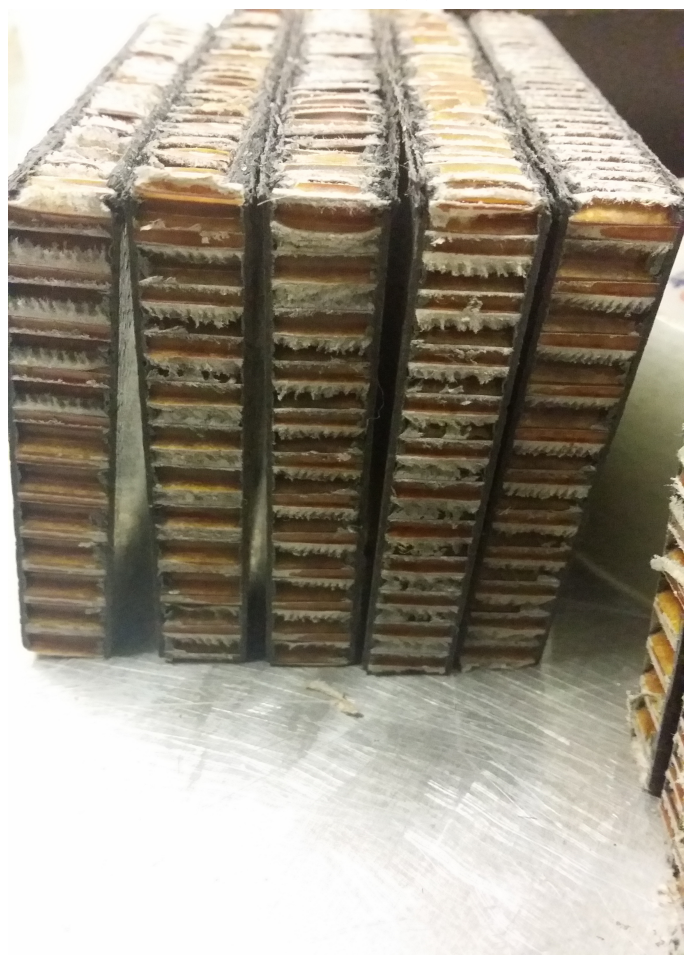

(c) Failure mode of carbon fiber sandwich

Figure 3.11: Failure mode of all carbon fiber sandwiches 


\subsubsection{Plain Weave Hemp Facesheet Sandwiches}

The plain weave hemp samples either delaminated at the facesheet/core bond or exhibited facesheet buckling as the failure mode is indicated in Table 3.15. The inherent buckling capabilities of hemp fabric is seen in Figure 3.12a.

Table 3.15: Edgewise-compressive failure mode for plain weave hemp sandwiches

\begin{tabular}{|c|c|}
\hline & Failure Mode \\
\hline Failure Type & Facesheet Buckling/Delamination \\
\hline Failure Area & Gage area \\
\hline Failure Location & Middle \\
\hline
\end{tabular}

The facesheet bonding seemed to be an issue for some of the plain weave hemp sandwiches. If it happened to not delaminate, then a facesheet buckling took place. This type of failure allowed for more deflection under max load and a more predictable failure. The fact that the edgewise strength before failure was a similar performance to carbon fiber without an end failure indicates that hemp may be the most advantageous facesheet to use with a compressive load. 


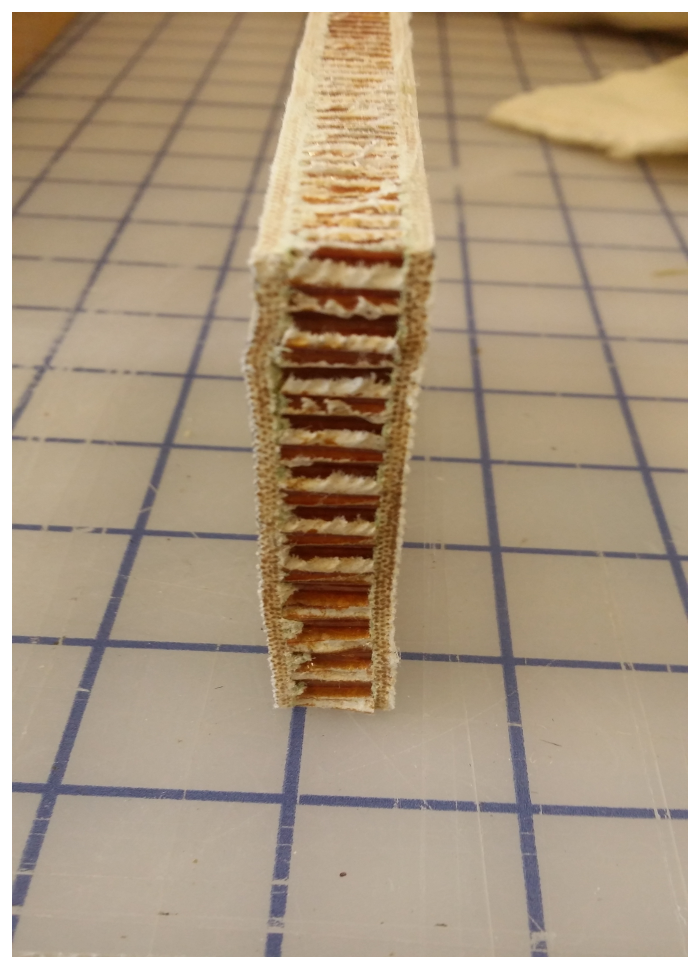

(a) Failure mode of plain weave hemp sandwich

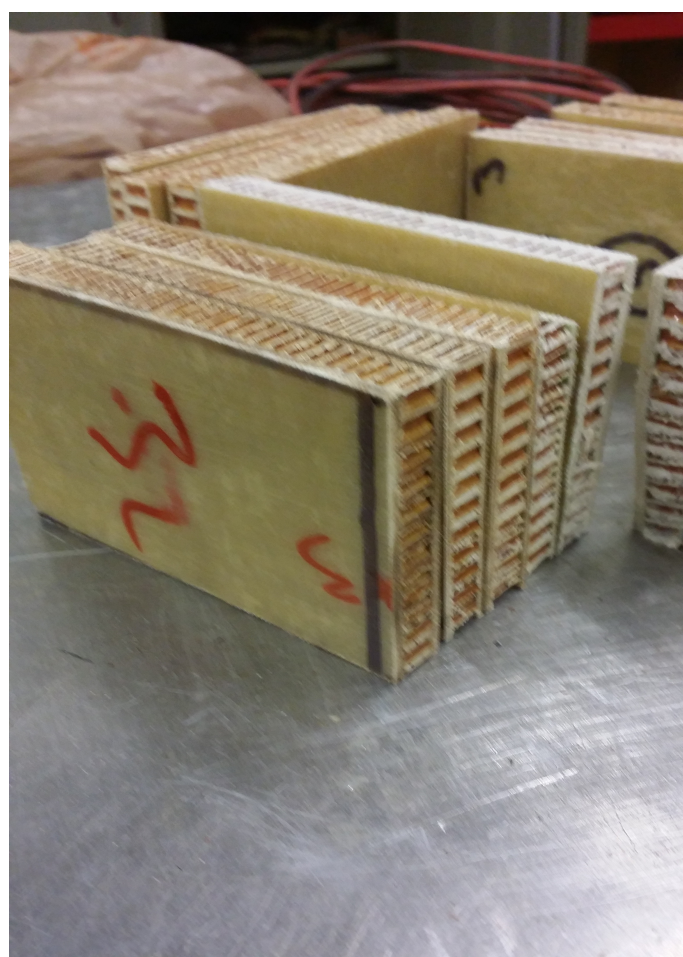

(b) Failure mode of plain weave hemp sandwich

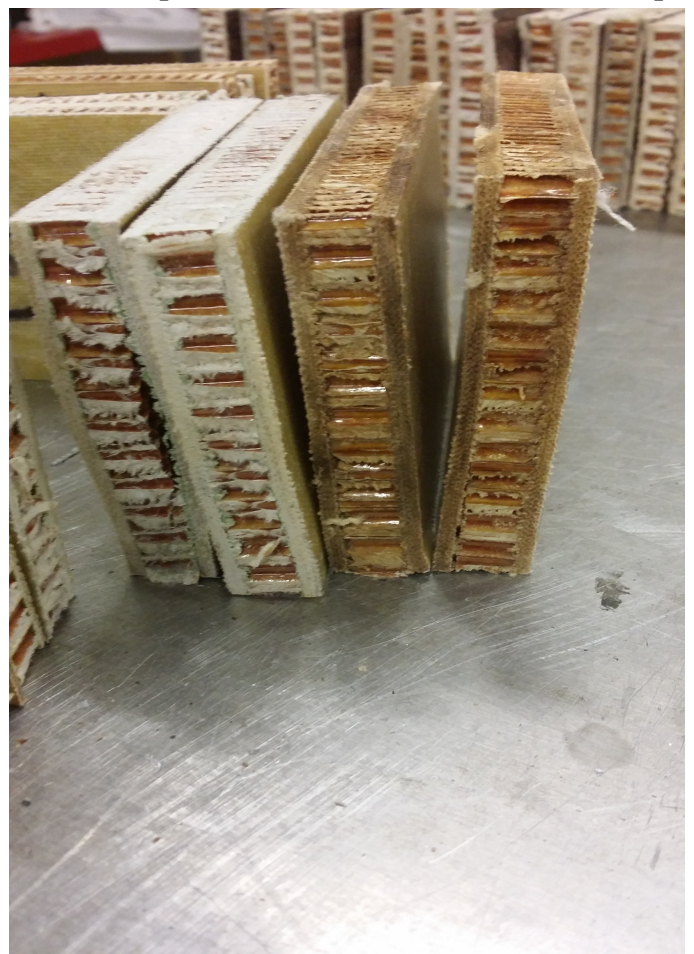

(c) Failure mode of plain weave hemp sandwich

Figure 3.12: Failure mode of all plain weave hemp sandwiches 


\subsubsection{Herringbone Weave Hemp Facesheet Sandwiches}

The herringbone weave hemp samples were very similar to the plain weave hemp samples and either delaminated at the facesheet/core bond or exhibited facesheet buckling. A tested specimen can be seen in Figure 3.13a and shows the permanent antisymmetric wrinkling that occured with the four layer specimen.

Table 3.16: Edgewise-compressive failure mode for herringbone weave hemp sandwiches

\begin{tabular}{|c|c|}
\hline & Failure Mode \\
\hline Failure Type & Facesheet Buckling/Delamination \\
\hline Failure Area & Gage area \\
\hline Failure Location & Middle \\
\hline
\end{tabular}




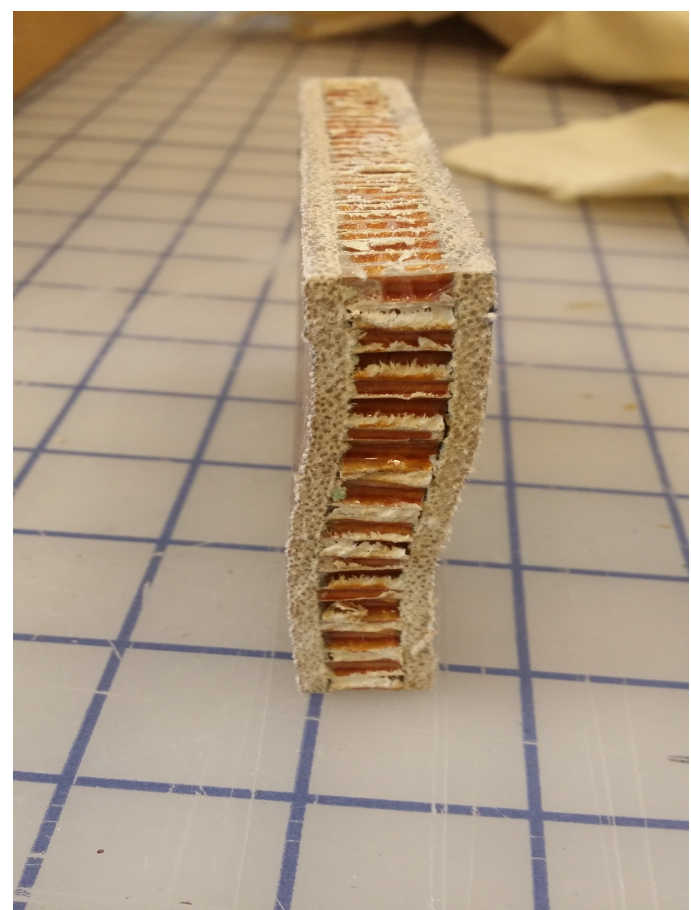

(a) Failure mode of herringbone weave hemp sandwich

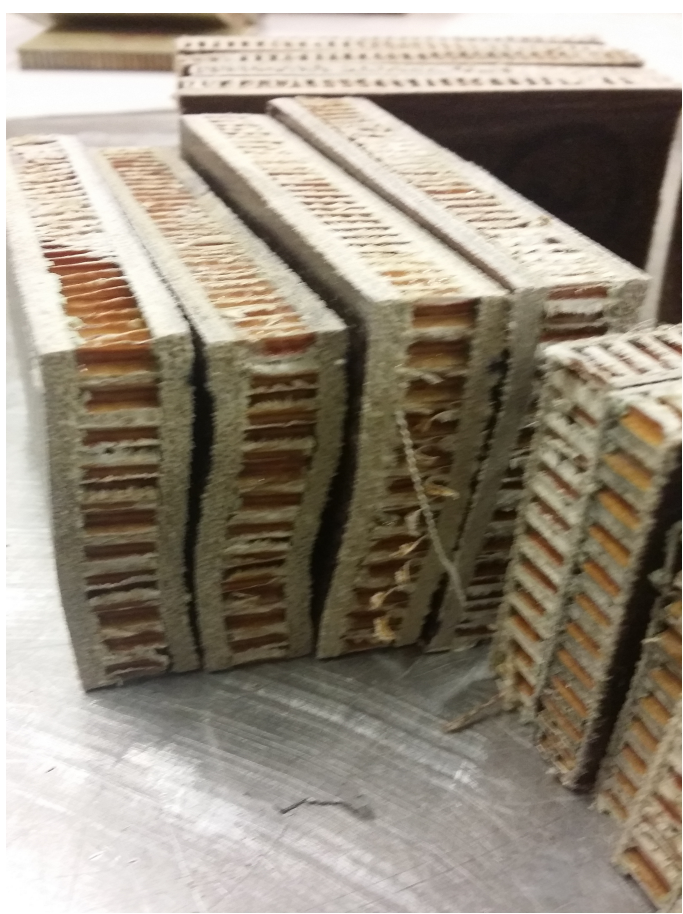

(b) Failure mode of herringbone weave hemp sandwich

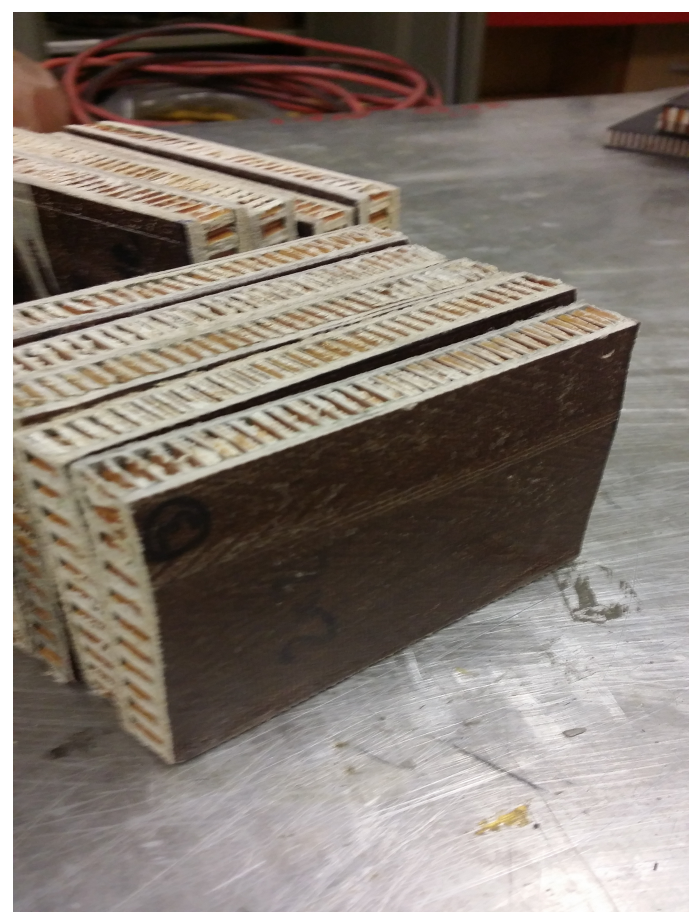

(c) Failure mode of herringbone weave hemp sandwich

Figure 3.13: Failure mode of all herringbone weave hemp sandwiches 


\subsubsection{Glass Fiber (Texalium) Facesheet Sandwiches}

The glass fiber samples either delaminated at the facesheet/core bond or exhibited facesheet compression failure at the top of specimen or middle of the facesheet. The failure mode is indicated in Table 3.17. The glass fiber sample seen in Figure 3.14a shows the facesheet compression at the top. This failure seemed to occur if the facesheet/core bond was strong enough to withstand the load and if it was not strong enough, then delamination occured. This appears to look like the carbon fiber end failure. Carbon fiber seemed to be more brittle than the glass fiber so, less of an end failure was apparent.

Table 3.17: Edgewise-compressive failure mode for glass fiber sandwiches

\begin{tabular}{|c|c|}
\hline & Failure Mode \\
\hline Failure Type & Facesheet Compression/Delamination \\
\hline Failure Area & Facesheet Edge/Gage area \\
\hline Failure Location & Top and Middle \\
\hline
\end{tabular}




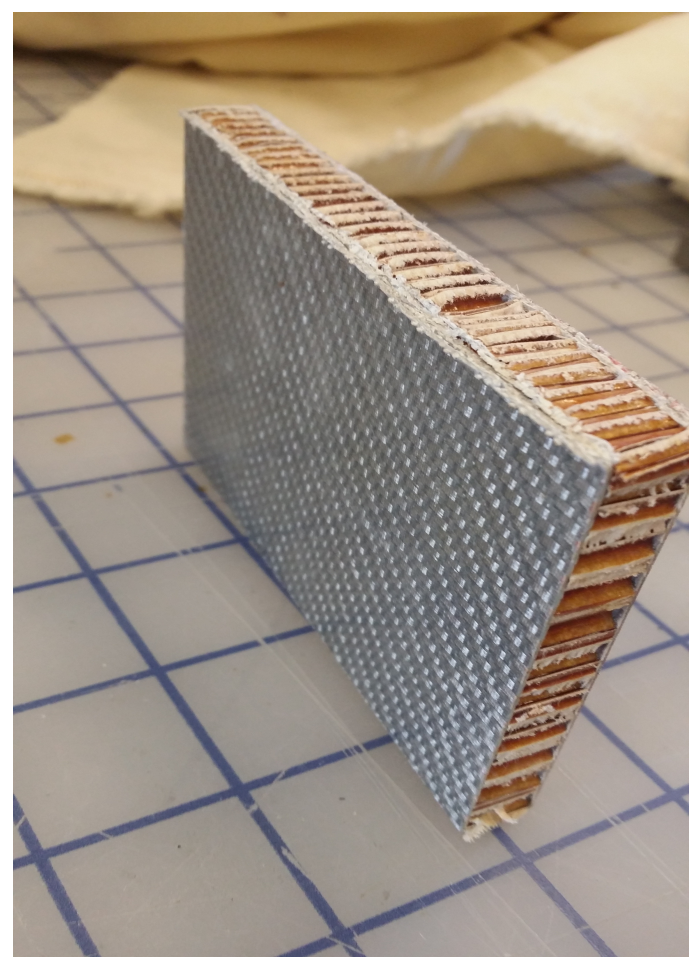

(a) Failure mode of glass fiber sandwich

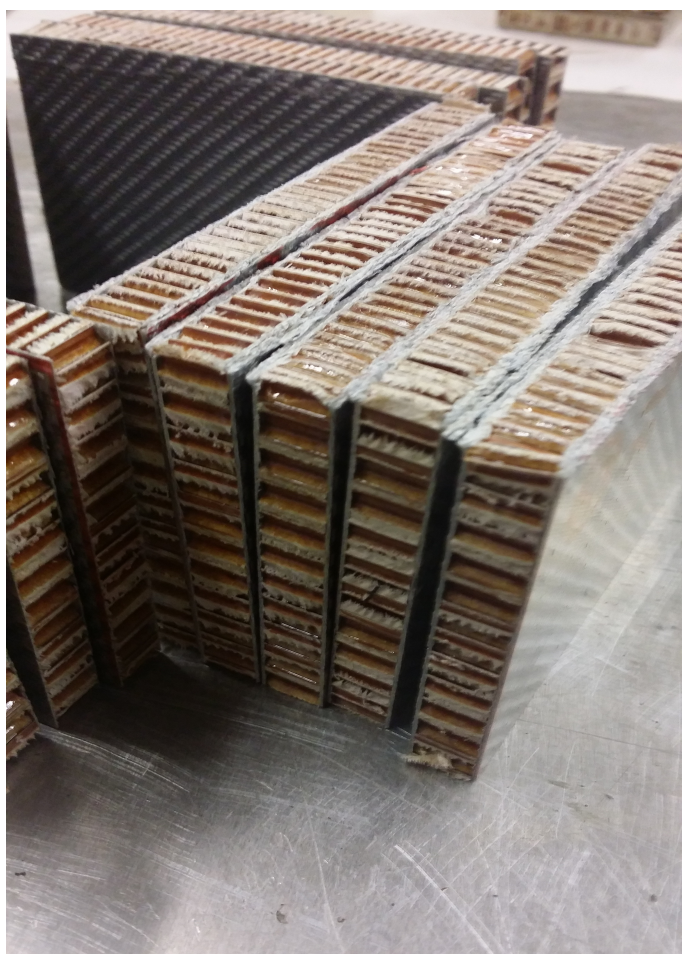

(b) Failure mode of glass fiber sandwich

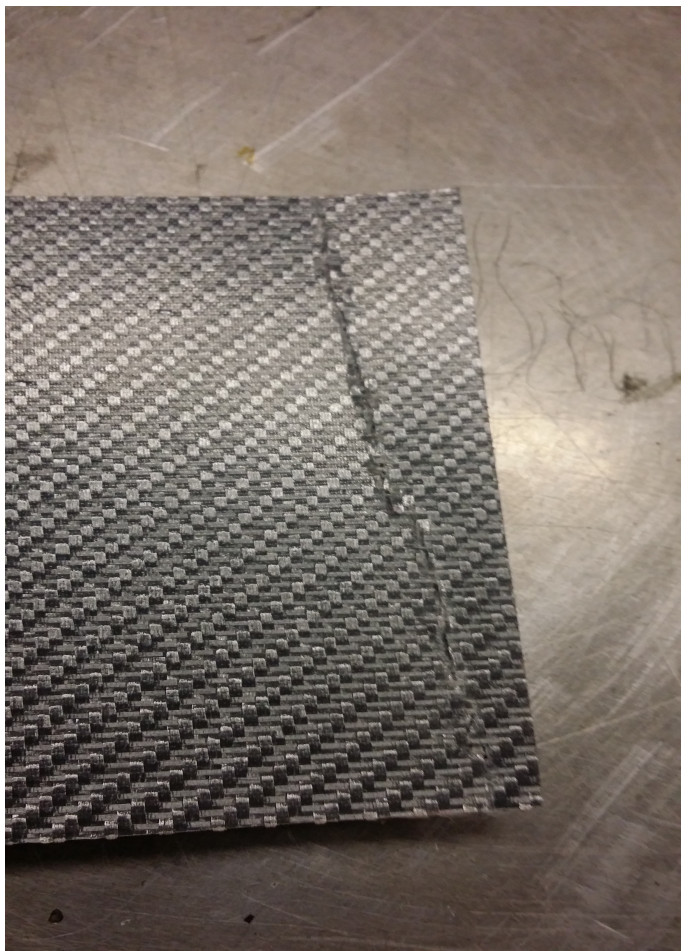

(c) Failure mode of glass fiber sandwich

Figure 3.14: Failure mode of all glass fiber sandwiches 


\subsubsection{Hybrid Sandwiches}

Failure of the hybrid sandwiches were a lot more stable and similar to the individual hemp specimen. The end failure of the carbon fiber was not apparent in the hybrid specimen even though carbon fiber was present as one of the facesheets.

Table 3.18 shows the failure mode of all the hybrid sandwiches. Facesheet buckling was the dominant failure but some specimen had some sort of major delamination when put under a load, as seen in Figure 3.15a. This problem could be fixed in future experimentation with better bonding to the core and an epoxy that can be used for both facesheets that have the same cure cycle. The drastic difference of cure cycles was a huge issue faced during the creation of the hybrid sandwiches. As seen in Figure 3.15b the end-damage after failing is not noticeable at all and overall looks the most in tact after failure than any of the individual facesheets. The end-failure seen in the carbon fiber was prevented by adding the hemp layer, whether it be on the outer facesheet or the inner facesheet. This proves that the ductility of the hemp can counter balance the brittleness of the carbon fiber and create a superior composite structure that minimizes damage upon failure.

Table 3.18: Edgewise-compressive failure mode for hybrid sandwiches

\begin{tabular}{|c|c|}
\hline & Failure Mode \\
\hline Failure Type & Facesheet Buckling/Delamination \\
\hline Failure Area & Gage area-between facesheets and core \\
\hline Failure Location & Middle \\
\hline
\end{tabular}




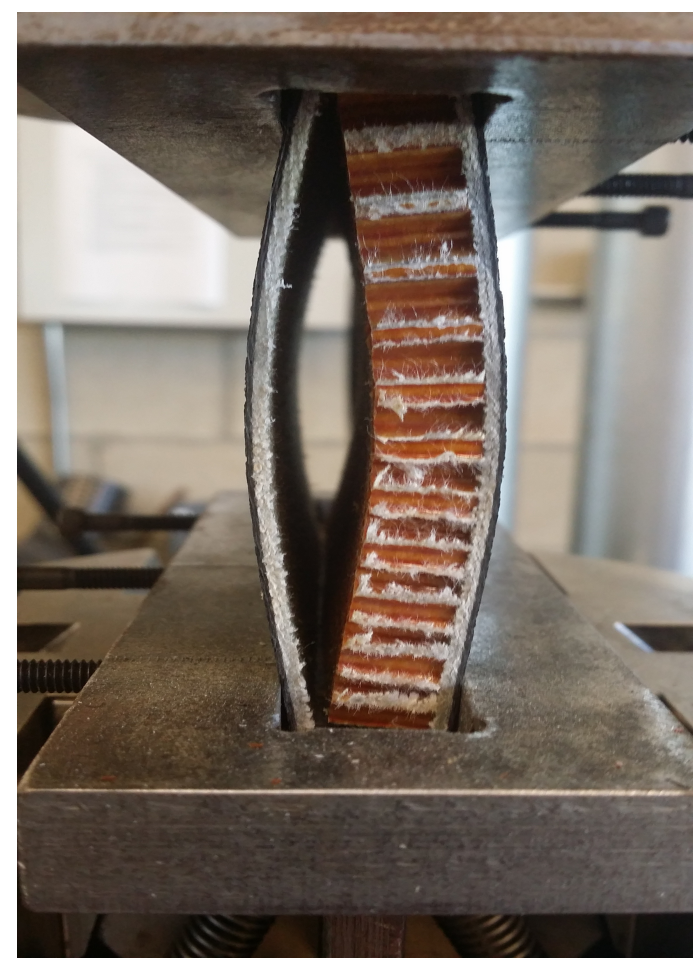

(a) Failure mode of hybrid sandwich

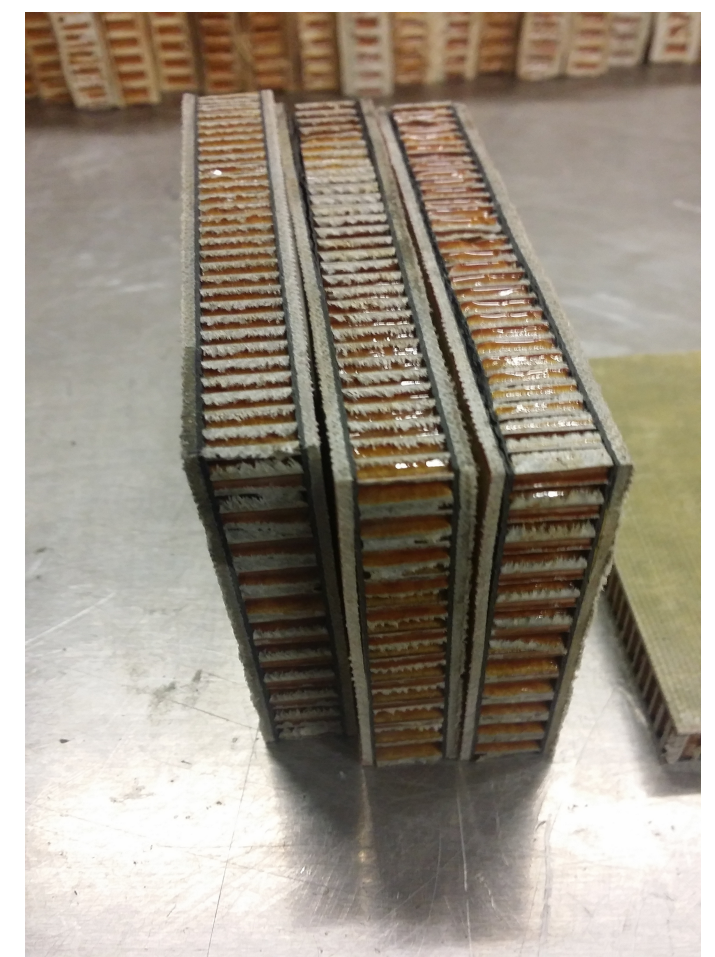

(b) Ideal Failure with minimal damage

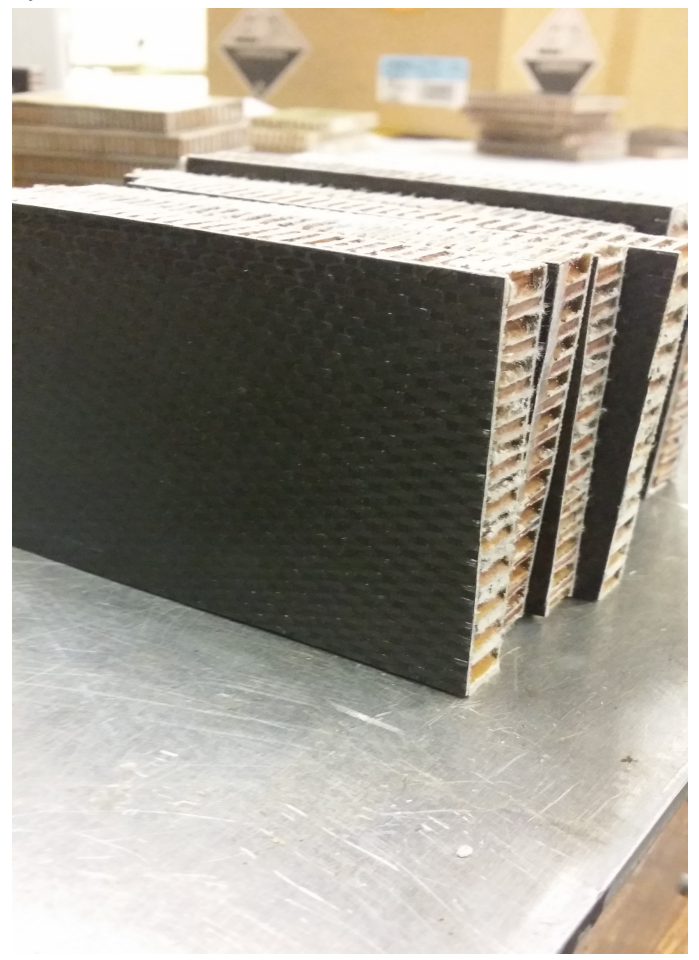

(c) Failure mode of hybrid sandwich

Figure 3.15: Failure mode of all hybrid sandwiches 


\subsubsection{Discussion of Individual and Hybrid Facesheets}

When examining laminated composite sandwiches under a compressive load, the failure mode is an important aspect to consider because they can be prone to fail many different ways. With edgewise-compressive testing, the core carries the transverse shear load, and the facesheets carry the bending and in-plane loads, so each facesheet and core combination will show a different type of failure mode depending on the mechanical properties of the material.

In the case of the carbon fiber sandwiches, end failure occurred at the ends for all specimen due to the brittleness of the individual fibers within the pre-preg material. Usually, a long fiber composite like carbon fiber is designed to possess a high stiffness and tensile strength while the matrix is designed to carry the in-plane loads and maintain ductility. But in this case of edgewise compression, if the matrix cannot handle the in-plane loads then the fibers will start to carry the load. Being that carbon fibers are not designed to carry such high compressive loads, each individual fiber will start to buckle and facesheet compression will occur at the weakest point, which in this case was the top and bottom of the composite sandwich.

Similar to the carbon fiber sandwiches, the glass fiber composite acted like the carbon fiber in that it started to compress at the ends when the matrix could not handle the compressive load. Being that it had a small bit of aluminum inter-laid with the glass fibers, bonding to honeycomb was not very efficient even with the adhesive layer, so it was observed to also fail by facesheet delamination.

In the case of both hemp weave sandwiches, facesheet delamination and facesheet buckling occurred. Being that the hemp fibers were not a pre-preg material and the epoxy matrix was not perfect for every sample, human error may have had a contribution to the delamination during testing. This type of failure is understandable and can be easily fixed with proper bonding techniques in the future. The interesting failure of the hemp sandwiches 
is the facesheet buckling, which is also known as local short wavelength buckling. This type of failure can have symmetric or antisymmetric wrinkling about the middle surface of the sandwich. With both hemp composite sandwiches, facesheet wrinkling proved that the hemp fibers were able to withstand the in-plane loads much better than the carbon and glass fibers. This failure allowed for a bigger deformation while still being able to carry similar if not higher compressive loads than the carbon fiber and glass fiber. Even though the hemp fibers were able to carry the compressive loads in a stable manner, in some cases the final failures of the hemp sandwiches were catastrophic. Whereas, the carbon fiber was not stable under the compressive loading and failure was almost uncertain due to the lack of deformation that was occurring and continual end crushing of the individual fibers.

When the hybrid facesheets were put to the test, the end failure did not occur even though carbon fiber was used as one of the facesheets within. The hemp facesheet seemed to balance the load and diminish that type of unsteady failure. Even though the max load and edgewise strength of the hybrid sandwiches were not as high as the individual carbon fiber or plain weave hemp as seen in the previous section, the failure mode of the hybrid sandwiches was a lot more stable and seemed to handle the load without as much damage as the individual facesheets. 


\section{Chapter 4}

THEORETICAL ANALYSIS

\subsection{Edgewise Compression Analysis Method}

The compression of rectangular plates subjected to an in-plane load has been a subject of study in solid mechanics for more than half of a century. Many exact solutions for thin isotropic plates have been developed; most of them can be found in Timoshenko and Woinwsky-Krieger.[28] Exact and approximate solutions for anisotropic plates and laminated plates have also been derived and subsequently compiled by Lekhnitskii [29]. However, even for a thin homogeneous orthotropic plate, analytical solutions given in the open literature are incomplete. Moreover, most of these available solutions are based on the assumption of uniform end loads in contrast to the real situation where the end load distribution may be far from the uniform distribution due to the complex support conditions and load bearing mechanisms.

\subsubsection{Orthotropic Plates under In-plane Uniaxial Compression}

Like the experimental setup, the theoretical assumption was a laminated composite plate that is subjected to a compressive edge force lying in the plane of the plate as shown in Figure 4.1.

Based on the usual assumptions in the theory of bending of thin plates, the governing equation [30] for displacement $\mathrm{w}$ of the plate in the $\mathrm{z}$-direction is, 

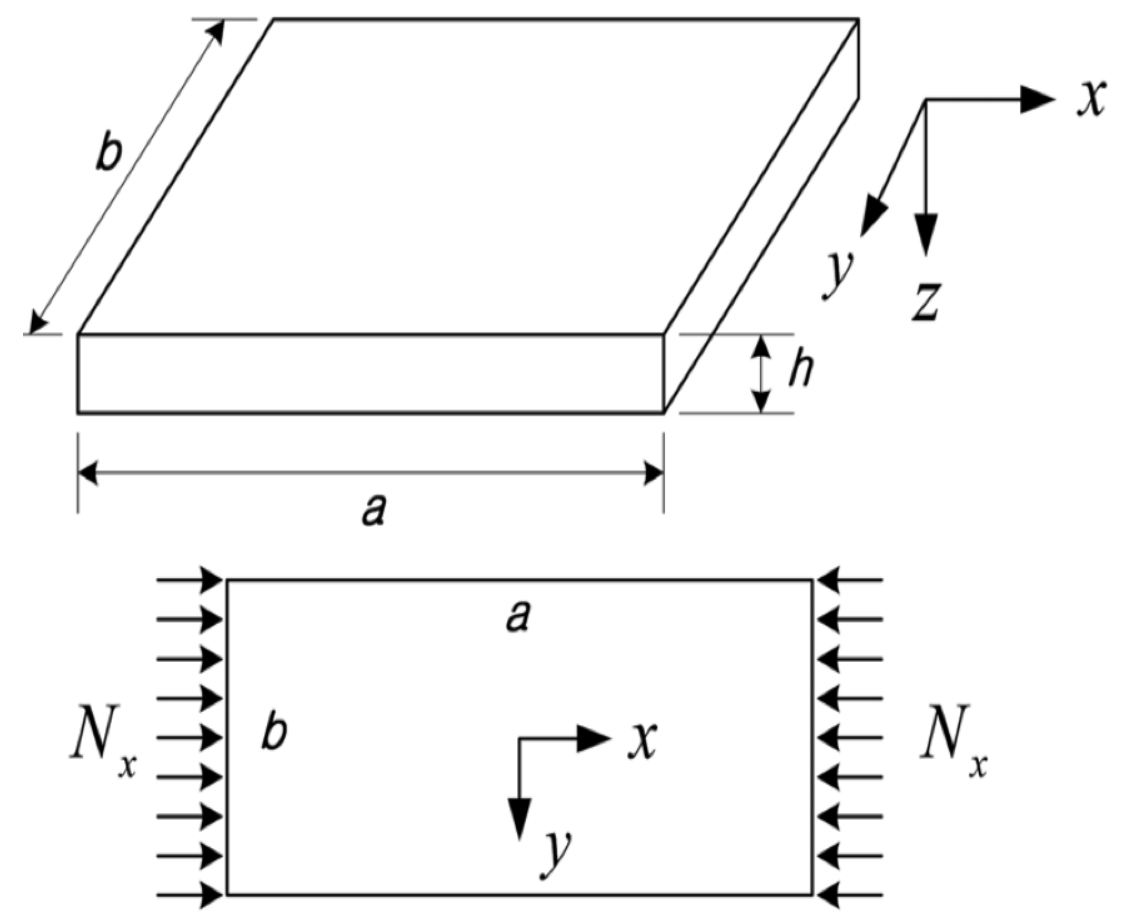

Figure 4.1: Orthotropic plate under in-plane uniaxial compression [30]

$$
F(x, y)=D_{11} \frac{\partial^{4} w}{\partial x^{4}}+2\left(D_{12}+2 D_{66}\right) \frac{\partial^{4} w}{\partial x^{2} \partial y^{2}}+D_{22} \frac{\partial^{4} w}{\partial y^{4}}
$$

where $D_{i j}$ are the flexural rigidities of the plate and found using the Grand Vector Equation. They are represented by the following,

$$
D_{11}=\frac{E_{x} h^{3}}{12\left(1-v_{x} v_{y}\right)}, D_{22}=\frac{E_{y} h^{3}}{12\left(1-v_{x} v_{y}\right)}, D_{12}=\frac{v_{y} E_{x} h^{3}}{12\left(1-v_{x} v_{y}\right)}, D_{66}=\frac{E_{s} h^{3}}{12}
$$

The function $\mathrm{F}(\mathrm{x}, \mathrm{y})$ depends on the problem under consideration. For a plate under in-plane compression in the $\mathrm{x}$-direction as shown in Figure 4.1, $\mathrm{F}(\mathrm{x}, \mathrm{y})$ is given by,

$$
F(x, y)=-N_{x} \frac{\partial^{2} w}{\partial x^{2}}
$$


The equations above are utilized along with the fact that the deflection of a compressed plate pinned on two sides can be written as,

$$
w=\sum_{m=1}^{\infty} \sum_{n=1}^{\infty} A_{m n} \frac{1-\cos m \pi x}{a} \frac{1-\cos n \pi y}{b}
$$

\subsection{Theoretical Deflection Results}

All different combinations of facesheets were analyzed for the deflection at a $1000 \mathrm{lbf}$ load. This was completed in MATLAB using the equations mentioned in the previous section along with the all mechanical properties found in previous testing. These mechanical properties include; Young's Moduli ( $\left.E_{1} \quad E_{2}\right)$, Shear Modulus, and Poisson's ratio. The honeycomb core used throughout this experiment was considered an isotropic material for theoretical analysis. Due to the complex shape of honeycomb and lack of theoretical equations pertaining to it, it was necessary to simplify it. The theoretical deflection found in MATLAB was using an edgewise compressive load of $1000 \mathrm{lbf}$, as was done during experimental testing. 


\subsubsection{Carbon Fiber Sandwiches}

Table 4.1: Theoretical deflection of carbon fiber sandwiches

\begin{tabular}{|l|c|}
\hline & Deflection at 1000lbf [in] \\
\hline 1X1 Layer & 0.0028 \\
\hline 2X2 Layer & 0.0026 \\
\hline 3X3 Layer & 0.0024 \\
\hline 4X4 Layer & 0.0023 \\
\hline
\end{tabular}

\subsubsection{Plain Weave Hemp Sandwiches}

Table 4.2: Theoretical deflection of plain weave hemp sandwiches

\begin{tabular}{|l|c|}
\hline & Deflection at 1000lbf [in] \\
\hline 1X1 Layer & 0.052 \\
\hline 2X2 Layer & 0.044 \\
\hline 3X3 Layer & 0.038 \\
\hline 4X4 Layer & 0.032 \\
\hline
\end{tabular}




\subsubsection{Herringbone Weave Hemp Sandwiches}

Table 4.3: Theoretical deflection of herringbone weave hemp sandwiches

\begin{tabular}{|l|c|}
\hline & Deflection at 1000lbf [in] \\
\hline 1X1 Layer & 0.041 \\
\hline 2X2 Layer & 0.037 \\
\hline 3X3 Layer & 0.034 \\
\hline 4X4 Layer & 0.029 \\
\hline
\end{tabular}

\subsubsection{Glass Fiber (Texalium) Sandwiches}

Table 4.4: Theoretical deflection of glass fiber (texalium) sandwiches

\begin{tabular}{|l|c|}
\hline & Deflection at 1000lbf [in] \\
\hline 1X1 Layer & 0.022 \\
\hline 2X2 Layer & 0.019 \\
\hline 3X3 Layer & 0.016 \\
\hline 4X4 Layer & 0.014 \\
\hline
\end{tabular}

\subsubsection{Hybrid Sandwiches}

Table 4.5: Theoretical deflection of hybrid sandwiches

\begin{tabular}{|c|c|}
\hline $\begin{array}{c}\text { 2X2 Layer-CF outer } \\
\text { face }\end{array}$ & Deflection at 1000lbf [in] \\
\hline $\begin{array}{c}\text { 2X2 Layer-Hemp } \\
\text { outer face }\end{array}$ & 0.018 \\
\hline $\begin{array}{c}\text { 4X4 Layer-CF outer } \\
\text { face }\end{array}$ & 0.018 \\
\hline $\begin{array}{c}\text { 4X4 Layer-Hemp } \\
\text { outer face }\end{array}$ & 0.015 \\
\hline
\end{tabular}




\section{Chapter 5}

FINITE ELEMENT ANALYSIS AND RESULTS

\subsection{Finite Element Methodology}

Finite element analysis (FEA) has become the prevalent method for analysis of the behaviors of solids, structures and fluid mechanics. Composite materials and structures can be modeled and successfully analyzed in finite element programs.

The aim of this chapter is to verify the deflection results found experimentally and theoretically in each of the sandwich cases by using finite element analysis. A pinnedpinned supported composite sandwich plate under a linear perturbation compression will be generated and analyzed using the finite element analysis software, Abaqus 6.11. Implicit finite element analysis will be conducted to numerically analyze the deflection of the test specimen. Eq ( 5.1) is the governing equation for implicit analysis.

$$
F=K \delta
$$

The finite element code assumes a prescribed force which then the stiffness of the structure $(\mathrm{K})$ is formed and the resulting displacements are then found. Implicit methods have the process re-iterated a number of times until a specified tolerance is met between iterations. Each plate was subjected to an edgewise compression with a ramped force acting across the width of the upper edge of the composite structure. 


\subsubsection{Geometric Definitions}

Each composite sandwich was assembled using three parts. The facesheet materials were sketched to the appropriate dimension and extruded as $3 \mathrm{D}$, deformable composite shells. The top and bottom facesheets were both identically built to keep the symmetrical aspect of the composite sandwich. The honeycomb core was modelled as a 3D deformable solid. In order to correctly apply the load on the structure that was seen by the experimental test, a top and bottom plate were created as 3D discrete rigid structures. The models of the structure can be seen in Figure 5.1. 


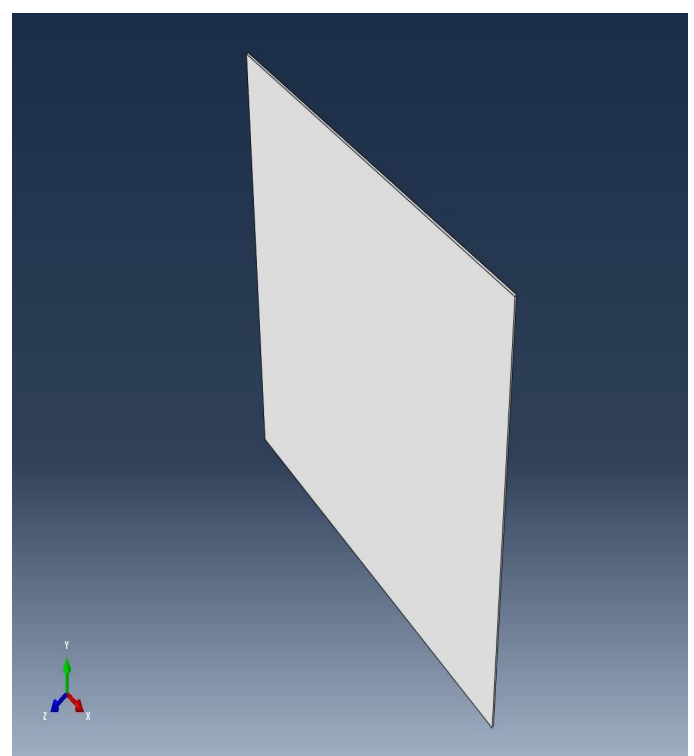

(a) Facesheet sketch extruded as a composite shell

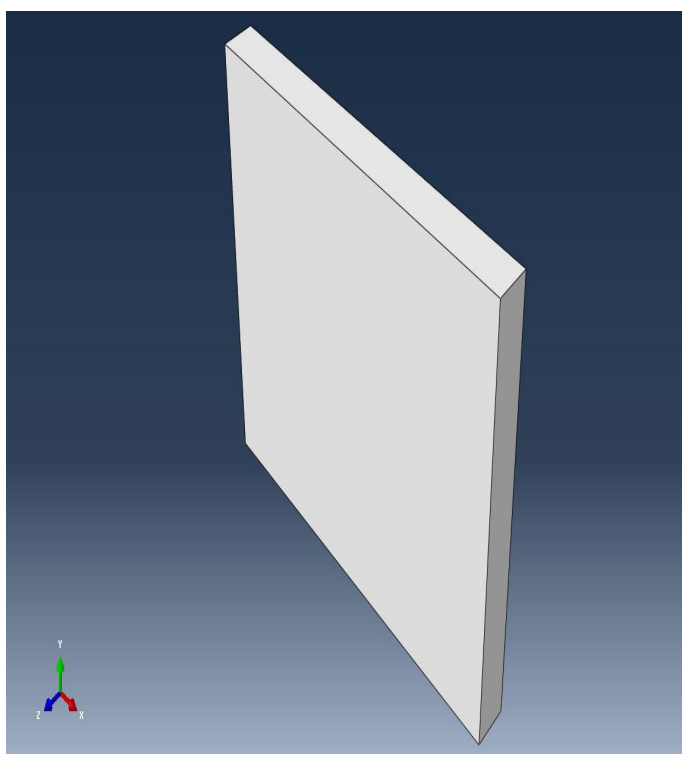

(b) Honeycomb core sketch extruded as a deformable solid

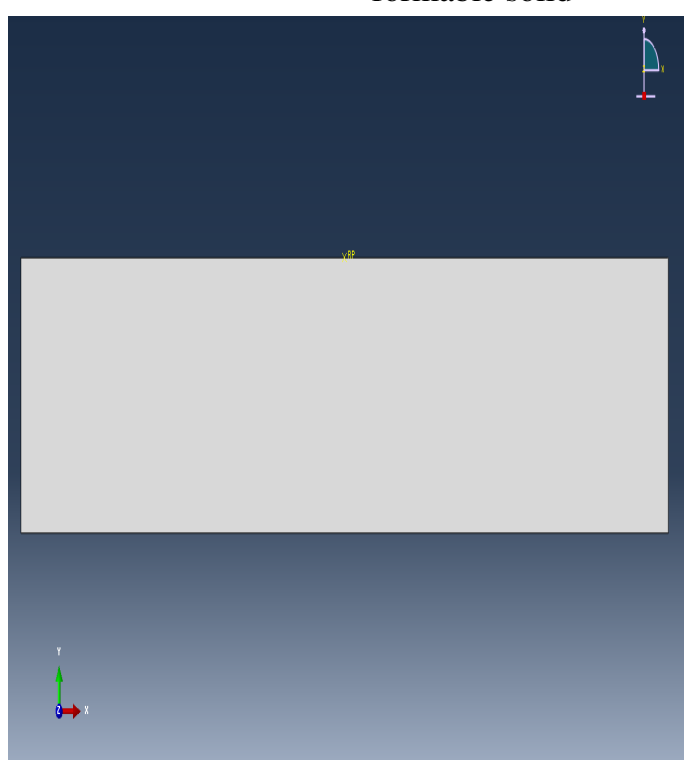

(c) Discrete rigid plate sketch

Figure 5.1: Facesheet, core and top plate sketched as 3D parts 


\subsubsection{Material Creation and Section Assignments}

All dimensions and mechanical properties were defined in English units and the same values were used that were found through ASTM mechanical property testing done in a previous section.

Each facesheet material property was created using elastic engineering constants. For all materials used the E1 and E2 elastic moduli were considered to be the same and the compressive modulus found in a previous section was used for the E3 component. The previous Poisson's ratio testing done was used as the input for the $v_{12}$ value. The $v_{13}$ and $v_{23}$ values could not be measured with the equipment in the lab, so a typical value of 0.3 was deemed to be appropriate to use. Each material was given a density from the manufacturer's data sheet and was entered in the material mass density column. The honeycomb core was also modelled using the same elastic engineering constants. Since honeycomb behaves differently in the longitudinal and transverse directions, the E1 value was assigned as the transverse modulus and the E2 value was assigned as the longitudinal modulus.

With all the material properties entered from previous mechanical property testing, two sections were necessary to assign the materials to. The facesheets were modelled as composite shell parts in order to accurately compare the experimental data. The facesheet section was given a composite shell section with orientation angle of 0 used and 3 integration points. The core was given a solid, homogeneous section.

\subsubsection{Assembly and Steps}

When assembling the facesheets to the core, each part was given a dependent instance and tie constraints were applied to all degrees of freedom to construct the sandwich structure. Face-to-face constraints were used to position the top and bottom facesheets in the same plane as the core and the top and bottom plate were positioned on the top and bottom edges of the sandwich structure. The facesheet was chosen as the master surface, and 
the core was chosen as the slave surface because the facesheet material is more rigid. The sliding formulation selected was finite sliding. Then, edge-to-edge constraints were used to perfectly align the facesheets to the core. The top and bottom rigid plates were also applied as a surface-to-surface interaction. The full assembly of the composite sandwich can be seen in Figure 5.2.

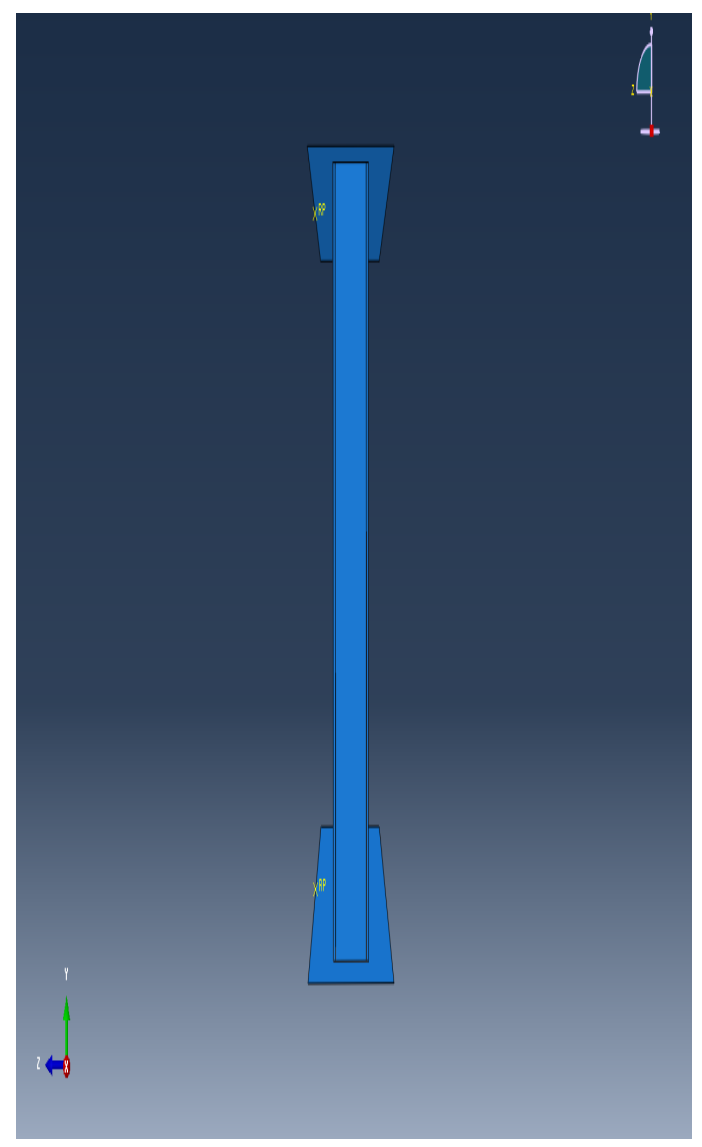

(a) Full assembly of composite sandwich with top and bottom plates

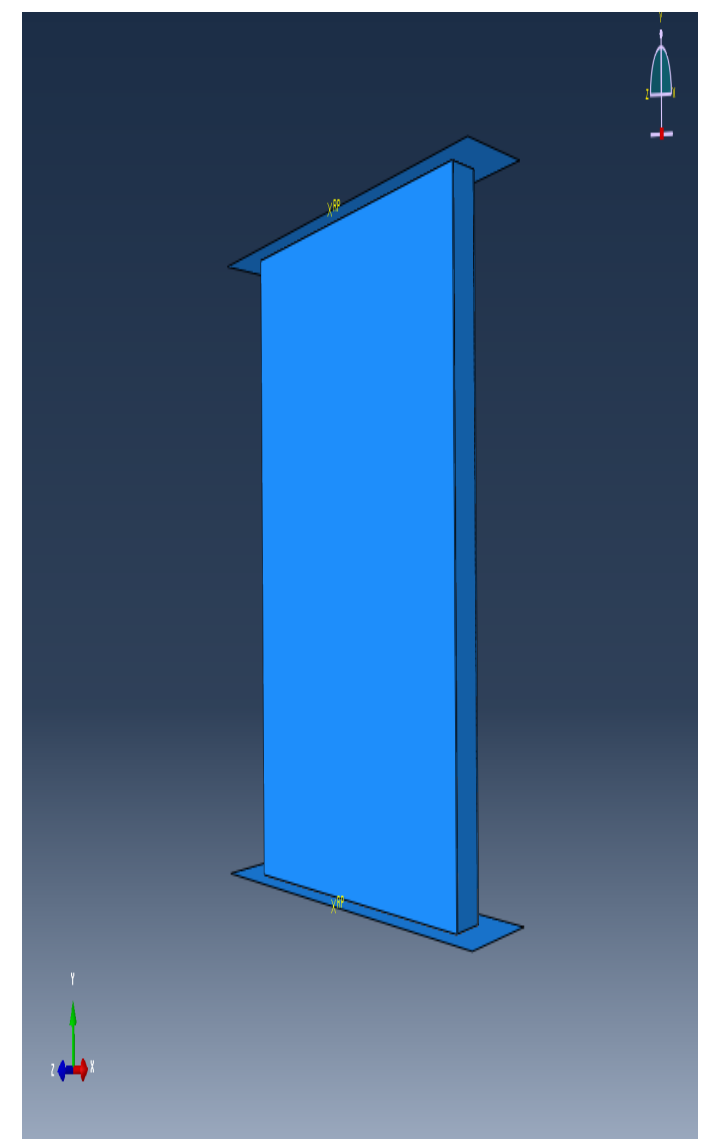

(b) Full assembly of composite sandwich with top and bottom plates

Figure 5.2: Full assembly of composite sandwich with top and bottom plates

After assembly of the composite sandwich was finished, a static general step was created after the initial step to be used for loading of the structure. 


\subsubsection{Boundary Conditions, and Loads}

To simulate the fact that the sandwich was on its edge being compressed by the top fixture without any slippage, two boundary condition were considered. The first boundary condition case was created on the top and bottom of the composite sandwich. The top and bottom surfaces were not allowed to rotate in any direction. The top surface was only allowed to displace in the Y-direction and the bottom surface was not allowed to displace in an direction. The second boundary condition case was also created on the top and bottom of the sandwich. Only this time, the top and bottom surfaces were allowed to rotate in the Z-direction only. Just like case one, the top surface was allowed to displace in the Ydirection and the bottom surface was not allowed to displace in any direction. After testing both cases in Abaqus, it was discovered that the first case was closer to the experimental values and therefore used throughout all the analysis. The errors for both cases are shown in Table A.1. The surface-to-surface interactions and boundary conditions are shown in Figure 5.3.

The prescribed load that was modelled was a $1000 \mathrm{lbf}$ on the top edge surface of the composite sandwich. To achieve this, a mechanical, pressure load was applied to the top plate within the static general step created in the previous section. The distribution chosen was the uniform option. But in order for the correct load to be applied, a simply calculation of the desired $1000 \mathrm{lbf}$ load had to be divided by the surface area that the load was acting on. The core was $1.5 \mathrm{in}^{2}$ and each increasing facesheet layer was $0.05 \mathrm{in}^{2}$. Since the facesheet layers were increasing from 1 layer to 4, the effective loads ranged from $625 \mathrm{lbf}$ for 1 layer to $526.3 \mathrm{lbf}$ for 4 layers. The fully constrained, fully loaded structure can be seen in Figure 5.4. 


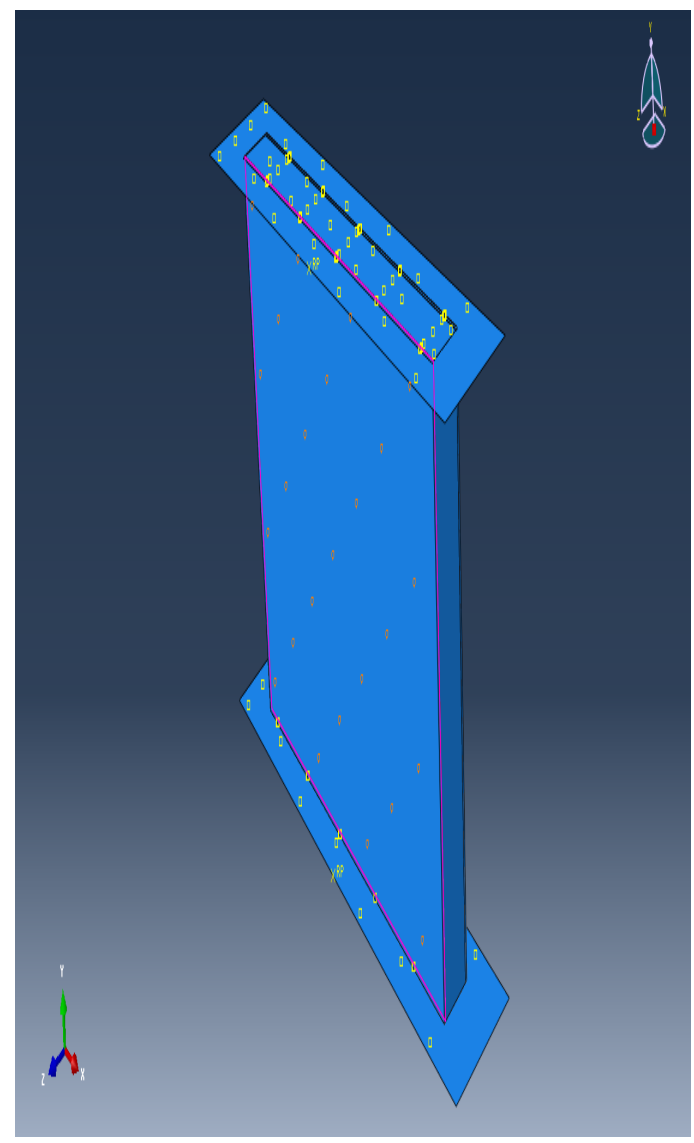

(a) All interactions

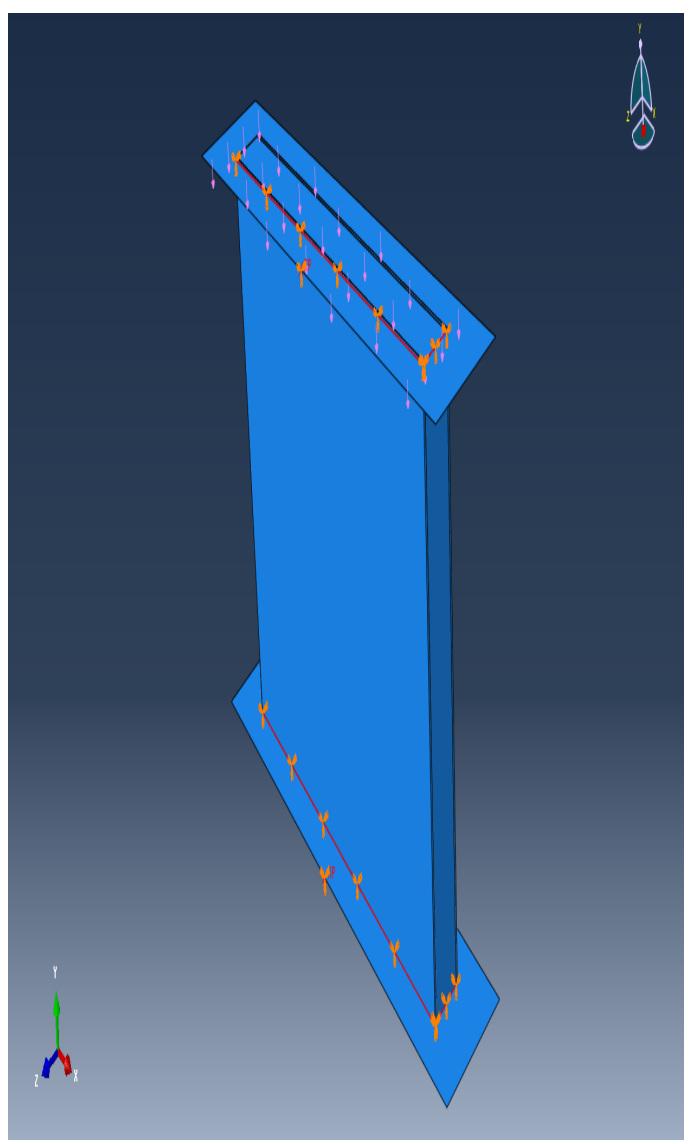

(b) Boundary conditions applied to the sandwich structure

Figure 5.3: Composite sandwich constraints and boundary conditions

\subsubsection{Meshing}

The facesheet parts were meshed using the standard, linear continuum shell elements with 8-node quadrilateral shells and reduced integration. Since the core was not a shell element, it was meshed using the standard, linear hexagonal brick elements with 8-nodes and reduced integration. All parts were meshed using a seed size of 0.1. The seed sizes were altered between 0.06 and 0.2 but the optimal seed size of 0.1 was found after a mesh convergence plot was created, as seen in A.2. The deflection values for the sandwich converged at 3150 elements which corresponds to a seed size of 0.1 . So, the seed size of 0.1 was deemed to be appropriate to use for all models. The meshed parts can be seen in Figure 5.5. 


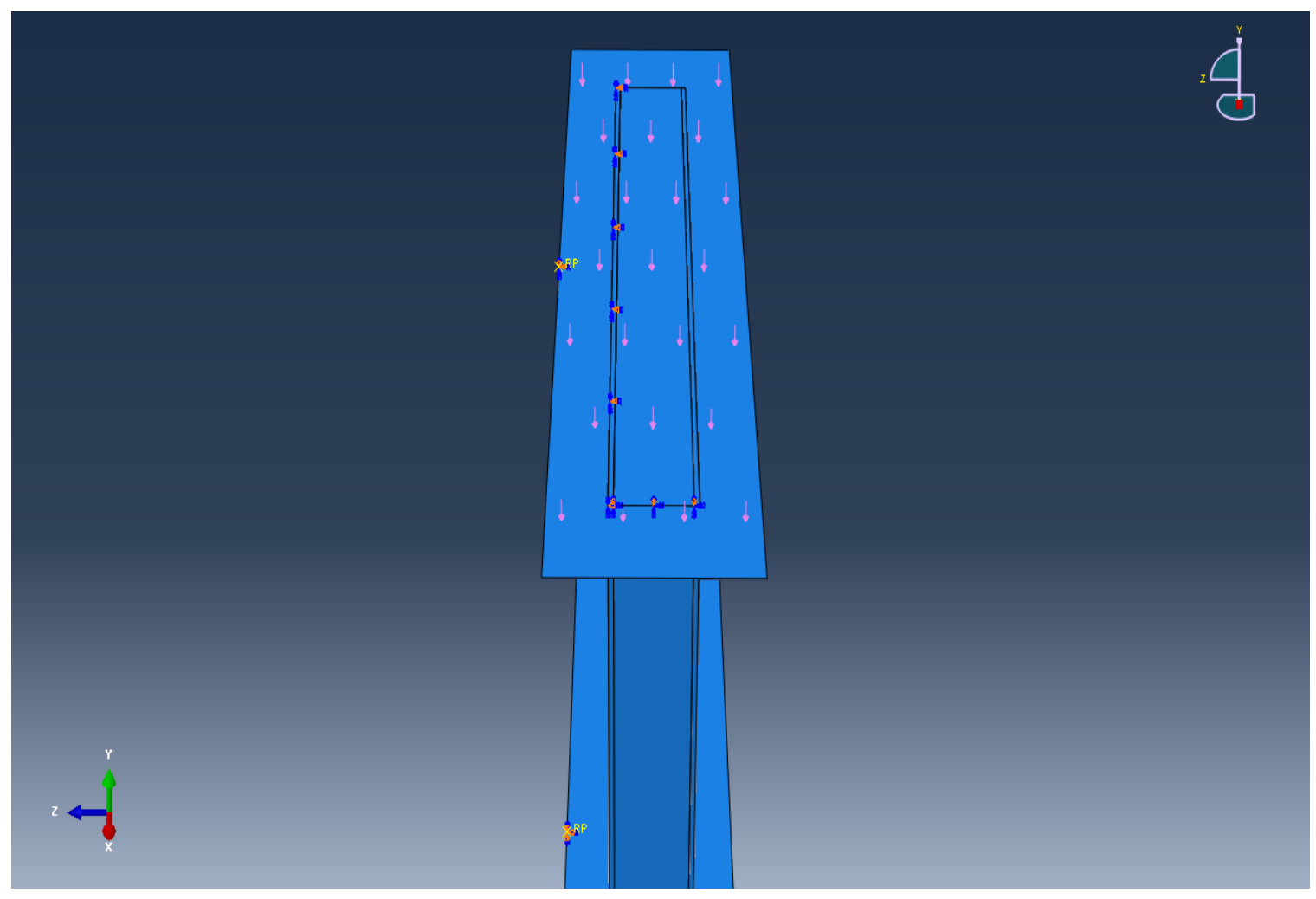

Figure 5.4: Edgewise compressive load applied

\subsubsection{Edgewise-Compressive Model with $1000 \mathrm{lbf}$ load applied}

After loading the composite sandwich with an edgewise-compressive load, the final prediction shows the structure to behave as seen in Figure 5.6. This is in accordance to how the experimental structures looked at $1000 \mathrm{lbf}$ load. The results and errors will be discussed in the next chapter. 


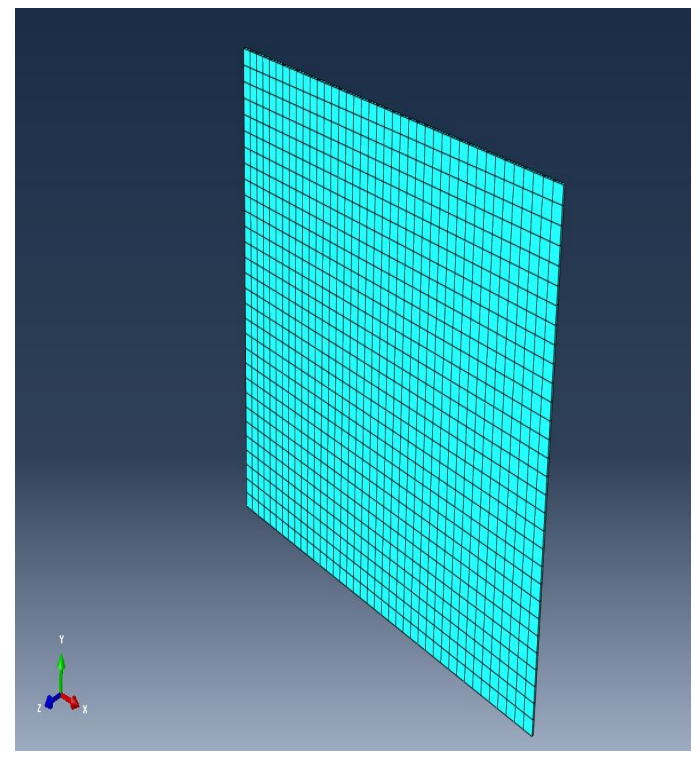

(a) Facesheet shell mesh

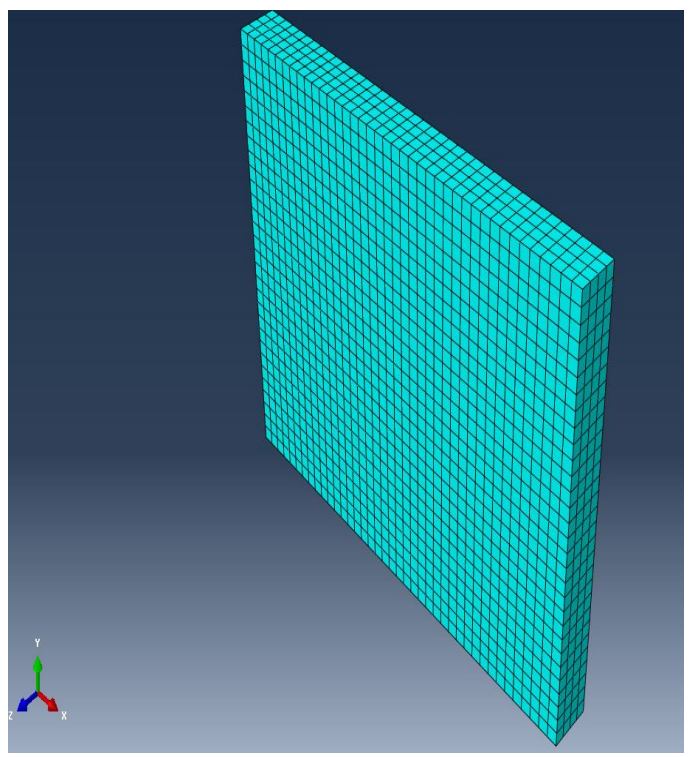

(b) Core mesh

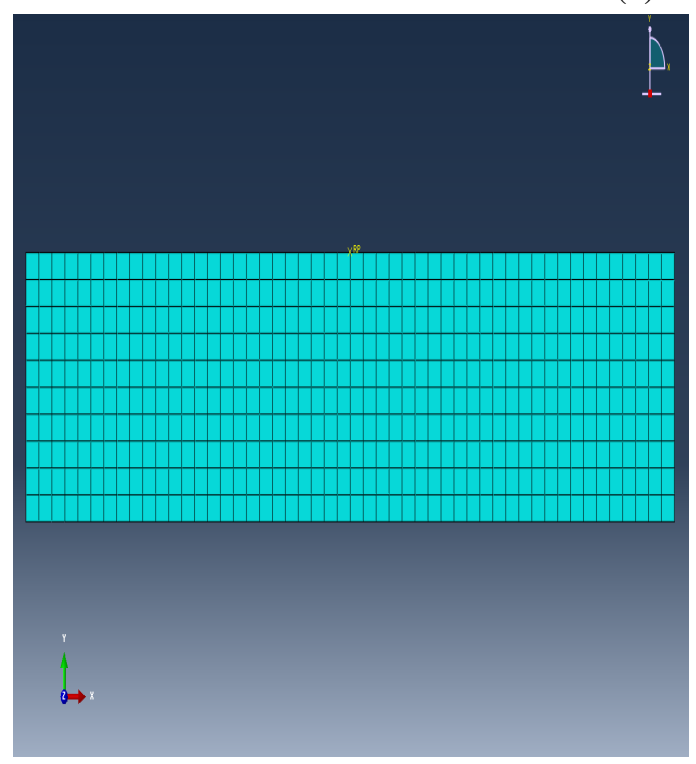

(c) Core mesh

Figure 5.5: Facesheet, core and plate meshes 


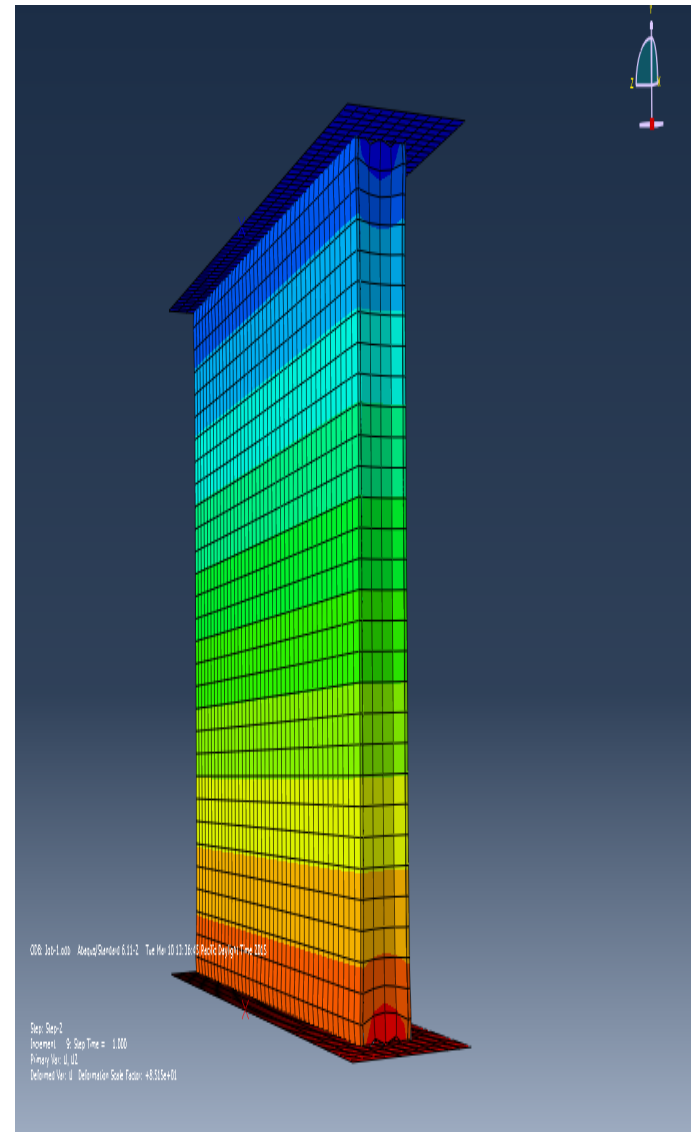

(a) Load applied

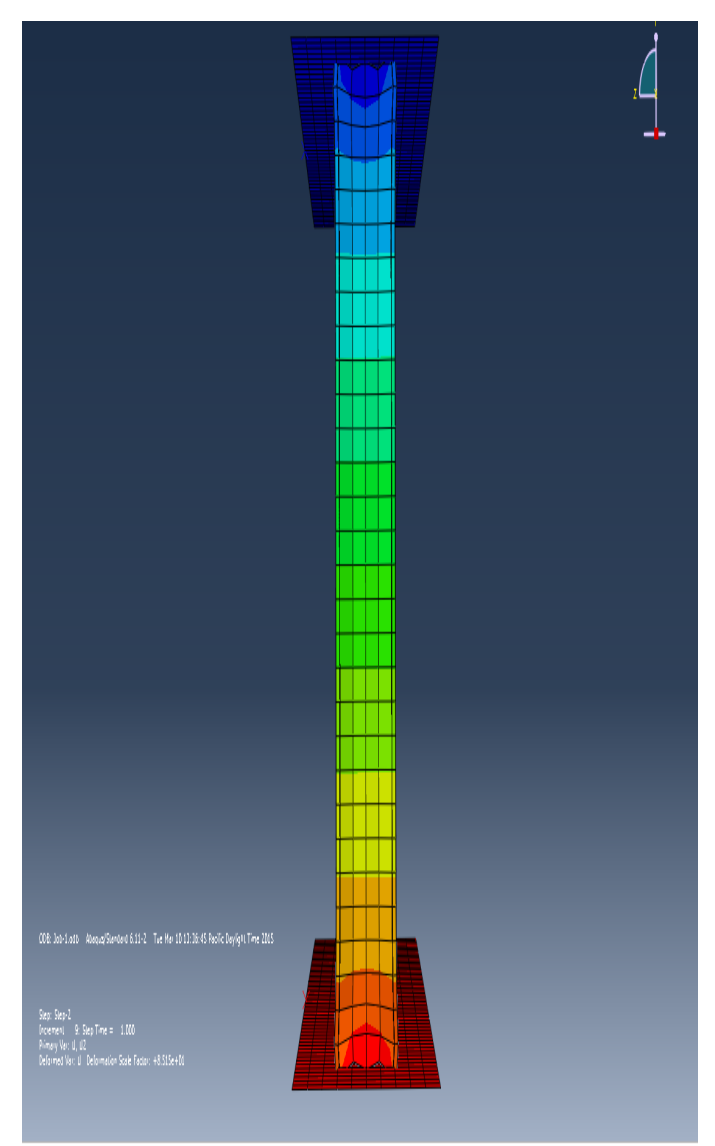

(b) Side view of load applied

Figure 5.6: Results of edgewise compressive load applied to structure 


\section{Chapter 6}

COMPARISON OF NUMERICAL, THEORETICAL, AND EXPERIMENTAL RESULTS

\subsection{Theoretical and Numerical}

The theoretical and numerical results were similar results due to a similar algorithm used by both programs, hence the lesser error. The only variant factor between the two is the ability to make a more accurate model when using Finite Element Analysis due to the fact that more nodes can be placed on the model. Although, this type of structure is not very geometrically complex so an abundant amount of nodes is not absolutely necessary. In most cases, the numerical analysis seemed to predict deflections closer to the experimental than the theoretical did.

\subsection{Theoretical and Experimental}

When comparing the theoretical to the experimental results, it seemed that the pre-preg composites had less of a deflection than the theoretical predicts. This happens possibly because the composite sandwiches had a bearing stress on the edges which allows less of a deflection than the theoretical predicts.

The theoretical deflection results for the bio-composite sandwiches also predicted more of an elongation than the experimental results showed. 


\subsection{Numerical and Experimental}

Numerical results were similar to the theoretical results. For the most part, the FEA results, when compared to the experimental results, seemed to predict more of a deflection for all sandwiches. The numerical was a little more accurate than the theoretical simply because it uses a finer mesh than the theoretical.

\subsection{Overall Comparison of Deflections at $1000 \mathrm{lbf}$}

Table 6.1: Numerical, theoretical, and experimental comparison of carbon fiber sandwiches

\begin{tabular}{|c|c|c|c|c|c|c|c|}
\hline & \multirow{2}{*}{$\begin{array}{c}\text { Experimental } \\
\text { Deflection } \\
\text { at } 1000 \mathrm{lbf} \\
{[\mathrm{in}]} \\
\end{array}$} & \multirow{2}{*}{$\begin{array}{l}\text { Theoretical } \\
\text { Deflection } \\
\text { at } 1000 \mathrm{lbf} \\
\text { [in] }\end{array}$} & \multirow{2}{*}{$\begin{array}{l}\text { Numerical } \\
\text { Deflection } \\
\text { at } 1000 \mathrm{lbf} \\
\text { [in] }\end{array}$} & \multicolumn{3}{|c|}{ Error [\%] } \\
\hline & & & & & $\mathbf{E x} / \mathbf{T h}$ & Ex/Num & Th/Num \\
\hline \multirow{4}{*}{ CF } & $\begin{array}{c}1 \mathrm{X} 1 \\
\text { Layers }\end{array}$ & $\begin{array}{c}0.0023 \\
+/-0.0013\end{array}$ & 0.0028 & 0.00266 & 17.9 & 13.5 & 5.3 \\
\hline & $\begin{array}{c}2 \mathrm{X} 2 \\
\text { Layers }\end{array}$ & $\begin{array}{c}0.0021 \\
+/-0.0033\end{array}$ & 0.0026 & 0.0025 & 19.2 & 16.0 & 4.0 \\
\hline & $\begin{array}{c}3 \mathrm{X} 3 \\
\text { Layers }\end{array}$ & $\begin{array}{c}0.0019 \\
+/-0.0021\end{array}$ & 0.0024 & 0.00236 & 20.8 & 19.5 & 1.7 \\
\hline & $\begin{array}{c}\text { 4X4 } \\
\text { Layers }\end{array}$ & $\begin{array}{c}0.0018 \\
+/-0.0039\end{array}$ & 0.0023 & 0.00221 & 21.7 & 18.6 & 4.1 \\
\hline
\end{tabular}


Table 6.2: Numerical, theoretical, and experimental comparison of plain weave hemp fiber sandwiches

\begin{tabular}{|c|c|c|c|c|c|c|c|}
\hline & \multirow{2}{*}{$\begin{array}{l}\text { Experimental } \\
\text { Deflection } \\
\text { at } 1000 \mathrm{lbf} \\
\text { [in] }\end{array}$} & \multirow{2}{*}{$\begin{array}{l}\text { Theoretical } \\
\text { Deflection } \\
\text { at } 1000 \mathrm{lbf} \\
\text { [in] }\end{array}$} & \multirow{2}{*}{$\begin{array}{c}\text { Numerical } \\
\text { Deflection } \\
\text { at } 1000 \mathrm{lbf} \\
\text { [in] }\end{array}$} & \multicolumn{3}{|c|}{ Error [\%] } \\
\hline & & & & & Ex/Th & Ex/Num & Th/Num \\
\hline \multirow{4}{*}{$\begin{array}{l}\text { PW- } \\
\text { Hemp }\end{array}$} & $\begin{array}{c}1 \mathrm{X} 1 \\
\text { Layers }\end{array}$ & $\begin{array}{c}0.054 \\
+/-0.012\end{array}$ & 0.052 & 0.050 & 3.9 & 8.0 & 4.0 \\
\hline & $\begin{array}{c}2 \mathrm{X} 2 \\
\text { Layers }\end{array}$ & $\begin{array}{c}0.041 \\
+/-0.010\end{array}$ & 0.044 & 0.043 & 6.8 & 4.7 & 2.3 \\
\hline & $\begin{array}{c}3 X 3 \\
\text { Layers }\end{array}$ & $\begin{array}{c}0.033 \\
+/-0.036\end{array}$ & 0.038 & 0.036 & 13.2 & 8.3 & 5.6 \\
\hline & $\begin{array}{c}4 \mathrm{X} 4 \\
\text { Layers }\end{array}$ & $\begin{array}{c}0.028 \\
+/-0.027\end{array}$ & 0.032 & 0.030 & 12.5 & 6.7 & 6.3 \\
\hline
\end{tabular}

Table 6.3: Numerical, theoretical, and experimental comparison of herringbone weave hemp fiber sandwiches

\begin{tabular}{|c|c|c|c|c|c|c|c|}
\hline & \multirow{2}{*}{$\begin{array}{c}\text { Experimental } \\
\text { Deflection } \\
\text { at } 1000 \mathrm{lbf} \\
\text { [in] }\end{array}$} & \multirow{2}{*}{$\begin{array}{l}\text { Theoretical } \\
\text { Deflection } \\
\text { at } 1000 \mathrm{lbf} \\
\text { [in] }\end{array}$} & \multirow{2}{*}{$\begin{array}{c}\text { Numerical } \\
\text { Deflection } \\
\text { at } 1000 \mathrm{lbf} \\
\text { [in] }\end{array}$} & \multicolumn{3}{|c|}{ Error [\%] } \\
\hline & & & & & Ex/Th & Ex/Num & Th/Num \\
\hline \multirow{4}{*}{$\begin{array}{l}\text { HB- } \\
\text { Hemp }\end{array}$} & $\begin{array}{c}1 \mathrm{X} 1 \\
\text { Layers }\end{array}$ & $\begin{array}{c}0.044 \\
+/-0.025\end{array}$ & 0.041 & 0.040 & 7.3 & 10.0 & 2.5 \\
\hline & $\begin{array}{c}2 \mathrm{X} 2 \\
\text { Layers }\end{array}$ & $\begin{array}{c}0.041 \\
+/-0.022\end{array}$ & 0.037 & 0.036 & 10.8 & 13.9 & 2.8 \\
\hline & $\begin{array}{c}3 \mathrm{X} 3 \\
\text { Layers }\end{array}$ & $\begin{array}{c}0.031 \\
+/-0.02\end{array}$ & 0.034 & 0.033 & 8.8 & 6.1 & 3.1 \\
\hline & $\begin{array}{c}4 \mathrm{X} 4 \\
\text { Layers }\end{array}$ & $\begin{array}{c}0.030 \\
+/-0.03\end{array}$ & 0.029 & 0.028 & 3.5 & 7.1 & 3.6 \\
\hline
\end{tabular}


Table 6.4: Numerical, theoretical, and experimental comparison of glass fiber sandwiches

\begin{tabular}{|c|c|c|c|c|c|c|c|}
\hline & \multirow{2}{*}{$\begin{array}{c}\text { Experimental } \\
\text { Deflection } \\
\text { at } 1000 \mathrm{lbf} \\
\text { [in] }\end{array}$} & \multirow{2}{*}{$\begin{array}{l}\text { Theoretical } \\
\text { Deflection } \\
\text { at } 1000 \mathrm{lbf} \\
\text { [in] }\end{array}$} & \multirow{2}{*}{$\begin{array}{c}\text { Numerical } \\
\text { Deflection } \\
\text { at } 1000 \mathrm{lbf} \\
\text { [in] }\end{array}$} & \multicolumn{3}{|c|}{ Error [\%] } \\
\hline & & & & & Ex/Th & Ex/Num & Th/Num \\
\hline \multirow{4}{*}{ GF } & $\begin{array}{c}\text { 1X1 } \\
\text { Layers }\end{array}$ & $\begin{array}{c}0.024 \\
+/-0.006\end{array}$ & 0.022 & 0.021 & 14.3 & 17.2 & 3.5 \\
\hline & $\begin{array}{c}2 \mathrm{X} 2 \\
\text { Layers }\end{array}$ & $\begin{array}{c}0.015 \\
+/-0.013\end{array}$ & 0.019 & 0.018 & 21.1 & 16.7 & 5.6 \\
\hline & $\begin{array}{c}3 \mathrm{X} 3 \\
\text { Layers }\end{array}$ & $\begin{array}{c}0.011 \\
+/-0.006\end{array}$ & 0.016 & 0.015 & 31.3 & 26.7 & 6.7 \\
\hline & $\begin{array}{c}4 \mathrm{X} 4 \\
\text { Layers }\end{array}$ & $\begin{array}{c}0.010 \\
+/-0.0056\end{array}$ & 0.014 & 0.013 & 28.6 & 23.1 & 7.7 \\
\hline
\end{tabular}

Table 6.5: Numerical, theoretical, and experimental comparison of hybrid sandwiches

\begin{tabular}{|c|c|c|c|c|c|c|c|}
\hline & \multirow{2}{*}{$\begin{array}{l}\text { Experimental } \\
\text { Deflection } \\
\text { at } 1000 \mathrm{lbf} \\
\text { [in] }\end{array}$} & \multirow{2}{*}{$\begin{array}{l}\text { Theoretical } \\
\text { Deflection } \\
\text { at } 1000 \mathrm{lbf} \\
\text { [in] }\end{array}$} & \multirow{2}{*}{$\begin{array}{c}\text { Numerical } \\
\text { Deflection } \\
\text { at } 1000 \mathrm{lbf} \\
\text { [in] }\end{array}$} & \multicolumn{3}{|c|}{ Error [\%] } \\
\hline & & & & & Ex/Th & Ex/Num & Th/Num \\
\hline \multirow{4}{*}{ Hy } & $\begin{array}{c}2 \mathrm{X} 2 \\
\text { Layers- } \\
\text { CF } \\
\text { out }\end{array}$ & $\begin{array}{c}0.014 \\
+/-0.009\end{array}$ & 0.018 & 0.016 & 22.2 & 12.5 & 12.5 \\
\hline & $\begin{array}{c}2 \mathrm{X} 2 \\
\text { Layers- } \\
\text { Hemp } \\
\text { out }\end{array}$ & $\begin{array}{c}0.015 \\
+/-0.009\end{array}$ & 0.018 & 0.017 & 16.7 & 11.8 & 5.9 \\
\hline & $\begin{array}{c}4 \mathrm{X} 4 \\
\text { Layers- } \\
\mathrm{CF} \\
\text { out }\end{array}$ & $\begin{array}{c}0.013 \\
+/-0.006\end{array}$ & 0.015 & 0.014 & 13.3 & 7.1 & 7.1 \\
\hline & $\begin{array}{c}4 \mathrm{XX} 4 \\
\text { Layers- } \\
\text { Hemp } \\
\text { out }\end{array}$ & $\begin{array}{c}0.012 \\
+/-0.021\end{array}$ & 0.016 & 0.015 & 25.0 & 20.0 & 6.7 \\
\hline
\end{tabular}




\section{Chapter 7 \\ CONCLUSION}

The first task of this study was to individually analyze all aspects of two types of hemp, a carbon fiber pre-preg, and a fiberglass pre-preg. Then, the second task was to create a multifunctional hybrid composite using a pre-preg material and bio-material that could be analyzed in the same manner. Discussion of failure modes was a main concern as was the strength-to-weight ratio of the different sandwich panels. Strength-to-weight ratio results showed that carbon fiber was advantageous to use but with future considerations of a better bonding technique, bio-composites will show as the advantageous facesheet to use, as it is able to elongate much more than the pre-preg composites before failure. Although hemp may not be useful for higher strength-to-weight applications, the average ultimate load before failure of hemp still performed similar to carbon fiber while elongating much more than that of carbon fiber and fiberglass. The main findings of this experiment were that the damage after failure of the hybrid sandwiches was very minimal when compared to the individual materials. Damage to composite materials is a major issue especially with thin composite wings and other delicate structures that undergo a long work life. If damage can be hindered by adding a simple layer of bio-composite to reinforce the carbon fiber, it could give major benefits for industry in the future.

\subsection{Future Considerations}

As composites and bio-composite sandwich structures become more widely used in engineering fields in the near future, the need for optimal sandwich structure design will be essential. Depending on design specifications, optimizing the strength-to-weight for the 
sandwiches could be an advantage or maximum elongation may be necessary for certain applications. Failure modes of the sandwiches is also an essential role in design study. As this report has shown, considering different facesheet layers within composite sandwiches results in a minimized weight design with a better overall performance, which, in any industry, leads to an increase in money saved. As previously stated, the bonding of facesheet to core is important and may have caused the anomaly in the hemp tested in this experiment. With a thicker facesheet, epoxy is more difficult to evenly spread throughout the specimen prior to curing. Pre-preg material is always more beneficial when creating composite plates to prevent any excess resin content or uneven spreading using the hand lay-up technique. Future research may consider the development of bio-composite pre-preg materials, which would help to solve this issue and also reduce the carbon footprint. Research could also lead to developing more sophisticated hybrid composites that utilize bio-composites. 


\section{BIBLIOGRAPHY}

[1] Todd Johnson. The Evolution of Lightweight Composite Materials. 2014. URL: http: //composite.about.com/HistoryofComposites.htm.

[2] Mar-bel. History of Composites. 2014. URL: http://www . mar-bal . com/historyof-composites/.

[3] truthonpot.com. The World's Most Eco-friendly car: The Kestrel. 2013. URL: http: / / www . truthonpot . com/2013/07/11/the-worlds-most-eco-friendlyhemp-car-the-kestrel/.

[4] Arjun Walia. The World's Most Eco-friendly car: Made entirely from Hemp. 2013. URL: http: / / www . collective-evolution . com/2013/11/01/the-worldsmost-eco-friendly-car-its-made-entirely-from-hemp/.

[5] Paul Benhaim. Hemp Plastics Biocomposites. 2004. URL: http://www. hemphas is. net/Building/plasticmettle.htm.

[6] Common Fund for Commodities. Symposium on Natural Fibers. 2009. URL: ftp: //ftp.fao.org/docrep/fao/011/i0709e/i0709e.pdf.

[7] Stephen R. Awanson. Introduction to Composites. 1997. URL: http: / / ib. znate. ru/docs/index-104219.html.

[8] Unknown. Composite Sandwich Example. 1997. URL: https:// lh6.ggpht.com.

[9] Pichai Rusmee. High Strength Composites. 2005. URL: http: / /www . mech . utah. edu/ rusmeeha/labNotes/composites.html. 
[10] Envirotextiles LLC. Sustainable biodegradable products. 2014. URL: http: / / www . envirotextile.com/standards-and-certifications/.

[11] Lisa Herbert. Industrial Hemp spoils the marijuana party. 2013. URL: http: / / www . abc.net.au/news/2013-10-05/hemp-vs-marijuana/4989566.

[12] The Amazing Benefits of Industrial Hemp. 2009. URL: http : / / hempnewstv . wordpress.com.

[13] JEC Magazine. JEC Innovation Report. 2013. URL: http: / /www. jeccomposites . com/sites/default/files/content/JCM79_JECEurope_Innovation.pdf.

[14] JEC Magazine. Introduction to Composite Materials. 2013. URL: http : / / www . asminternational.org/documents/10192/3449368/05287G_Sample_Chapter. pdf/7c5b99aa-25f6-4f08-abfd-b666c88eaf67.

[15] ASTM International. Standard Terminology of Structural Sandwich Constructions. 2007. URL: http://www.astm.org/Standards/C274.htm.

[16] Trevor Gundberg. Foam Core Materials in the Marine Industry. 2004. URL: http: //www.boatdesign.net/articles/foam-core/.

[17] ASTM International. Standard Test Method for Edgewise Compressive Strength of Sandwich Constructions. 2012. URL: http: / / www . astm. org/Standards / C364. htm.

[18] Jamaludin Mohamad Yatim. BIOCOMPOSITES FOR THE CONSTRUCTION MATERIALS AND STRUCTURES. 2011. URL: http: / / www . academia . edu/1266940/ BIOCOMPOSITES_FOR_THE_CONSTRUCTION_MATERIALS_AND_STRUCTURES.

[19] T Makinamuh. Modeling Composite Sandwich Structures. 2011. URL: http : / / library.iyte.edu.tr/tezler/master/makinamuh/T000703.pdf.

[20] Thomas A. Grandine. Surface Modeling for Composite Materials. 2013. URL: http: //siags.siam.org/siaggd/problems/grandine/. 
[21] M K Khan. "Compressive and lamination strength of honeycomb sandwich panels with strain energy calculation from ASTM standards". In: Journal of Aerospace Engineering, Vol. 220, No.5, pp.375-386 (2006).

[22] SE Hoff NJ Mautner. "Buckling of sandwich type panels". In: Journal of Aeronaut Science, Vol. 1945, No.12, pp.285-97 (1997).

[23] Victor Birman. "Wrinkling of Composite-facing Sandwich Panels Under Biaxial Loading”. In: Journal of Sandwich Structures and Materials, Vol. 6, pp.217-37 (2004).

[24] ASTM International. Standard Test Method for Tensile Properties of Polymer Matrix Composite Materials. 2014. URL: http: / / www . astm. org/Standards / D3039 . htm.

[25] ASTM International. Standard Test Method for Compressive Properties of Polymer Matrix Composite Materials with Unsupported Gage Section by Shear Loading. 2014. URL: http://www.astm.org/Standards/D3410.htm.

[26] ASTM International. Standard Test Method for Poisson's Ratio at Room Temperature. 2014. URL: http://www.astm.org/Standards/E132.htm.

[27] ASTM International. Standard Test Method for Determining Poisson's Ratio of Honeycomb Cores. 2014. URL: http://www. astm.org/Standards/D6790.htm.

[28] S. Timoshenko. Theory of Plates and Shells. 1959. URL: http://155.207.34.6/ files/Timoshenko.pdf.

[29] Lekhnitskii S. Lekhnitskii Formalism. 1968. URL: http: / / www . springer. com / cda / content / document / cda_downloaddocument / 9781441959140 - c1 . pdf? SGWID $=0-0-45-910341-\mathrm{p} 173953523$.

[30] Inho Hwang. "Buckling of Orthotropic Plates under Various Inplane Loads". In: Journal of Civil Engineering, Vol. 10, No.5, pp.349-56 (2006). 


\section{APPENDICES}

\section{A.1 Layer Comparison}

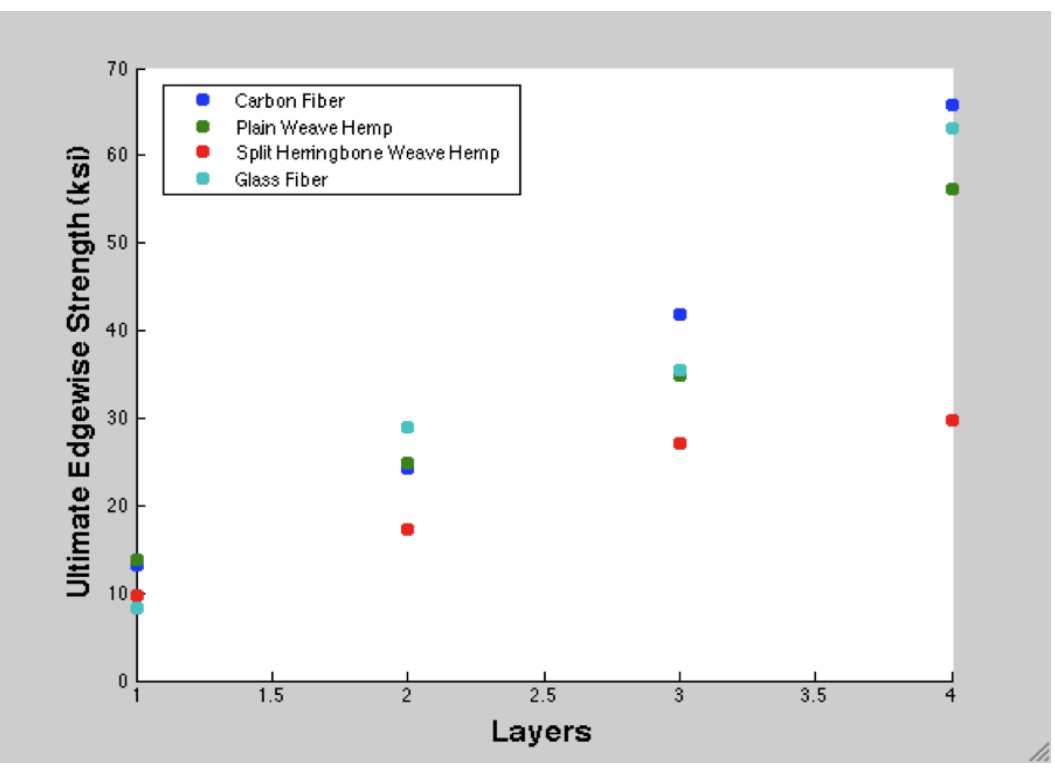

Figure A.1: Edgewise strength versus number of layers 


\section{A.2 Boundary Condition Cases}

Table A.1: Boundary condition comparison of carbon fiber sandwiches

\begin{tabular}{|c|c|c|c|c|c|c|}
\hline & \multirow{2}{*}{$\begin{array}{l}\text { Experimental } \\
\text { Deflection } \\
\text { at } 1000 \mathrm{lbf} \\
\text { [in] }\end{array}$} & \multirow{2}{*}{$\begin{array}{c}\text { Case } 1 \text { at } \\
1000 \mathrm{lbf} \\
\text { [in] }\end{array}$} & \multirow{2}{*}{$\begin{array}{c}\text { Case } 2 \text { at } \\
1000 \text { lbf } \\
\text { [in] }\end{array}$} & \multicolumn{2}{|c|}{ Error [\%] } \\
\hline & & & & & Ex/Case 1 & $\begin{array}{c}\text { Ex/Case } \\
2\end{array}$ \\
\hline \multirow{4}{*}{$\mathrm{CF}$} & $\begin{array}{c}1 \mathrm{X} 1 \\
\text { Layers }\end{array}$ & $\begin{array}{c}0.0023 \\
+/-0.0013\end{array}$ & 0.00266 & 0.00281 & 13.5 & 18.2 \\
\hline & $\begin{array}{c}2 \mathrm{X} 2 \\
\text { Layers }\end{array}$ & $\begin{array}{c}0.0021 \\
+/-0.0033\end{array}$ & 0.00250 & 0.00262 & 16.0 & 19.9 \\
\hline & $\begin{array}{c}3 X 3 \\
\text { Layers }\end{array}$ & $\begin{array}{c}0.0019 \\
+/-0.0021\end{array}$ & 0.00236 & 0.00240 & 19.5 & 20.8 \\
\hline & $\begin{array}{c}4 \mathrm{X} 4 \\
\text { Layers }\end{array}$ & $\begin{array}{c}0.0018 \\
+/-0.0039\end{array}$ & 0.00221 & 0.00225 & 18.6 & 20.0 \\
\hline
\end{tabular}

\section{A.3 Numerical Model Mesh Convergence Plot}

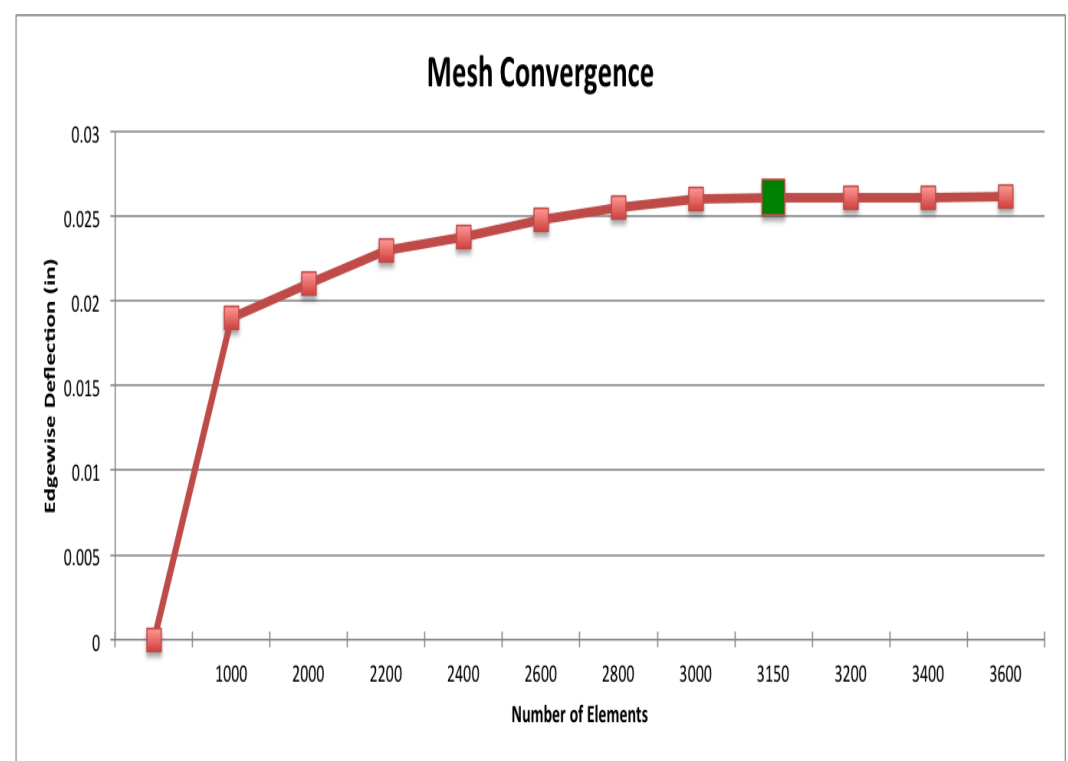

Figure A.2: Mesh convergence plot 